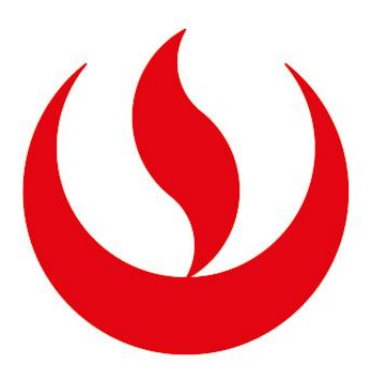

UNIVERSIDAD PERUANA DE CIENCIAS APLICADAS

Facultad de Comunicaciones

Programa Académico de Comunicación y Publicidad

\title{
La percepción de influencia del product placement de productos de belleza en los vlogs de Youtubers sobre los elementos del proceso de decisión de compra. Caso: Vogue Cosméticos Perú.
}

Tesis para optar por el título profesional de Licenciado en Comunicación y Publicidad

\section{AUTOR}

Polo Moreno, Génesis Ángela (0000-0002-2107-7037)

\section{ASESOR}

Peñaflor Guerra, Renato (0000-0003-3663-565X) 


\section{RESUMEN}

El product placement es un recurso que usa el marketing para posicionar determinados productos o marcas de forma menos invasiva para el público. La saturación publicitaria hizo necesario encontrar formas más sutiles de acercarse al consumidor lejos de la tanda publicitaria que se veía afectada por el zapping. El product placement enfrentó este problema al posicionar positivamente una marca anunciándola en un espacio de entretenimiento donde agarraba al espectador por sorpresa.

Con el desarrollo tecnológico, más medios se abrieron a esta forma de publicidad. Youtube, por ejemplo, tiene centenas de videos donde se puede apreciar product placement pues en su red existen canales destacados que terminan convertidos en espacios de anuncio. Quienes dirigen estos canales son llamados "youtubers" y en sus videos hacen de todo: desde compartir su vida personal con el público hasta probar productos en vivo. Sin embargo, la efectividad que podría tener el product placement para incrementar las ventas o la recordación de marca todavía no resulta concluyente cuando se entra al campo de las redes sociales. En la industria de la belleza, se ha hecho regla ver a youtubers recomendando marcas en sus videos o usándolas como parte del programa, pero no hay ninguna prueba de qué es lo que se está logrando al hacerlo.

Es así como surge el interés de investigar la relación que tiene el product placement de productos de belleza en los vlogs de youtubers con distintos elementos que podrían tener un impacto sobre la decisión de compra del público. En el siguiente trabajo, a fin de estudiar el tema propuesto, se toma como caso de estudio la campaña que Vogue Cosméticos utilizó durante su introducción al mercado peruano. Mediante un estudio exploratorio, se demostró que aunque la tendencia de los influencers esté en alza, no existe una relación directa entre el product placement y un incremento en la recordación de marca, al menos para las usuarias del mercado peruano. Los resultados de este estudio contribuyen a entender el comportamiento de la consumidora moderna de productos de belleza en una era dominada por el prosumidor.

Palabras clave: Product placement ; Youtube ; beauty guru ; productos de belleza. 


\section{ABSTRACT}

The Product placement is a resource that marketing uses to position certain products or brands in a less invasive way for the public. Advertising saturation made it necessary to find more subtle ways of approaching the consumer away from the advertising about that was affected by the zapping. The product placement faced this problem by positively positioning a brand by announcing it in an entertainment space where it grabbed the viewer by surprise.

With the technological development, more means were opened to this form of advertising. YouTube, for example, has hundreds of videos where you can see product placement because in its network there are prominent channels that end up converted into ad spaces. Those who run these channels are called "youtubers" and in their videos they do everything: from sharing their personal life with the audience to tasting live products. However, the effectiveness that product placement could have to increase sales or brand recall is still not conclusive when entering the field of social networks. In the beauty industry, it has become a rule to see youtubers recommending brands in their videos or using them as part of the program, but there is no proof of what is being achieved by doing so.

This is how interest arises in investigating the relationship that the product placement of beauty products has in the vlogs of youtubers with different elements that could have an impact on the purchasing decision of the public. In the following work, in order to study the proposed topic, the campaign that Vogue Cosméticos used during its introduction to the Peruvian market is taken as a case study. Through an exploratory study, it was shown that although the tendency of the influencers is on the rise, there is no direct relationship between the product placement and an increase in brand recall, at least for the users of the Peruvian market. The results of this study contribute to understand the behavior of the modern consumer of beauty products in an era dominated by the prosumer.

Keywords: Product placement; Youtube ; beauty guru; beauty products. 


\section{Tabla de contenido}

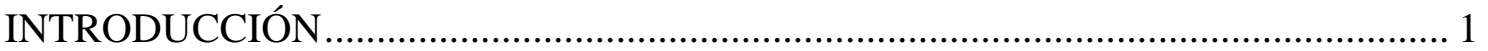

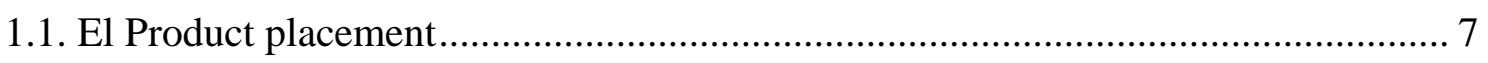

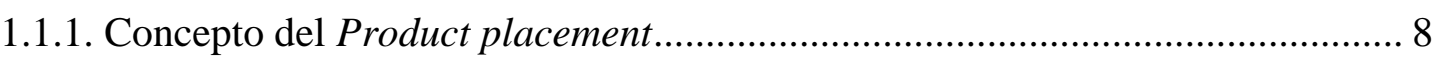

1.1.2. Modalidades de emplazamiento: ................................................................. 10

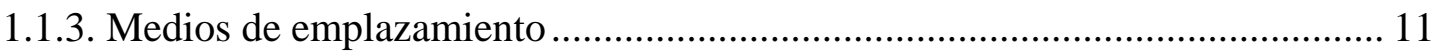

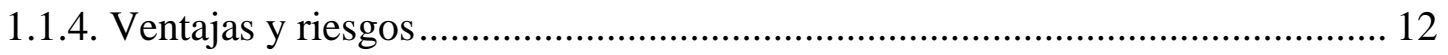

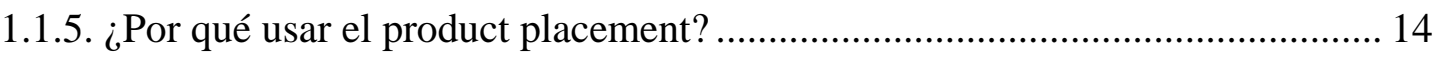

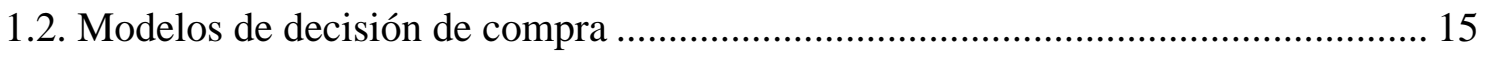

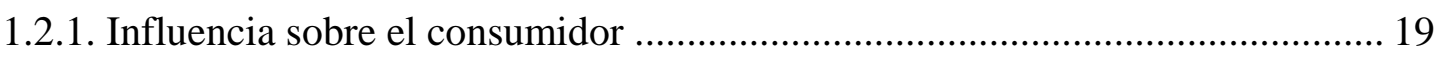

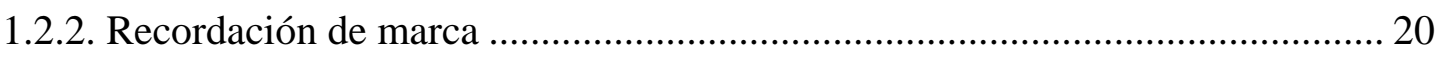

1.2.3. Nuevos canales para acercarse al consumidor............................................... 23

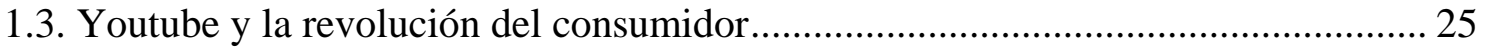

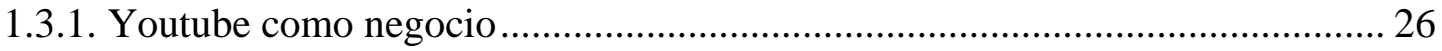

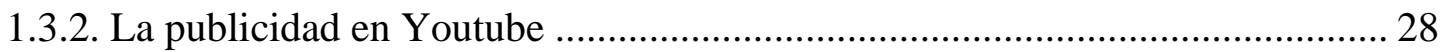

1.3.3. Los Youtubers: nuevos agentes publicitarios ................................................ 29

1.3.4. Publicidad en el UGC y product placement en Youtube.................................. 30

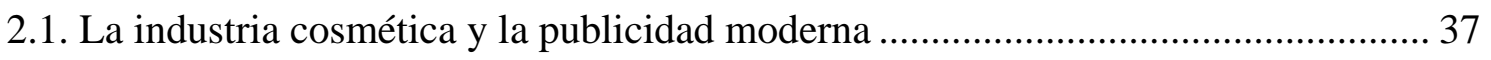

2.1.1. Importancia del posicionamiento y la recordación de marca para la industria

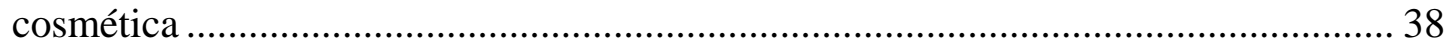

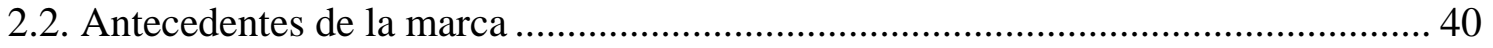

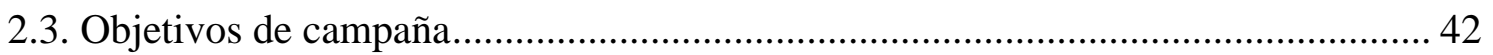

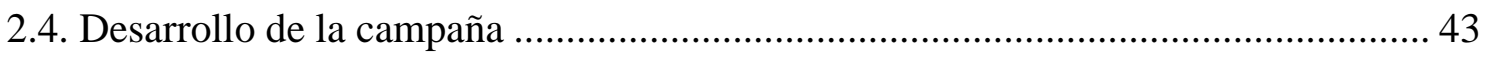

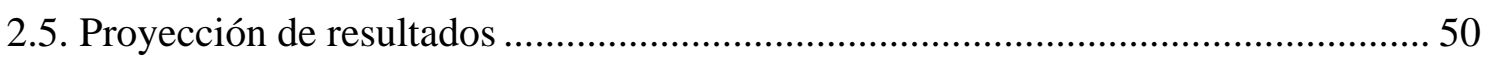

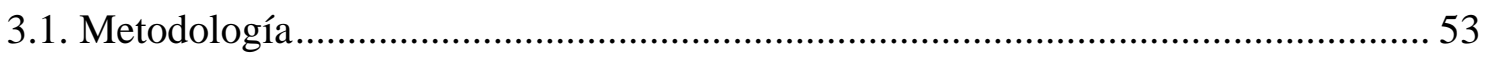

3.1.1. Planteamiento de la investigación .................................................................. 53

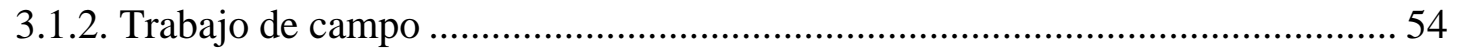

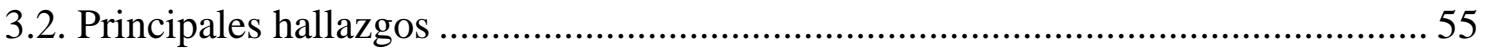

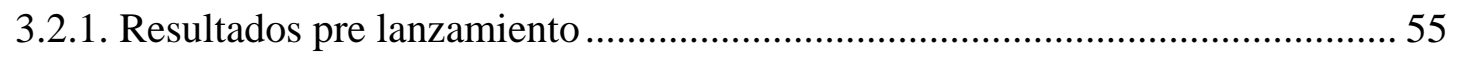

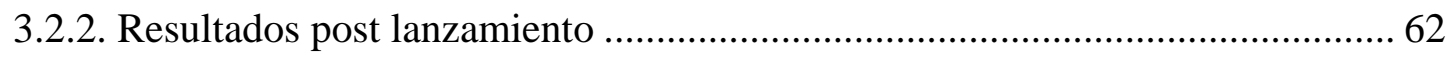

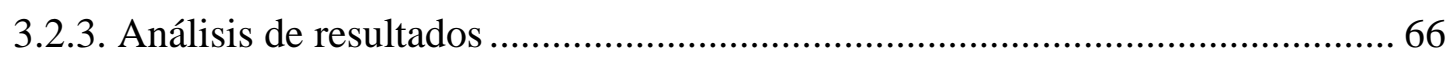

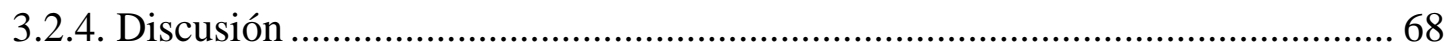




\section{Índice de figuras}

Figura 1. Modelo Howard-Sheth (1969) .................................................................. 15

Figura 2. Modelo de decisión de compra de Nicosia (1974)........................................ 17

Figura 3. Modelo de toma de decisiones del consumidor .......................................... 18

Figura 4. Grado de confianza de los consumidores en el mundo respecto a ciertas

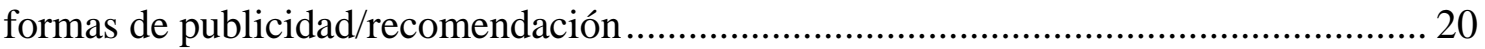

Figura 5. Modelo de Conocimiento de Marca de Keller (1998) ..................................... 22

Figura 6. Visitas por categorías de los videos de Youtube........................................... 26

Figura 7. Análisis demográfico del público de Youtube.com ........................................ 27

Figura 8. Rol de los Youtubers en la vida de los adolescentes..................................... 31

Figura 9. Captura de publicidad en el fanpage de Vogue Perú del día 8 de septiembre 44

Figura 10. Captura de publicidad en el fanpage de Vogue Perú del día 4 de septiembre

Figura 11. Captura de video promocional en el fanpage de Vogue Perú ...................... 46

Figura 12. Captura de publicidad en el fanpage de Vogue Perú del día 31 de agosto ... 47

Figura 13. Captura de los canales de ManiMake Perú, Adistyling y Vibela Mood ....... 48

Figura 14. Captura de publicidad en el fanpage de Vogue Perú ..................................... 49

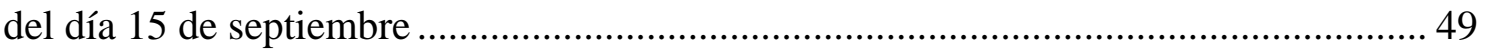

Figura 15. Las marcas de cosméticos más recordadas por la muestra ........................... 55

Figura 16. Reconocimiento de la marca Vogue antes y después de la campaña.............56

Figura 17. Presencia de Vogue Cosméticos en medios y publicidad ..............................5 57

Figura 18. Frecuencia de visualización de videos en Youtube.........................................57

Figura 19. Videos más vistos por la muestra en Youtube ….......................................... 57

Figura 20. Percepción de la influencia de las amistades ............................................. 58

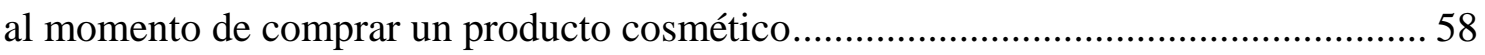

Figura 21. Percepción de influencia de los colegas al momento.....................................59

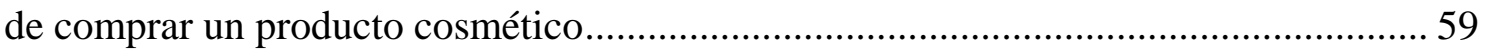

Figura 22. Percepción de influencia de los comerciales de televisión ............................ 59

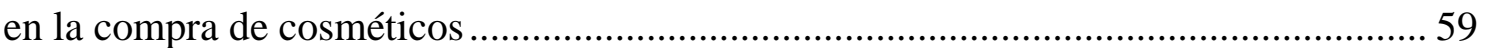

Figura 23. Percepción de influencia de Facebook en la compra de productos cosméticos

Figura 24. Percepción de la influencia de la recomendación de youtubers...................... 60

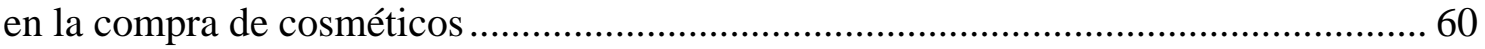


Figura 25. Percepción de influencia de blogueras e influencers en la compra de productos cosméticos 60

Figura 26. Percepción de la influencia de las recomendaciones de tiendas 61

en la compra de cosméticos 61

Figura 27. Percepción de la influencia de la prueba de producto 62

antes de comprar un cosmético. 62

Figura 28. Percepción de la importancia del product placement en blogs de belleza.... 62

para la decisión de compra de un producto cosmético 62

Figura 29. Uso de los productos de la marca Vogue.... 63

Figura 30. Comparación de la percepción de la influencia de la publicidad en Facebook

sobre la decisión de compra de productos cosméticos 64

Figura 31. Comparación de la percepción de la influencia de las recomendaciones de Youtubers sobre la decisión de compra de productos cosmético 64

Figura 32. Comparación de la influencia de recomendación de blogueras e . 64 influencers sobre la decisión de compra de productos cosméticos 65

Figura 33. Comparación de la importancia que tiene el uso de productos cosméticos por parte de blogueras de belleza o youtubers sobre la decisión de compr 65 


\section{Índice de tablas}

Tabla 1. Mención de la marca en Youtube y su relación con la recordación.................. 66

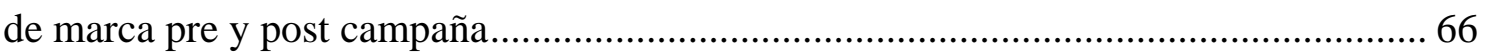

Tabla 2. Influencia de la recomendación de Youtuber y su relación con la.................... 66

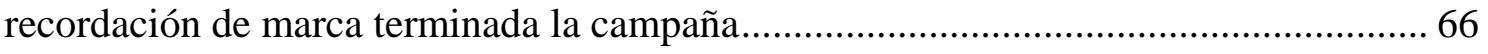

Tabla 3. Influencia de la recomendación de bloguera y su relación con la.................... 67

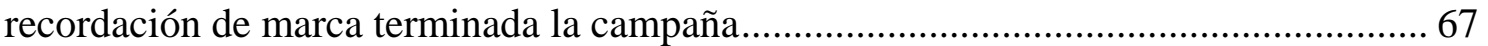

Tabla 4. Influencia del uso de los productos por Youtubers antes y después de la campaña y su relación con la recordación de marca pre y post campaña.

Tabla 5. Factor de correlación del uso de los productos por Youtubers y ..................... 67

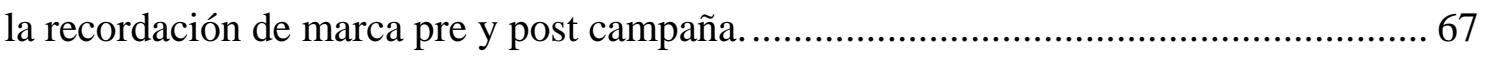

Tabla 6. Diferencias en la recordación de marca pre/post campaña y su relación con la mención de la marca en Youtube

Tabla 7. Prueba Chi-cuadrado para las diferencias en la recordación de marca pre/post campaña y su relación con la mención de la marca en Youtube 71

Tabla 8. Factor de Correlación entre las diferencias en la recordación de marca .......... 72

de Vogue pre/post campaña y la mención de la marca en Youtube 


\section{INTRODUCCIÓN}

La saturación publicitaria es una realidad. Casi en todas partes se ven cientos de marcas, cientos de anuncios que promocionan sus ofertas por las calles sin que los consumidores puedan tener un descanso frente a tantos estímulos. Sin embargo, en la década de los 90, el zapping y otras opciones creadas para bloquear anuncios publicitarios amenazaron con la muerte de la publicidad televisiva. Para 1999, el 62\% de los publicistas mostraba abiertamente su falta de confianza hacia la publicidad para la televisión (Association of National Advertisers, 2010), así que los anunciantes se vieron en la necesidad de encontrar nuevos espacios donde promocionar sus productos de modo que resultara menos intrusivo para la audiencia (Baños y Rodríguez, 2003).

Uno pensaría que así es como se dio a parar con la invención del product placement, pero la verdad es que los registros indican que se hizo por primera vez en 1985, cuando los hermanos Lumière colocaron una marca de cervezas en uno de sus primeros cortos mudos (Al Kadi, 2013). Aun así, la moda del product placement no floreció hasta su llegada a la radio. En 1930 se comenzó a dar la práctica de que ciertas marcas financien el desarrollo de un producto narrativo a cambio de promocionarse. Este fue el caso de las soups operas, novelas radiales en vivo que eran financiadas, inicialmente, por alguna conocida marca de detergente (Russel y Belch, 2005). Posteriormente llegaría a Hollywood para dar el boom en 1948, tras el desarrollo de la película Mildred Pierce y la inclusión de la marca de whisky Jack Daniel's dentro del largometraje (Nebenzahl y Secunda, 1993).

Hoy sabemos que el product placement constituye una de las herramientas más recurrentes para que un publicista pueda promocionar determinado producto de forma masiva. Sea en la televisión, en el cine o incluso en los anaqueles para coleccionistas, ver a nuestros personajes favoritos junto a las marcas de moda se ha comprobado como un estupendo gancho entre los clientes (Thielman, 2013). Pasó con los chocolates Reese's Pieces luego del estreno de E.T. y con los relojes Omega gracias a James Bond: Die Another Day; se ve en los programas de televisión local a diario y en la radio. Posicionar un producto dentro de un contenido atractivo para el espectador es una forma de fortalecer la relación que este tiene con una marca (Wolfe, 2010). 
En principio, el emplazamiento buscaba un retorno inmediato mediante la influencia sobre la decisión de compra entre los consumidores. Sin embargo, lo riesgoso de esta estrategia y las dificultades que se encuentran para ejercer un control certero sobre su impacto en el público, hizo que el objetivo fuera, de modo más realista, dar a conocer el producto y generar recordación hacia la marca (Baños y Rodríguez, 2012). Distintos estudios se dedicaron a analizar si la influencia que tenía el product placement en medios tradicionales como el cine y la televisión era efectivamente positiva sobre la recordación de marca (Abdul Adis et al., 2015). La mayoría demostraba que esta técnica aumentaba la decisión de compra y la recordación de los productos; sin embargo, llevada la investigación al campo de lo digital, los resultados no resultaban confiables por la falta de control en los resultados que existe alrededor de estas campañas y las muchas variables a las que son sensibles (Abdul Adis et al., 2015; Gageler y Van Der Schee, 2016).

Como los medios digitales son espacios abiertos, desarrollados en colaboración por usuarios y empresas privadas, las redes sociales se posicionaron como un espacio de encuentro para comunicarse con nuevos consumidores potenciales (Abdul Adis et al., 2015). Por eso no sorprende que una de las primeras marcas en encontrar lo que la audiencia buscaba en materia de contenidos audiovisuales que podían compartirse de manera libre fue Youtube, empresa que ahora es reconocida como el tercer destino digital más popular entre los usuarios (Holland, 2016).

Youtube ofrecía a los usuarios la posibilidad de ser generadores de contenidos audiovisuales en lugar de solo consumidores y, luego de algunos años, un grupo de usuarios populares dio lugar al término youtuber para referirse a quienes hacían negocio mediante el contenido que compartían en sus canales de Youtube (Holland, 2016). Es por ello que las marcas vieron en este portal una posibilidad de inversión para anunciar sus productos mediante celebridades que se mostraban más cercanas al público y que parecían ofrecer una opinión honesta desde su experiencia como consumidores independientes.

Youtube empezó como un negocio que buscaba generar dinero desde una necesidad simple en los usuarios: compartir contenido propio. Sin embargo, desde su compra por parte de uno de las empresas más importantes de hoy, Google, el contenido que se ve en el portal ha sido desplazado por videos cada vez más comercializados y profesionales (Holland, 2016). Producto de esa experiencia, se sabe que "Youtube tiene más espectadores americanos entre las edades de 18 y 49 años que cualquier canal de cable, 
lo que ayuda a que su retorno incremente en \$1 billón en el 2015" (Luscombe, 2015) y se ha convertido en el principal destino para los niños que hacen logg in en Internet.

Este es el product placement que la tecnología ofrece actualmente para acercarse a distintos nichos: grupos que consumen a diario el contenido que crean estos youtubers y que simbolizan una tajada nada despreciable del mercado de consumidores. Hoy, cientos de personas trabajan generando contenido propio y atractivo para colgar en Youtube. De este modo pueden promocionar marcas que les paguen por representarlas y recomendarlas.

Dicho lo anterior, queda clara la relevancia de este medio para los anunciantes y la gran posibilidad que ofrece para acercarse al público de sus productos en un entorno dominado por el contenido digital. Si se quiere, podría decirse que los youtubers cumplen la misma función que E.T. y James Bond: respaldan marcas aprovechando la empatía que generan con el espectador. No sorprende entonces encontrar ejemplos de éxito entre youtubers que crean contenido cómico o que tengan alguna utilidad puntual para los usuarios. Esto pasa, especialmente, en la industria cosmética que aprovecha la imagen de distintas blogueras para compartir consejos de belleza y recomendar "sus marcas favoritas" (Lima, Carvalho y Pinto, 2016, p. 2721).

Como señala un artículo del portal Perú Marketing "YouTube es ya la primera fuente de información sobre productos entre jóvenes y consumidores" (2015). YouTube se posiciona como la primera fuente de formación sobre productos para los Millennials. Dicho hecho se ve reflejado en el primer informe trimestral del 2014 de YouTube Insights, donde el 100\% de los usuarios entre 18 y 34 años accede a la plataforma de videos online cuando necesita conocer más detalles sobre aquellos productos que están interesados en comprar (Puro Marketing, 2015).

Sin embargo, por mucho que se pueda aumentar la visibilidad de una marca, a veces es difícil trasladar esa información a los aumentos en índices de venta (Wolfe, 2010). "Pese al vasto crecimiento de la web 2.0., la investigación académica no ha seguido el paso al desarrollo de técnicas de publicidad para el contenido generado por el usuario" (Verhellen, Den y De Pelsmacker, 2013, p. 287) y los efectos que tiene en sus espectadores. La mayoría de investigaciones se han quedado en un análisis superficial del "fenómeno youtuber" y no han descubierto su verdadero potencial como técnica de 
mercadeo; ni hablar de los efectos de posicionar una marca en línea (Verhellen, Den y De Pelsmacker, 2013).

Investigaciones recientes se han enfocado en analizar cómo es que los youtubers han resultado capaces de construir comunidades digitales tan rápido y en espacios donde las marcas profesionales habían fallado al intentarlo (Chen, 2013 y Franssen, 2015). También se ha estudiado el proceso de "celebrificación" mediante el cual los youtubers convierten su imagen pública en una marca que puede llevarse bien con otros productos y servicios de cierto tipo que sea afín a la imagen que quieren proyectar (Page, 2012 y Smith, 2014). Sin embargo, más allá del proceso de creación de marca (sea para los mismos youtubers o las empresas patrocinadoras), falta mayor investigación sobre los logros tangibles del product placement en los canales de youtube cuando es usado por marcas comerciales.

Es por ello que, mediante un estudio cuasi exploratorio, se buscará en esta investigación responder a la siguiente pregunta: ¿Cuál es la percepción de influencia del product placement de productos belleza sobre el proceso de decisión de compra cuando este se ubica en el contenido de vlogs de Youtubers? Para responder a esta duda se analizará el desarrollo de una campaña digital iniciada por Cosméticos Vogue con motivo de su ingreso al mercado peruano en el año 2017. Para ayudar a entender la influencia que puede tener el emplazamiento de productos de belleza en videos subidos por youtubers, nuestro público de estudio comprenderá mujeres entre los 24 y 32 años, pertenecientes al nivel socio-económico $\mathrm{BC}$, que residan en la ciudad de Lima y que usen regularmente la red social Youtube. 


\section{Marco teórico}


A lo largo de este primer capítulo, se buscará ofrecer un marco teórico completo que luego sea útil para responder a la pregunta que tiene como objeto esta investigación. Para ello, primero será necesario definir los conceptos más relevantes en torno al product placement, la recordación de marca y otros conceptos publicitarios que resulten relevantes al momento en que un cliente se decide a comprar determinado producto.

Así mismo, el significado de product placement, además de atender a distintos conceptos, comprende ciertos elementos a considerar para su comprensión, tales como las modalidades de empleo y los distintos medios en los que se puede ubicar. Así mismo, entenderemos las ventajas y desventajas que ofrece su uso dentro del marco de la práctica publicitaria.

Posteriormente, se revisará el modelo de decisión de compra y los pilares sobre los que se sostiene la acción de compra según la entienden marketeros y publicistas. Aquí revisaremos conceptos como la influencia sobre el consumidor, el posicionamiento y la recordación de marca, entre otros.

Para cerrar el capítulo, se dará un repaso a la evolución de la red social de videostreaming Youtube, dado que es el nuevo gran medio del que la publicidad puede valerse para tener una aproximación positiva con su público, fuera de los canales tradicionales. Por ello es que estudiaremos su trayectoria: desde su reciente creación hasta su posicionamiento actual como una de las páginas web más visitadas y usadas de la actualidad. 


\subsection{El Product placement}

Las marcas están en todas partes; las vemos a diario. Todas son diferentes y todas tienen algo que ofrecernos. Algunas prometen darnos algo muy original, necesario o de una calidad sorprendente, y otras, resultan siendo más de lo mismo o peor. Es aquí donde se hace necesaria la presencia de la publicidad como una herramienta que nos permite comunicar al consumidor ciertos atributos y beneficios que diferencian a un producto del resto (Martí, Cabrera y Aldás, 2012). De este modo, los usuarios pueden escoger la oferta que mejor satisfaga sus necesidades sin quedar perdidos entre la gran cantidad de opciones que se les ofrece.

Con el pasar del tiempo, las técnicas publicitarias han ido evolucionando y perfeccionándose; han encontrado nuevas formas de acercarse al público y se han ido desarrollando para integrarse al mercado. Si en un inicio se soportaban en la imprenta y en la radio, luego se hicieron paso a la televisión y el cine (National Association of Advertisers, 2010). Más recientemente, al Internet y las redes sociales (Wolfe, 2010). La rutina de los consumidores se hallaba tan saturada de mensajes publicitarios que estos empezaron a desarrollar defensas contra los anuncios y cada vez recordaban menos lo que se les decía (Baños y Rodríguez, 2003) o se volvían más hábiles en ignorarlo (Rose, 2012).

Los profesionales del marketing y la publicidad no tardaron en darse cuenta de que debía encontrar a su público en el momento menos esperado, mientras veían su programa favorito o cuando iban a ver una película. De ahí nació el product placement (o emplazamiento de productos, en español), de la oportunidad de asociar una marca a la experiencia positiva que un producto ofrecía para los espectadores (Baños y Rodríguez, 2012).

Desde entonces, esta técnica de publicidad con miras a incrementar las ventas utilizando una comunicación relativamente menos intrusiva ha sido estudiada por distintos profesionales. Aunque al ser una práctica que va evolucionando junto a su audiencia y a los medios en que se posiciona, es entendible que las investigaciones no sean concluyentes sobre sus resultados. Esto se debe a que entran en juego más variables que 
puedan afectar la experiencia de compra de los usuarios, así como las impresiones que reciben del product placement (ocasionadas por el argumento del producto audiovisual, simpatías por los actores, una temporada de moda, etc.), por lo que resulta más difícil llegar a una conclusión definitiva sobre su efectividad para incrementar las ventas.

Sin más dilataciones, veamos lo que se puede entender por product placement. En primera instancia, tomaremos como definición principal la descripción que hacen los autores Miguel Baños y Teresa Rodríguez, quienes han realizado ya varias publicaciones que apuntan a entender la actividad del product placement. Ambos son comunicadores con una larga trayectoria en publicidad, narrativas audiovisuales y estudios sobre la construcción de marca desde el empleo del marketing comercial, razón por la cual ofrecen una visión amplia de la práctica.

No obstante, esta visión por sí sola no sirve de mucho si no se articula con otras conceptualizaciones, como las que hacen los autores Bouton y Yustas para diferenciar entre las distintas modalidades de product placement. Otros, también dan una brevísima explicación de los medios y modos en los que esta práctica se puede ir aplicando durante el trabajo publicitario.

\subsubsection{Concepto del Product placement}

El product placement no es una práctica nueva y, desde su aparición, se ha ido aprovechando de los cambios en el mercado y la dinámica que existe entre marcas y usuarios para comunicar determinados mensajes (Baños y Rodríguez, 2012). Para aproximarnos a un concepto temprano del product placement, podemos acudir a la siguiente definición:

El product placement consiste en colocar un producto, marca, servicios, ...de forma intencionada en una obra audiovisual, gráfica o literaria, a cambio de una retribución económica o de cualquier otro intercambio entre la empresa y la productora, intercambio que puede ser de abastecimiento de equipos, asesoramiento, etc. (Baños y Rodríguez, 2003, p. 37).

La masificación de esta técnica de mercadeo en el cine se produjo por el año de 1946, luego de que Joan Crawford saliera tomando un whisky de Jack Daniel's en la película de Michael Curtiz titulada Mildred Pierce. Antes ya se habían visto etiquetas o logotipos 
apareciendo en otras películas, pero aquella fue la primera vez que una marca solicitó aparecer en una producción narrativa y pagó como anunciante por el espacio dado (Nebenzahl y Secunda, 1993).

Naturalmente, también se hizo común que el product placement se produjera por pedido del proyecto audiovisual para contar con un auspicio económico. Uno de los casos más recordados en estos casos es el de Steven Spielberg y los chocolates que comía un tierno extraterrestre perdido en la Tierra. Cuando el joven director se encontraba preparando el largometraje E.T. El extraterrestre imaginó que los M\&M serían los dulces favoritos del alienígena protagonista (Wolfe, 2010). La compañía se negó pues temían que la apariencia de E.T. espantara a los niños pequeños que vieran la película. Spielberg entonces intentó con los chocolates Kisses de la Hershey's Chocolate Company. La empresa también evitó poner en riesgo su imagen, pero propuso realizar el product placement con uno de sus productos menos conocidos: los Reese's Pieces. La película estrenó en 1982 y las ventas de Reese's Pieces se dispararon en todas las tiendas y autoservicios estadounidenses (Newell, Salmon y Chang, 2006). Los espectadores habían simpatizado con E.T. y con todo lo que les gustaba a él y a su compañero terrestre, Eliot, así que comer los chocolates Reese's Pieces les permitía vincularse emocionalmente con sus héroes del momento; los hacía sentirse cerca de ellos (Wolfe, 2010).

Tras ganar su lugar en el cine y la televisión, el product placement siguió incursionando en nuevos espacios, como la música. La producción de videos musicales inicialmente solo era un medio para que los artistas mostraran su creatividad y añadieran contenido a sus obras, pero las empresas empezaron a descubrir que también podían generar valor de marca y retorno (Plambeck, 2010). La realidad es que la colaboración entre artistas y marcas ha dado frutos para ambos y se ha mostrado como un negocio más que rentable. Desde la marca inglesa Mini hasta la compañía telefónica Virgin, todas las grandes marcas que coexisten en la actualidad buscan asociarse con cantantes y grupos musicales para publicitar sus productos y beneficiarse de sus círculos de fans (Plambeck, 2010). No sorprende entonces que la industria del product placement esté creciendo más del $30 \%$ cada año (Kowalczyk y Royne, 2012) ni que su valor fuera estimado en 8.25 billones de dólares americanos para el 2012 (Belasubramanian et al., 2014). 


\subsubsection{Modalidades de emplazamiento:}

El product placement puede darse de tres maneras, según lo definen los autores Bouton y Yustas en su texto Product placement. La publicidad eficaz. La principal diferencia entre cada modalidad radica en el protagonismo que se le da al emplazamiento y el nivel de relevancia que tiene el producto o servicio para el desarrollo de la historia presentada en el proyecto audiovisual, así como si puede verse a la marca físicamente o si solo es mencionada. A continuación se explicará cada una de las modalidades:

\section{- Emplazamiento visual:}

Hablamos de un emplazamiento visual cuando el producto o marca son mostrados en pantalla (Bouton y Yustas, 2012). Además, se dice que el emplazamiento es activo si algún personaje interactúa con el producto. Mientras que, si solo figura como un elemento decorativo, estaremos ante un emplazamiento pasivo. En algunas ocasiones, la presencia de una marca es tan fuerte que la sugerencia del empaque en el encuadre es suficiente para tener un emplazamiento visual efectivo (Bouton y Yustas, 2012).

\section{- Emplazamiento verbal:}

Cuando el producto o servicio es mencionado por algún personaje durante el transcurso del guión. No es muy frecuentado en medios tradicionales como el cine o la televisión porque pierde el factor visual, pero permite darle personalidad a una marca o producto mediante el sonido (Bouton y Yustas, 2012).

\section{- Emplazamiento conjunto:}

Es una combinación de las dos modalidades anteriores e implica un alto nivel de interacción con el producto, servicio o marca. Hace que el emplazamiento tome un rol central en la escena, por lo que puede generar un alto nivel de recordación si se ejecuta adecuadamente (Bouton y Yustas, 2012).

Para los fines concretos de esta investigación, el estudio deberá centrarse en el emplazamiento conjunto ya que, al analizar un espacio audiovisual dedicado al videostreaming, tendrá tanta importancia lo que digan los youtubers sobre las marcas y/o productos, como lo que se muestre en el video mientras tanto. Un ejemplo cotidiano de emplazamiento conjunto se encuentra en los reviews de productos que ahora son tan comunes de ver en Youtube. Estos muestran a los vloggers probando en vivo los 
productos que reciben de las marcas y producen un mayor nivel de interacción con el público ya que dan una idea de cómo aplicarse el producto, los efectos inmediatos que puede tener sobre su cuerpo, los complementos con los que viene, etc.

\subsubsection{Medios de emplazamiento}

El product placement tiene muchas aplicaciones y cada una ofrece diferentes posibilidades de interacción con el usuario dependiendo de la estrategia que se quiera seguir. El nivel de inmersión que percibe el usuario dependerá del medio en el que se sustente el product placement. Por ejemplo, las redes sociales que ofrecen la opción de jugar en línea generarán mayor impacto que un comercial de televisión por la forma en la que el contenido interactúa con el usuario (Ansons, Wan y Leboe, 2011). Los medios más comunes en los que se puede ejecutar de forma tradicional el product placement son los siguientes:

\section{- En cine y televisión:}

Cuando se busca un emplazamiento masivo y de gran impacto, son los primeros medios a los que se piensa recurrir. El objetivo es, por el lado del anunciante, dar a conocer su marca y, por el de la productora, recibir una retribución económica a cambio (Córdoba, 2015).

\section{- En videojuegos:}

El emplazamiento en la industria de los videojuegos es un negocio que lo ha hecho incluso más rentable que otras industrias del entretenimiento, como la musical. Lo que pasa es que se aprovecha de una narrativa lúdica e interactiva para que el jugador sienta mayor conexión hacia la marca y sus valores (Maraña, 2016).

\section{- En videoclips:}

Aunque el videoclip nació para incentivar la compra de música entre el público más joven, con el desarrollo del Internet, las disqueras terminaron por rentabilizar este recurso. Esto ocurrió en parte para compensar la baja en sus ingresos luego de que la red permitiera que se compartan de forma pirata millones de discos digitalizados y se infrinjan los derechos de autor sobre las obras de sus artistas (Maraña, 2016). 
Cabe mencionar que estas categorías se han visto desdibujadas por la aparición de las nuevas tecnologías, haciendo que la distinción entre una y otra muchas veces no sea tan clara (Rose, 2014). Con el progreso de la "inserción digital”, las empresas publicitarias han hallado nuevas formas de acercarse a sus potenciales clientes. Mark Popkiewicz, CEO de la agencia británica de publicidad Mirriad, comentó lo siguiente en una entrevista para el diario The Guardian: "Hay un creciente entendimiento de que estamos siendo entrenados para ser ciegos a la publicidad" (Rose, 2014).

Una clara muestra de ello está en que ahora las empresas llegan a alterar series de televisión y películas antiguas para posicionar sus marcas mediante imágenes hechas por computadora (Rose, 2014). Esto incluso se puede hacer de modo que la publicidad sea escogida en base a cada localidad para lograr un product placement más relevante. Mientras tanto, las redes sociales han abierto nuevos caminos para que las marcas puedan anunciarse de modo más amigable ante sus usuarios (La Ferle, Edwards y Lee, 2008). Para efectos de esta investigación es necesario explicar algunos de los nuevos canales que se utilizan en el ejercicio del product placement.

\section{- En blogs:}

A este tipo de product placement se le ha llamado Blogvertising y nace al reconocerse el nivel de confianza con que cuentan algunos blogueros entre los seguidores de su comunidad (Sosa, 2016). Estos blogueros, que pueden liderar blogs personales o temáticos, son usuarios activos en sus redes sociales y creadores de contenido para sus propios medios por lo que la repercusión que tienen sobre sus seguidores es mayor a la que tienen los anuncios tradicionales (Sosa, 2016).

\subsubsection{Ventajas y riesgos}

Aunque todavía falta mucho por descubrir sobre el emplazamiento de productos, hay algunas ventajas y desventajas que se le han probado a esta práctica tan común. Los autores Baños y Rodríguez lo explican muy bien en su libro Imagen de marca y product placement, por lo que reproduciremos sus argumentos a continuación.

La principal ventaja que ofrece el product placement es que las marcas pueden ahorrarse los costos que traería una producción audiovisual para televisión de modo tradicional 
(Baños y Rodríguez, 2012). Lo mismo se ven reducidos los costos por la transmisión del anuncio, ya que el pago por los espacios publicitarios en medios tradicionales puede implicar cifras millonarias (Baños y Rodríguez, 2012). A estos beneficios se suman la capacidad de segmentación que permite instalar un mensaje dentro de un producto audiovisual como una serie o una película, además de la posibilidad de reposiciones en el futuro (Baños y Rodríguez, 2012).

Como el emplazamiento se da en el contexto de otra producción mucho más grande además, el realismo y la naturalidad que posee la historia también corren por cuenta de la producción original y no de la empresa anunciante. De esta afirmación se desprende que el nivel de atención que los espectadores prestan al anuncio de la marca y la predisposición con la que lo reciben es más favorable que cuando se presenta un anuncio tradicional (Baños y Rodríguez, 2012).

No obstante, aunque las ventajas que ofrece el product placement suenan más que atractivas, los anunciantes deberán asumir también algunos riesgos al escoger esta opción de publicidad. El más importante es la falta de control que se tiene sobre el mensaje. Las marcas no pueden tener un control real sobre las asociaciones que harán los espectadores una vez que noten la marca puesta en escena. Así mismo, si el emplazamiento es muy sutil, el producto podría pasar desapercibido entre el resto de elementos de la imagen y resultar un desperdicio de dinero (Baños y Rodríguez, 2012).

Otros problemas como la falta de coherencia entre el producto o servicio publicitado y el producto audiovisual en el que aparece pueden ser resueltos con un buen diálogo entre el anunciante y el equipo del proyecto audiovisual. Del mismo modo, con una buena estrategia se puede evitar que la marca cobre una relevancia innecesaria capaz de convertir el emplazamiento en una acción intrusiva para el espectador (Baños y Rodríguez, 2012).

El problema de fondo es, entonces, la falta de control que tiene el anunciante sobre los efectos de la mención y la eficacia del mensaje una vez que el producto — sea una película, un videoclip, el capítulo de una serie, etc.- es lanzado (Baños y Rodríguez, 2012). Es más, aunque muchas veces es considerada una estrategia obligada entre las herramientas de marketing modernas que utilizan las grandes corporaciones, la investigación actual sobre el product placement no permite anticipar resultados y no hay 
un modelo estandarizado que ayude a analizar cuantitativamente los beneficios de su uso (Baños, Rodríguez, Galiano, Marín y Ruiz, 2005).

\subsection{5. ¿Por qué usar el product placement?}

La investigación respecto de la efectividad del product placement se ha concentrado, principalmente, en el espectador televisivo y cinematográfico. Estudios previos han demostrado a lo largo de varias décadas que el emplazamiento de producto en estos medios tradicionales, cuando se hace de forma prominente y muy visible, produce una mayor capacidad para recordar una marca que la publicidad (Gupta y Lord, 1998; Williams, Petrosky, Hernández y Page, 2011).

El emplazamiento de producto puede usarse para atender a distintas necesidades, pero las más recurrentes son incrementar la visibilidad y exposición de la marca, así como capturar la atención e interés del público espectador. Se busca para aumentar el conocimiento de marca, incrementar la recordación en el público y facilitar su reconocimiento en los puntos de venta. También se usa para cambiar la actitud de los consumidores frente a las evaluaciones de preferencia y alentar comportamientos positivos respecto del posicionamiento de la marca (Panda, 2004; Kureshi y Sood, 2010). No obstante, los estudiosos coinciden en que una parte sustancial de los efectos del product placement se mantienen desconocidos (Van Reijmersdal, Neijens y Smit, 2009).

Para los profesionales del marketing, una de las razones primordiales para hacer uso del product placement es aumentar la recordación de marca (Panda, 2004). Por supuesto, hay ciertos detalles que ayudan a hacer efectivo el emplazamiento, como cuando se acompaña la aparición de algún sonido evocador de la marca o cuando el emplazamiento de la marca se muestra congruente con el producto audiovisual que se está observando (Williams, Petrosky, Hernández y Page, 2011). 


\subsection{Modelos de decisión de compra}

Desde siempre, las prácticas de mercadeo han tenido un origen empírico y analítico más que tratarse de una ciencia exacta. Y, obviamente, una de las principales preocupaciones de quienes las ejercían era entender qué lleva a que un individuo decida comprar una marca específica en lugar de otra de la competencia. Por ello, los profesores John Howard y Jagdish Sheth publicaron a finales de los 60 su Teoría del Comportamiento del Comprador, y con su nuevo modelo revolucionaron la forma en que comerciantes e inversionistas entendían el proceso de compra. Los especialistas sugirieron un modelo confiable para explicar el proceso de toma de decisión, que según ellos constaba de cuatro fases secuenciales: las entradas, los constructos perceptuales, los conscructos de aprendizaje y, finalmente, las salidas (Howard y Sheth, 1969).

Figura 1. Modelo Howard-Sheth (1969) ${ }^{1}$

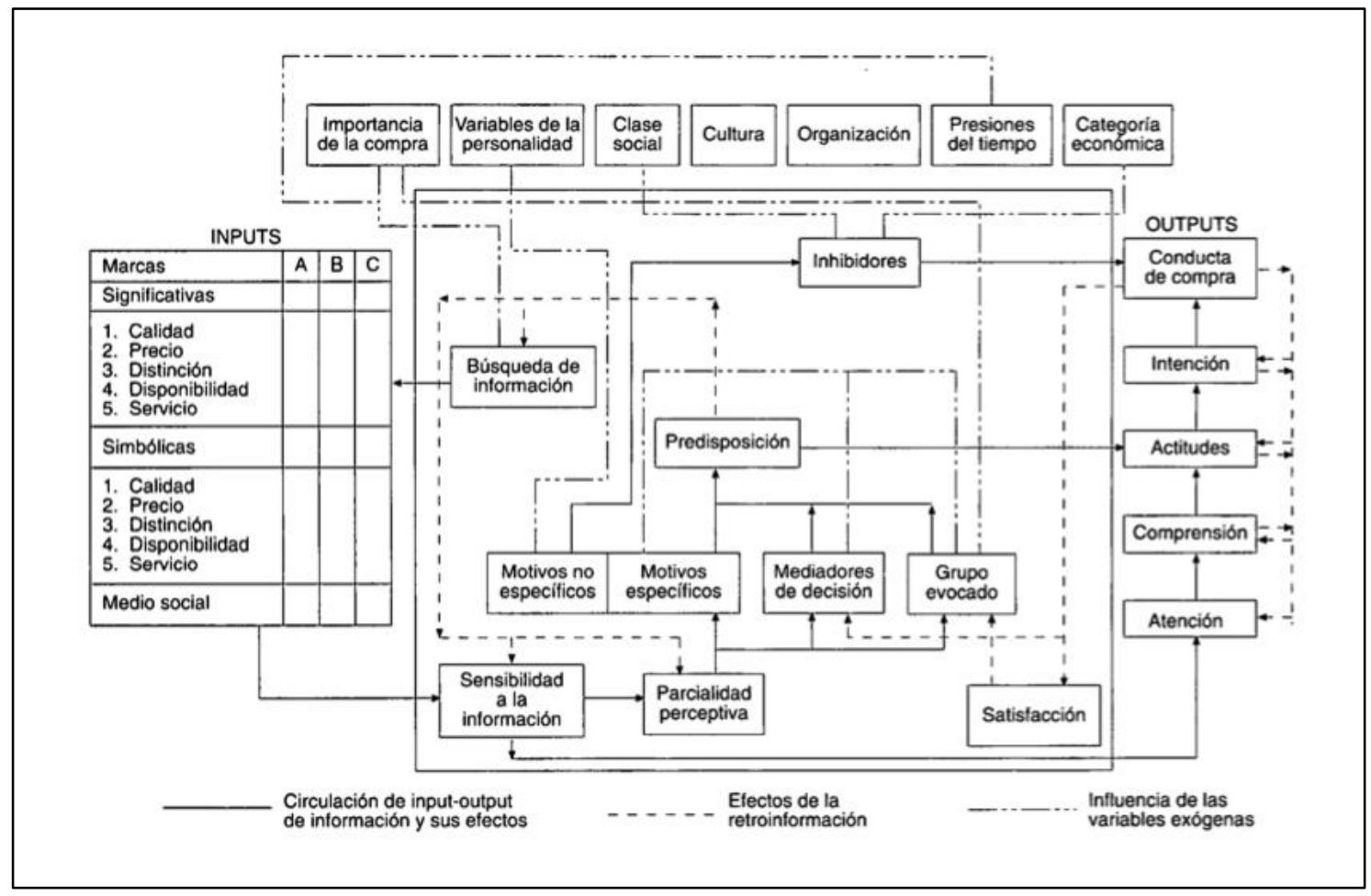

${ }^{1}$ Figura 1. Modelo del proceso de decisión de compra de John Howard y Jagdish Sheth. Tomado de Los modelos microanalíticos del comportamiento del comprador como herramientas para la estrategia comercial de la empresa por Luis Vivar Nebrada, 1991. 
El modelo propuesto por Howard y Sheth inicia su recorrido con las entradas o inputs, es decir, la información obtenida de distintas fuentes para responder las preguntas más básicas sobre un producto, servicio o marca: su utilidad, su apariencia y las opiniones que otros tienen de ello (Vivar, 1991). Estos estímulos luego son filtrados mediante ciertas variables endógenas y exógenas que permiten al individuo contrastar y comparar la información recibida con estímulos pasados o nueva información que es buscada a propósito durante el proceso de decisión (Howard y Sheth, 1969).

Una vez se ha alcanzado la tercera etapa del modelo, los autores proponen que es aquí donde entran en juego los constructos de aprendizaje del individuo, que son 4: la motivación, la comprensión de la marca, la confianza y, por último, la actitud (Howard y Sheth, 1969). Para hilvanar estos conceptos brevemente, podría decirse que la motivación es lo que impulsa al consumidor a iniciar el proceso de decisión. La comprensión de la marca es lo que se sabe al momento de evaluar la posibilidad de compra, quizás alguna distinción o una mención negativa en la prensa. La confianza es lo que determina si el comprador va a continuar o no con su decisión y la actitud, la predisposición frente a la marca que resulta de la experiencia propia de quien decide (Howard y Sheth, 1969), pues lógicamente el modelo culmina con la compra.

Si bien la propuesta de la dupla era revolucionaria para el campo del marketing por su carácter integrador, ha sido criticado en más de una ocasión por sus limitaciones dado el número de variables que contempla, así como que muchas de sus medidas utilizadas suelen tener baja correlación (Vivar, 1991). Muchos incluso se han aventurado a decir que, aunque el marco propuesto por Howard y Sheth es integrador, resulta una simple descripción del proceso de elección ya que sus variables son de difícil observación y, por lo tanto, carecen de validez experimental (Vivar, 1991). Por estos motivos es que al modelo de los profesores le siguieron otros como el de Francesco Nicosia (ver Figura 2) o el que propusieron en conjunto los autores Engel, Kollat y Blackwell.

Por ejemplo, el modelo de Nicosia busca aprovechar los elementos comunes entre distintas variables que, para él, tienen influencia sobre el consumidor. Estas variables pueden ser individuales y ambientales y las dispone de modo circular según lo que él llama “la visión amplia del comportamiento del consumidor” (Vivar, 1991). 
Figura 2. Modelo de decisión de compra de Nicosia $(1974)^{2}$

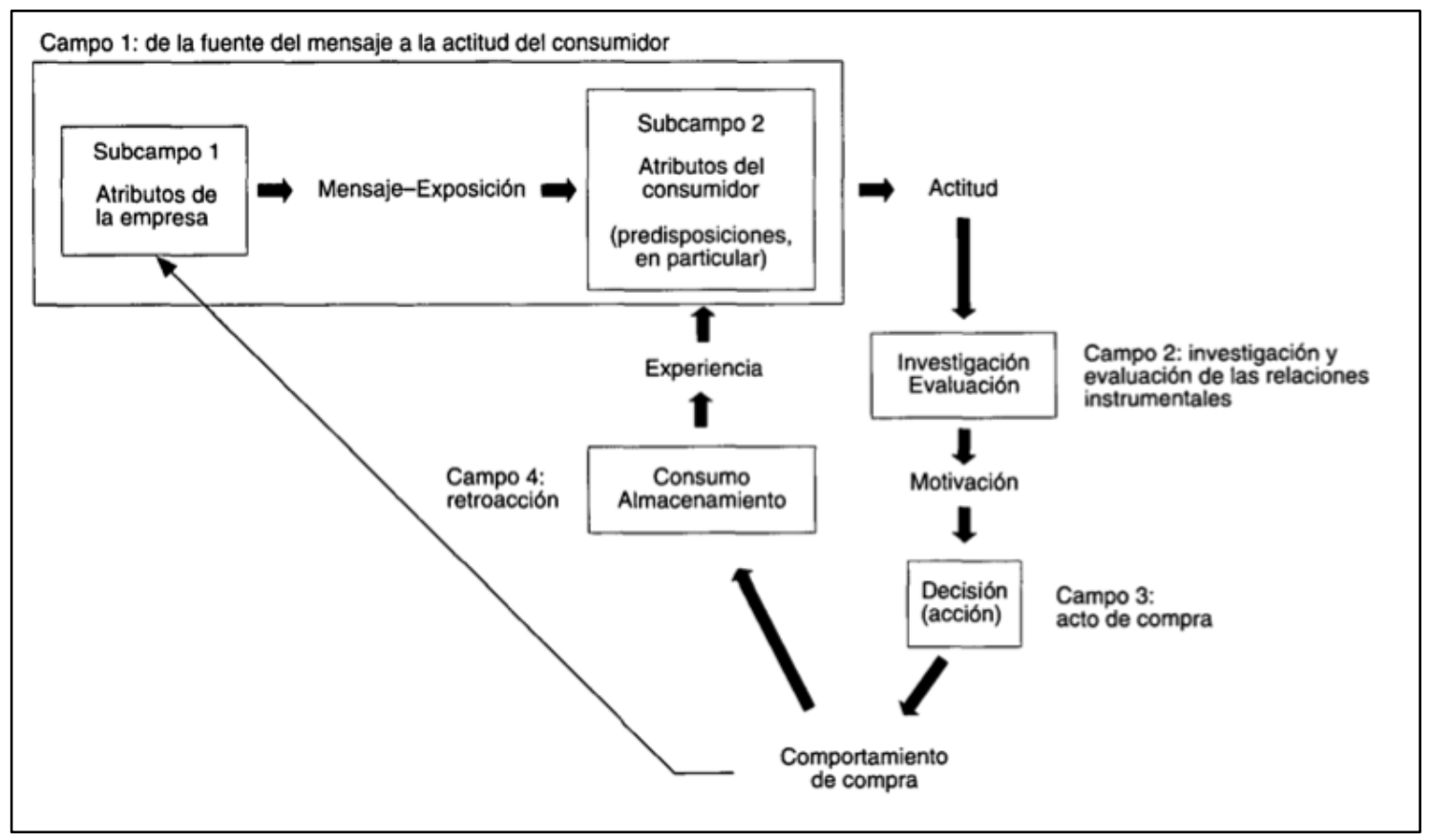

Por otra parte, modelos como el de Engel, Kollat y Blackwell suponen una complejidad muy alta para ser de utilidad práctica en esta investigación. Según estos tres autores, lo que determina una alta o baja complejidad del proceso de decisión de compra es la relevancia personal que el consumidor da al acto de compra (Vivar, 1991). No es igual comprar un lápiz labial a comprar un paquete de galletas, ni tampoco se puede comparar el proceso de elegir un auto nuevo con el de comprar una prenda. Por lo mismo, se habrá que considerar más o menos variables según la complejidad de la adquisición que impulsa el proceso de compra.

De todos los modelos, el más actualizado y aceptado es el de los autores Schiffman y Kanuk (ver Figura 3). En su modelo están consideradas distintas influencias del entorno, sean la cultura, la familia, la clase social, las influencias personales y la situación en que

\footnotetext{
${ }^{2}$ Figura 2. Modelo del proceso de decisión de compra de Francesco Nicosia. Tomado de Los modelos microanalíticos del comportamiento del comprador como herramientas para la estrategia comercial de la empresa por Luis Vivar Nebrada, 1991.
} 
se produce la compra. De este modo se puede tener una visión amplia pero simplificada de los factores que intervienen en el proceso de decisión de compra.

Figura 3. Modelo de toma de decisiones del consumidor ${ }^{3}$

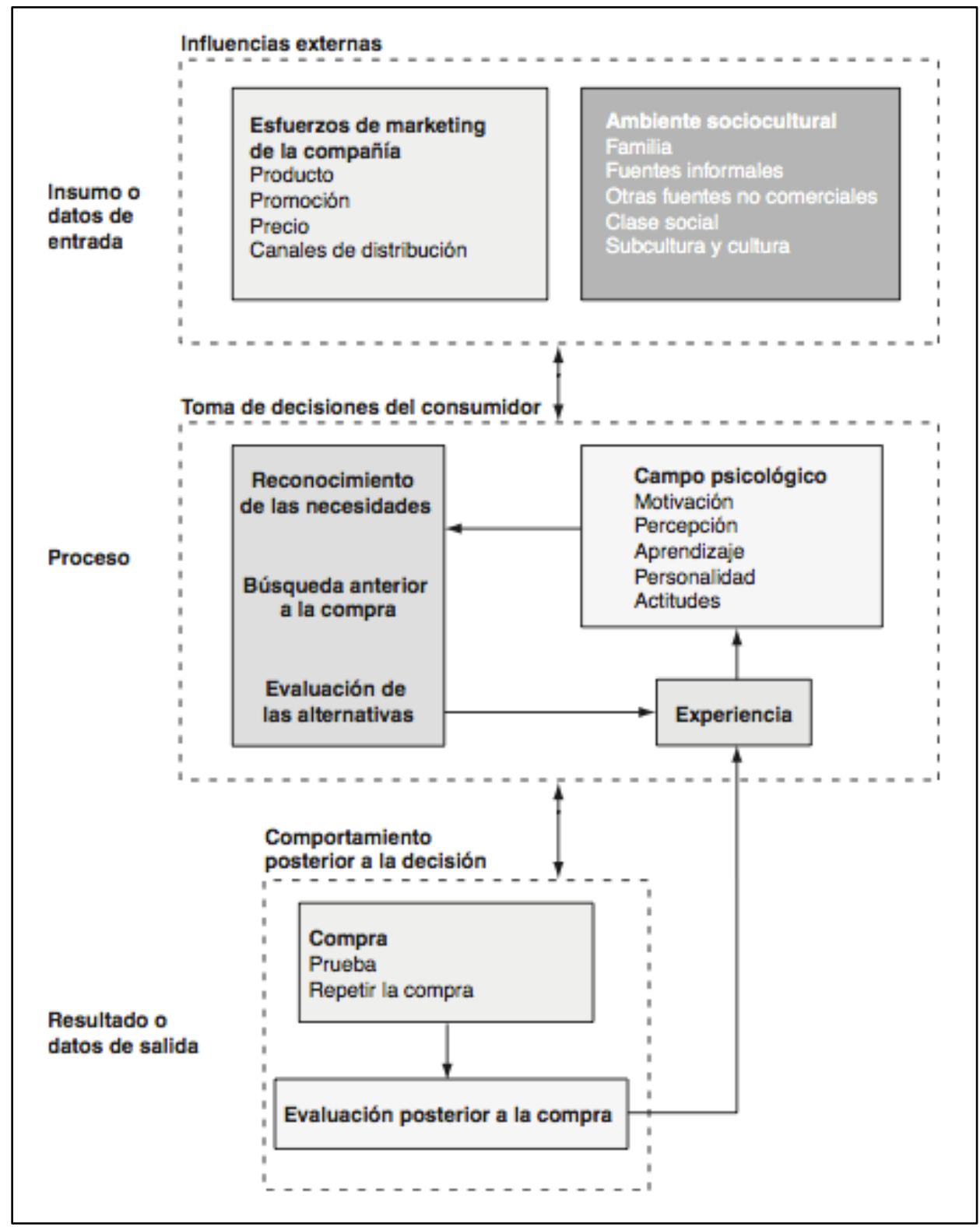

${ }^{3}$ Figura 3. Modelo de toma de decisiones del consumidor propuesto por Leon Schiffman y Leslie Kanuk. Tomado de la décima edición de su libro Comportamiento del Consumidor, 2010. 
Aunque los modelos difieren entre sí, hay conceptos recurrentes que parecen definir el proceso de decisión de compra de los consumidores. Tal es el caso de la influencia sobre el consumidor y la recordación de marca. Ambos serán explicados a continuación:

\subsubsection{Influencia sobre el consumidor}

En este apartado se comenzará dando una definición exacta de la palabra "influencia" según la Real Academia Española. La primera definición es "acción, efecto de influir" (Diccionario de la lengua española, 2018), pero otra que parece oportuno citar es la siguiente: "persona con poder o autoridad con cuya intervención se puede obtener una ventaja, favor o beneficio" (Diccionario de la lengua española, 2018).

De esto se desprende que la influencia sobre el consumidor responde a la suposición de que determinadas variables puedan ejercer una influencia sobre el consumidor de modo que se lleve indefectiblemente a la compra. Esto se ejemplifica mejor con la teoría de Schor:

Según Schor (2004) los consumidores (i) abordan el proceso de compra como una lucha de poder, en el que las marcas no otorgan a los compradores toda la información que ellos necesitan para tener éxito; de igual manera, muchas veces (ii) se sienten forzados a consumir enormes cantidades de información irrelevante llevándolos a un estado de saturación, y por último (iii) sienten que es difícil para ellos navegar por toda la información disponible (Zevallos-Miranda, 2014, p. 10)

Entre los factores que influyen sobre la decisión de compra se encuentran la publicidad online y offline, pero en ambos entornos destacan las recomendaciones, sea por boca a boca entre amistades y familiares, por alguna recomendación leída en Internet o la promoción de alguna celebridad con la que pueda simpatizar el posible usuario (ver Figura 4). Por supuesto, las nuevas tecnologías crean dinámicas totalmente nuevas que deben seguir siendo estudiadas durante los próximos años, como las influencias que generan sobre los adolescentes las nuevas personalidades que surgen de la Internet, como en el caso de los Youtubers. Estas celebridades son vistas por las marcas como minas de dinero porque reconocen su capacidad de influenciar al público adolescente de modo que puedan probar nuevos productos, generar recordación y conciliar comunidades dentro de sus redes sociales (Westenberg, 2016); sin embargo, ya se empiezan a generar espacios de diálogo con otras generaciones que se hacen más adeptas a las plataformas digitales. 
Figura 4. Grado de confianza de los consumidores en el mundo respecto a ciertas formas de publicidad/recomendación ${ }^{4}$

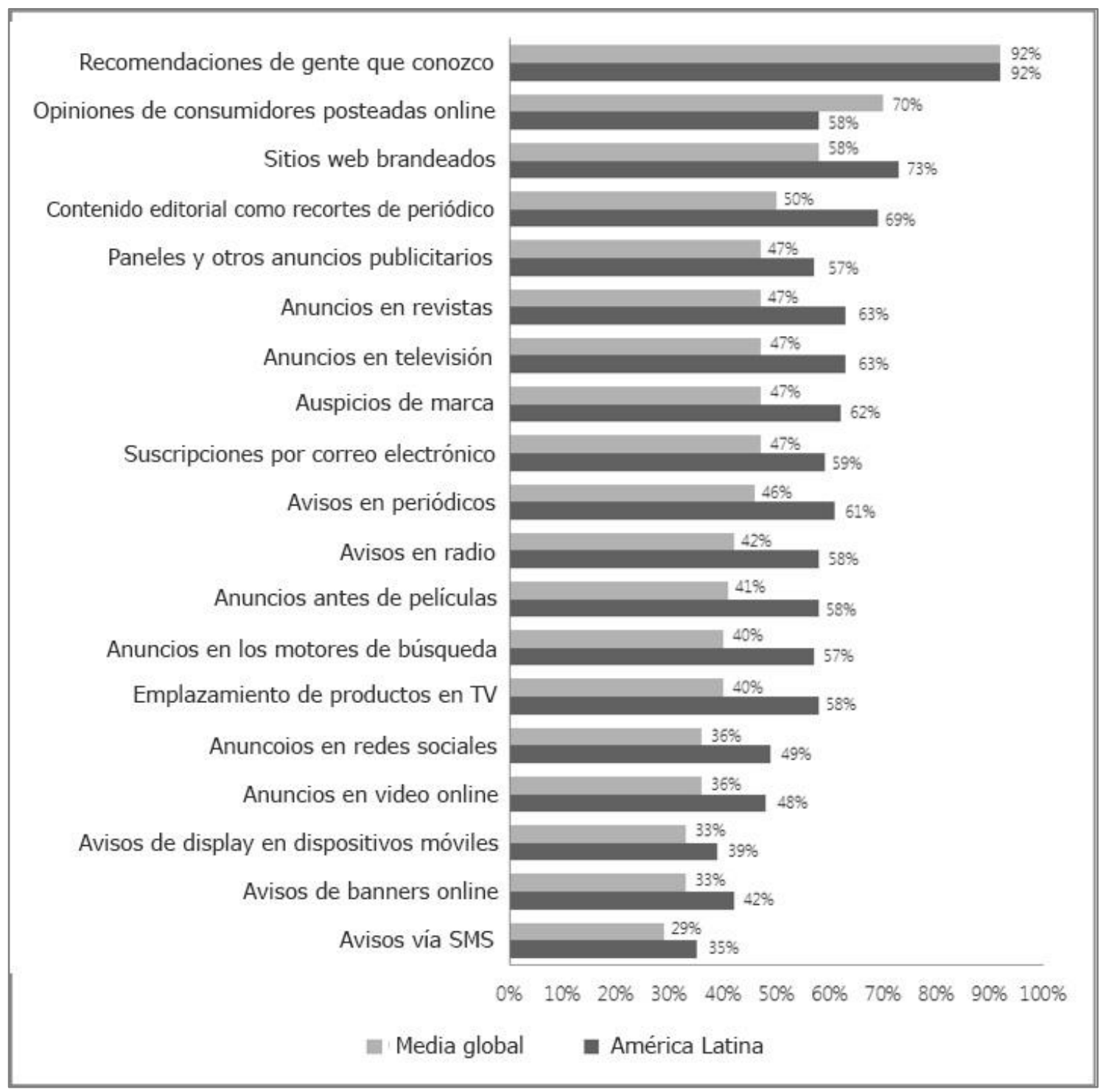

\subsubsection{Recordación de marca}

La Recordación de Marca (o Brand Recall, en inglés) es un concepto que apela a la posibilidad de que el consumidor pueda verse influenciado para comprar una marca con

\footnotetext{
${ }^{4}$ Figura 4. Contraste entre los grados de confianza que tienen los consumidores a nivel mundial respecto de ciertas formas de publicidad y recomendación. Adaptado de Nielsen Global Trust in Advertising Survey, 2012
} 
la que ya se sentía familiarizado de una forma positiva anteriormente (Thoma y Williams, 2013).

La mayor parte de la publicidad se basa generalmente en el supuesto de que existe un fuerte vínculo entre la Recordación de Marca y las preferencias del consumidor (Hauser, 2011). Del mismo modo, muchos estudios han demostrado que los sujetos prefieren estímulos que han visto previamente, incluso si no estuvieron conscientes de ellos, a otros de los que no conservan una experiencia previa (Zajonc, 1968). Un modelo propuesto por Gigerenzer, Todd y ABC Research Group sugiere que, si uno de dos objetos es reconocido y el otro no, la gente se sentirá inclinada por el objeto reconocido asumiendo que es el que posee mayor valor (Thoma y Williams, 2013). Es así como la recordación de marca ha llegado a ser entendida como un factor capaz de conducir a un consumidor potencial hacia la compra. No obstante, esta es solo una de las dimensiones mediante las que un usuario puede "conocer" a una marca, producto o servicio.

Kevin Lane Keller, al publicar su libro Strategic Brand Management (1998), proponía un modelo para estructurar el Conocimiento de una marca (ver Figura 5) donde se partía de dos aspectos de la marca para entender su acercamiento a la mente de los consumidores: el primero estaba ligado a la conciencia de la existencia de la marca, mientras que el segundo analizaba la imagen que proyectaba hacia el público, sea que esté o no usando la marca.

Para Keller, lo primero que debe evaluarse es la conciencia de marca o lo que los especialistas del marketing conocen como awareness. Este concepto, aunque algo complicado de definir, involucra la capacidad de un consumidor para relacionar una marca a determinada categoría de productos o servicios (Keller, 1998). Luego de este primer acercamiento es que ya se puede hablar propiamente de Recordación de Marca y también de Reconocimiento de Marca (Keller, 1998). 
Figura 5. Modelo de Conocimiento de Marca de Keller (1998) ${ }^{5}$

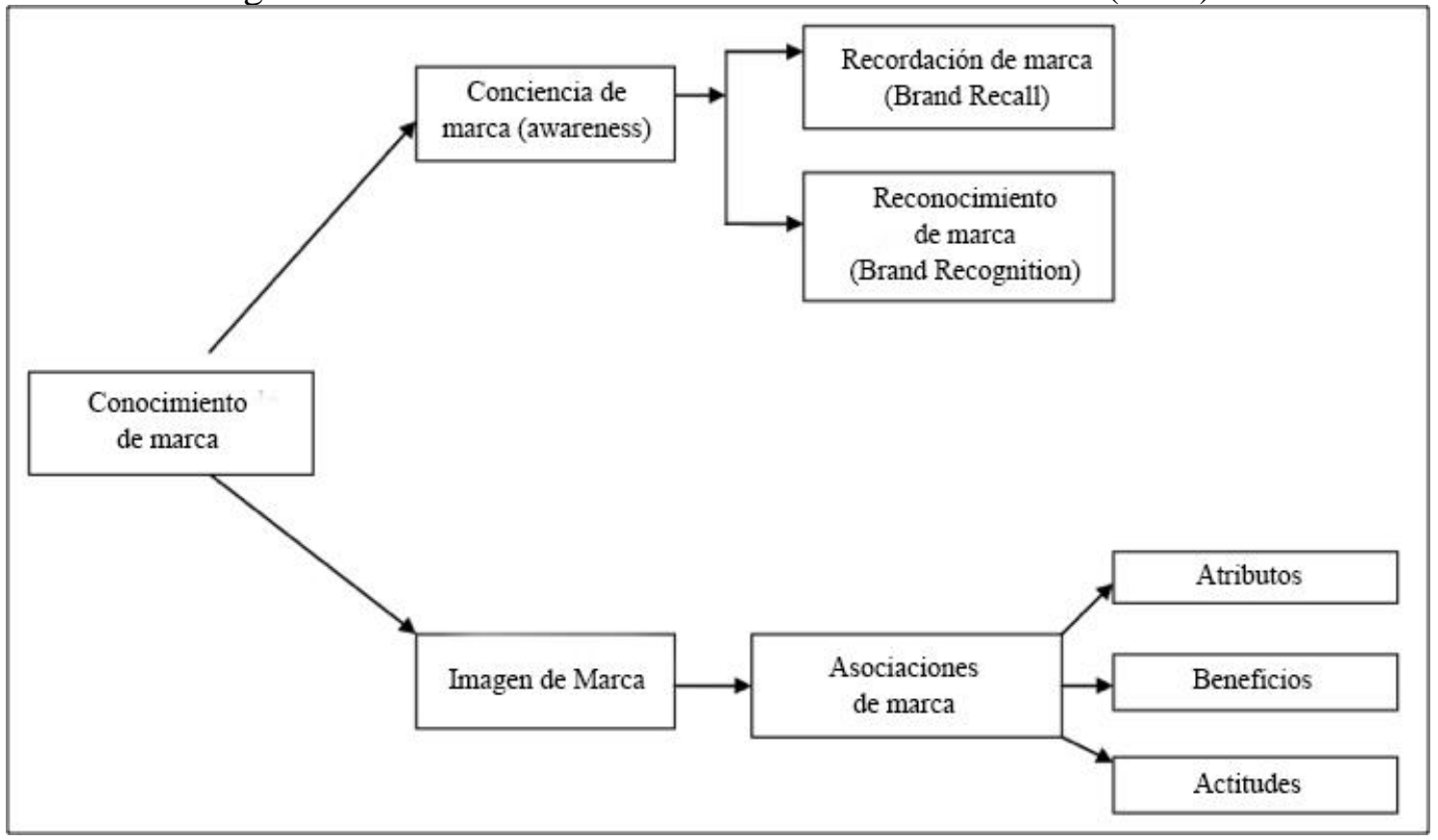

\section{- Reconocimiento de marca:}

Es una variable del Conocimiento de Marca que evalúa la capacidad del consumidor para recordar haber tenido un contacto previo con determinada marca cuando se le ofrece información clave. Refleja la familiaridad que un consumidor tiene frente a ciertos rasgos distintivos de una marca (imagen, nombre, entre otros), pero no implica que este sepa a qué categoría pertenece (Keller, 1998).

\section{- Recordación de marca:}

A diferencia del Reconocimiento de Marca, esta variable evalúa una asociación correcta entre una marca y la categoría de producto o servicio a la cual pertenece, así como la necesidad que cubre su uso (Keller, 1998). Cuando la recordación de marca es fuerte y un producto o servicio en particular se vuelve la primera que el consumidor puede recordar en su mente, estamos hablando de que se ha alcanzado el Top of mind. En oposición, Keller menciona algunas marcas que no son fáciles de recordar pese a que

${ }^{5}$ Figura 5. Modelo de conocimiento de marca propuesto por el autor Kevin Keller. Adaptado de Strategic Brand Management. Building, Mesuring and Managing Brand Equity, 1998. 
cuentan con un alto reconocimiento entre el público. A estas, el autor las llama "marcas cementerio".

El reconocimiento y la recordación están relacionados por un proceso mental donde ambas actividades se retroalimentan constantemente. Cuando alguien recupera un poco de información desde su memoria, está haciendo uso de la recordación, y cuando toma decisiones en base a cierta familiaridad, es producto del reconocimiento (Haist, Shimamura y Squire, 1992). No obstante, para hacer efectiva su influencia sobre el consumidor, se deberá escoger el objetivo más relevante para llegar a la compra. Por ejemplo, apelar al reconocimiento de marca en un supermercado podría devenir en futuras ventas si se trata de una marca bien establecida en el mercado; sin embargo, cuando el consumidor hace la compra lejos del punto de venta -que es cuando los elementos representativos de una marca no están presentes para apoyar el reconocimiento- la recordación de marca puede resultar más importante para conducir a la venta (Lynch y Srull, 1982).

Con la introducción de un concepto más amplio del posicionamiento gracias a un anuncio escrito por David Ogilvy en 1971, la publicidad y la labor de mercadeo dieron un giro radical que nos acercaría a la forma en que las marcas hacen publicidad actualmente. Un año después, los autores Jack Trout y Al Ries publicaron un artículo titulado The Positioning Era Cometh, y en él destacaban la importancia de trabajar la imagen de un producto o servicio en la mente del consumidor de modo que la publicidad ya no solo servía para comunicar, como fue tan propio de los 50, ni para cautivar al espectador mediante la creatividad como se hizo en los 60. Trout y Ries afirmaban entonces que había empezado "la era del posicionamiento" y con ella, se había puesto en marcha una carrera para ocupar un espacio privilegiado en la mente del consumidor que, según estudios del psicólogo de Harvard George A. Miller, solo puede recordar siete elementos de una misma categoría (Trout y Ries, 1972).

\subsubsection{Nuevos canales para acercarse al consumidor}

Con el desarrollo de las redes sociales durante las últimas dos décadas, los profesionales del marketing encontraron nuevas rutas para dar a conocer las marcas entre sus consumidores. Invirtiendo en estas nuevas plataformas, las marcas pudieron escapar de 
los medios tradicionales de publicidad que ya se encontraban saturados y vieron una manera para hablarle a sus clientes en un medio libre de los prejuicios que traía la televisión (Gageler y Van Der Schee, 2016). Sin embargo, estas plataformas son todavía recientes, por lo que su uso continúa crecimiento conforme se muestran resultados positivos tal y como ilustra el siguiente párrafo:

Dada esta realidad, muchas compañías han empezado a redefinir aspectos claves en su mezcla de marketing para incluir redes sociales, ajustando su presupuesto como corresponde. De acuerdo a Burson-Marsteller, el 79\% de las 100 primeras compañías más importantes del ranking Fortune 500 ya están usando Twitter, Facebook y Youtube o blogs corporativos para comunicarse con sus clientes (Armelini y Villanueva, 2011, p. 30).

Plataformas como Snapchat e Instagram — que son incluso más nuevas que las mundialmente famosas Facebook, Youtube y Twitter - se siguen sumando como medios novedosos donde las empresas pueden anunciar sus productos y servicios esperando una comunicación más efectiva. Todo gracias a la influencia que pueden tener ciertos usuarios claves sobre las simpatías y decisiones de consumo que tienen sus grupos sociales (Adhiambo, 2012). A estos usuarios se les conoce como influencers.

Las campañas planteadas principalmente en un entorno digital suelen tener tanto éxito que algunos directivos de agencias y gestores de marcas han empezado a solicitar a los directores creativos que recorten sus actividades offline y busquen la ayuda de las redes sociales para optimizar los resultados y las ganancias (Armelini y Villanueva, 2011). Tan solo en 2015, la revista Harper's Bazaar declaraba que las marcas estadounidenses gastaban cerca de \$1 billón anuales en anuncios pagados en Instagram (Gageler y Van Der Schee, 2016). 


\subsection{Youtube y la revolución del consumidor}

En la búsqueda por democratizar el contenido y entregarle el poder de producirlo a los mismos usuarios apareció un portal web tan adelantado al concepto de prosumidor que hoy se ha convertido en el segundo buscador digital más grande del mundo (Coursaris y Van Osch, 2016). Se llama Youtube y es tan conocido como Google o Facebook, dos potencias de la Internet. La página web nació como una plataforma donde los usuarios podían compartir sus propios videos de manera sencilla y se fue creando una comunidad a partir de esta propuesta (Larrañaga y Ruiz, 2009). Los usuarios podían comentar los videos, crear canales, colaborar con otros usuarios, etc. Como mencionan los autores Burgees y Green (2009) en su texto Youtube, digital media and society series:

YouTube mayormente debe su éxito a ser reconocido, no solo como un archivador de datos multimedia, sino como una plataforma que emite contenido cultural a gran escala, es accesible para todo el mundo y además es considerada como una red social (p. 88).

El contenido de los videos que son subidos día a día al buscador de videostreaming es más que basto y cuenta con opciones para todos los gustos, idiomas, edades, etc. En el 2010, la web de análisis de datos Sysomos realizó un estudio de visitas por categoría en Youtube (ver Figura 6) en base a las siguientes categorías: (1) Ciencia, tecnología, (2) «how to», estilo, (3) animación, (4) películas, (5) educación, (6) comedia, (7) deportes, (8) noticias y políticas, (9) gente y blogs, (10) entretenimiento, (11) música y (12) otros.

El resultado del estudio mostraba que la música configuraba una de las categorías más populares entre los usuarios con un $31 \%$ de las visitas. Las categorías menos relevantes eran las de estilo y cosas relacionadas a ciencia y tecnología. 
Figura 6. Visitas por categorías de los videos de Youtube ${ }^{6}$

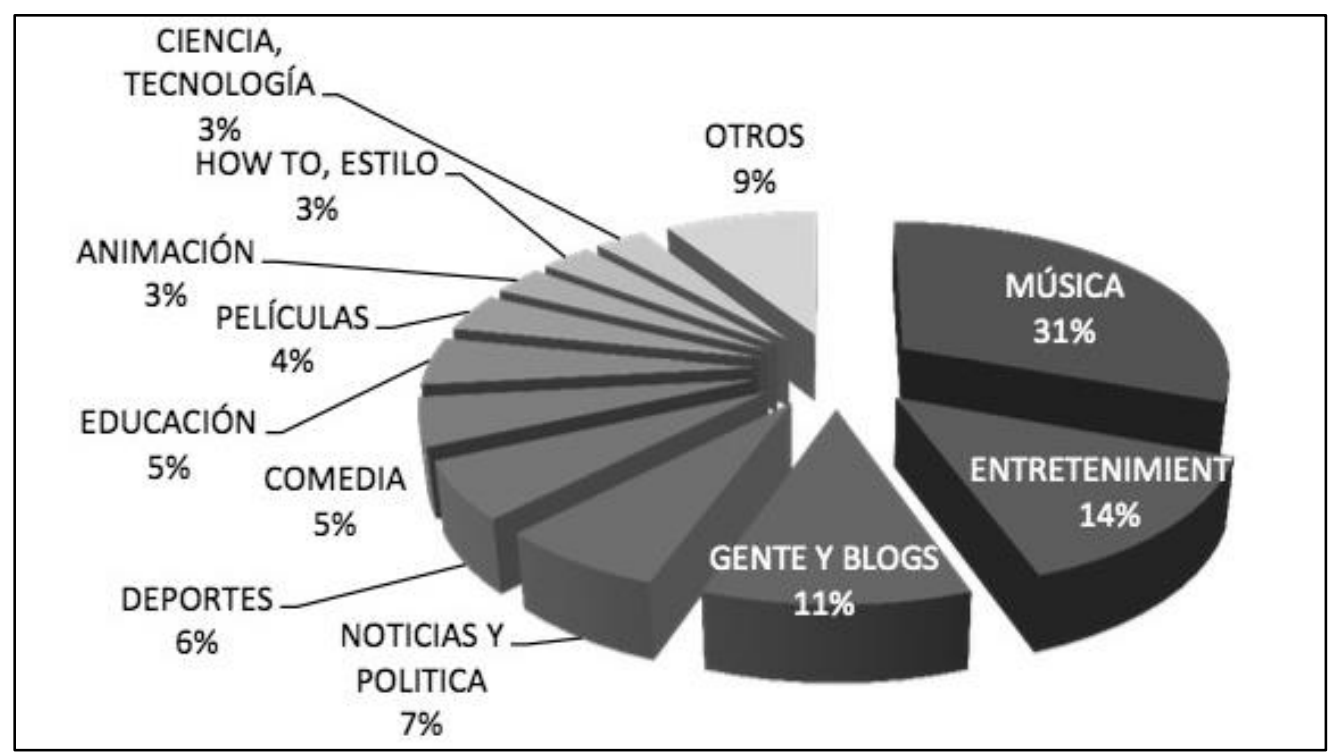

\subsubsection{Youtube como negocio}

Youtube es una plataforma de video online en streaming. En su portal, cada usuario puede crear un perfil al que se le conoce bajo el nombre de canal. En dicho canal se pueden compartir videos propios y se pueden agrupar los videos del portal en listas que se comparten con el resto de la comunidad o que se mantienen de forma privada, si se desea (Burgess y Green, 2009).

El proyecto nació en el 2005, cuando tres antiguos empleados de PayPal (Chad Hurley, Steve Chen y Jawed Karim) fundaron la empresa Youtube. Un año después, fue adquirida por Google Inc. a cambio de acciones valoradas en 1.650 millones de dólares americanos (Larrañaga y Ruiz, 2009).

Lo que hizo tan rentable un proyecto open source como este fue la posibilidad de ubicar publicidad en la página web. En el 2006, año en el que se hizo la transferencia a Google Inc., la empresa tenía ingresos mensuales de 7.5 millones de dólares por publicidad, considerando un estimado de 400.000 usuarios (Larrañaga y Ruiz, 2009).

${ }^{6}$ Figura 6. Torta de las vistas de los videos de Youtube segmentados por categorías. Tomado de Sysomos Inside Youtube Video Statistics, 2010 
Las cifras mundiales revelan, según las estadísticas de YouTube, que más de 1000 millones de usuarios únicos visitan YouTube cada mes, se ven más de 100 millones de horas de videos y se generan más de 1000 millones de reproducciones; además el tiempo de visualización se ha incrementado un $50 \%$ interanual, y el número de horas que la gente dedica a ver videos en dispositivos móviles se ha incrementado un 100\% (Enríquez 2016, p. 9).

Según la página web Alexa y su documento anual Alexa Traffic Ranks, donde se hace un reporte de los índices de tráfico más relevantes de Internet, Youtube.com es la tercera página con más tráfico a nivel global (Alexa, 2015). Sus directivos afirmaban en 2015 que Youtube contaba con una audiencia de más de mil millones de usuarios, lo que equivale a un tercio de los usuarios totales de la Internet (Youtube, 2015).

El éxito de Youtube entre los usuarios solo ha ido en aumento desde su lanzamiento. Esto debido a "una necesidad del usuario de Internet de contar cosas, de recibir información, de compartir" (Larrañaga y Ruiz, 2009, p. 112). Las estadísticas que arroja y el análisis inmediato del impacto por publicidad que ofrece la red hoy en día hace de esta herramienta uno de los principales aliados en la labor publicitaria (Enríquez, 2016). A continuación, se puede ver un cuadro con la distribución demográfica de los usuarios de este portal:

Figura 7. Análisis demográfico del público de Youtube.com ${ }^{7}$

\begin{tabular}{|c|c|c|c|c|c|}
\hline \multicolumn{2}{|l|}{ Género } & \multicolumn{2}{|l|}{ Educación } & \multicolumn{2}{|c|}{ Locación de navegación } \\
\hline & promedio en internet & & promedio en internet & & promedio en internet \\
\hline Masculino & $\mathrm{n}$ & Sin educación & & Casa & I \\
\hline \multirow[t]{4}{*}{ Femenino } & 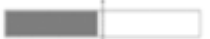 & Poca educación & & Escuela & \\
\hline & debajo encima & Graduado & 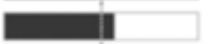 & Trabajo & \\
\hline & & Universitario & & & encima \\
\hline & & & encima & & \\
\hline
\end{tabular}

${ }^{7}$ Figura 7. Análisis demográfico del público en el portal de broadcasting Youtube, dividido por género, nivel de educación y locación de navegación del público. Adaptado de Alexa, 2015. 


\subsubsection{La publicidad en Youtube}

Youtube supuso una mejoría por la posibilidad que ofrecía de dar un mensaje audiovisual entretenido, que estuviese dirigido a la medida de los usuarios. Para los publicistas, esto sugería la posibilidad de hacer frente al gran problema de la publicidad en televisión: el zapping. "Desde un primer momento publicistas y anunciantes intuyeron el potencial que ofrecía este site (Youtube) para llegar a un público receptivo y perfectamente localizado" (Larrañaga y Ruiz, 2009, p. 120).

La compañía inició replicando las opciones que ofrecía la publicidad tradicional: Daban distintos espacios publicitarios para los anunciantes; pasaban publicidad en video mediante segmentos pre-roll o post-roll, banners y pop-ups; dejaban a las marcas patrocinar concursos para los usuarios y les dejaban crear sus canales para llenarlos de su propio contenido original (Larrañaga y Amelia, 2009, p. 121).

Posteriormente, conforme los usuarios ganaron poder sobre las marcas con el desarrollo de la web 2.0, se desarrollaron más formas de hacer publicidad en Youtube. Se trasladó el concepto de "boca a boca" a una plataforma conocida por permitirle a sus usuarios generar contenido propio y dialogar con otros usuarios.

La segunda forma para hacer publicidad en esta plataforma es lo que se conoce desde épocas muy remotas como boca a boca, pero con la diferencia de que este boca a boca se da de una manera digital. Al mismo tiempo que YouTube ha crecido significativamente, del mismo modo lo han hecho los creadores de contenido que suben y comparten sus videos con gente de todo el mundo. Existen muchos creadores de contenido dentro de YouTube que se han posicionado a sí mismos como una marca y una persona influyente gracias a sus opiniones, consejos, humor y carisma en sus videos. Estas personas cuentan con una gran cantidad de suscriptores y un gran poder de influencia sobre sus seguidores. Para muchas personas esto no fue nada sorprendente pero para algunas marcas visionarias, esto podía llegar a ser la mejor oportunidad de publicidad para sus productos. La idea era muy sencilla, las marcas les ofrecen productos o descuentos a los creadores de contenido en YouTube y ellos comparten su experiencia con sus seguidores (Torres, 2014, p. 16).

De esta forma, Youtube daba a sus creadores de contenido la posibilidad de sacar ganancias por su influencia entre otros usuarios al recomendar productos o comentarlos abiertamente en sus canales mediante contenido propio o solicitado por las marcas. Luego 
cambió su slogan de "Your Digital Video Repository" a "Broadcast Yourself", porque representaba mejor el espíritu de la marca y la promesa que daba a sus usuarios (Burgess y Green, 2009).

Esta nueva clase trabajadora, que siendo remunerada por Youtube y las marcas auspiciadoras generaba contenido libre para otros usuarios, dio origen a la figura del “youtuber”. Usuarios empoderados por la empresa y por la preferencia de los espectadores se convirtieron en influencers de sus propias redes sociales (Westenberg, 2016). El prosumidor se hizo capaz de hacer publicidad para su propio grupo cerrado.

\subsubsection{Los Youtubers: nuevos agentes publicitarios}

Uno de los mayores logros de Youtube es popularizar el término "vlogging” y el concepto de Youtuber, que no es otra cosa que la aplicación del blogging dentro de su propia comunidad. Los youtubers son personas que crean un canal y por medio de él se comunican con otros usuarios de Youtube. Lo hacen por distintos motivos: para soltar sus opiniones y generar debate, expresarse artísticamente, informar o compartir el trabajo de otros. Inicialmente estas personas lo hacían como un pasatiempo, pero con el desarrollo de la empresa y sus canales de negocio, hay youtubers que pueden considerar esta actividad un trabajo formal y que se dedican a ello seriamente (Torres, 2014).

Lo más importante es que el youtuber se encarga de proponer contenido y ponerlo a prueba frente a la comunidad. Finalmente son los espectadores quienes deciden qué tiene éxito y qué no lo tiene, por lo que las marcas hacen una apuesta al elegir colaborar con estos personajes. Por eso es tan importante que analicen la audiencia potencial a la que se dirigen con cada patrocinio (Westenberg 2016). Afortunadamente, anunciantes y youtubers han aprendido a colaborar para generar una industria que provea de trabajo a estos comunicadores digitales y a su vez beneficie la imagen de las marcas ( $\mathrm{Wu}, 2016)$.

El product placement en Youtube se da por dos motivos: bien por pedido de la empresa o por iniciativa propia de los usuarios. Del mismo modo, hay cuatro formas en las que los youtubers anuncian en colaboración con las marcas (Enríquez 2016): 
- Branded content, generado por pedido de la marca. El contenido útil o entretenido se combina con información de la marca y su identidad (Enríquez 2016).

- Promoted content, cuando la empresa pide a alguien influyente en el medio web que muestre o promocione sus productos en el contenido que genera por medio de notas escritas y material audiovisual (Enríquez 2016).

- Patrocinio, cuando la empresa ayuda mediante un aporte económico u otro tipo de asistencia para que un video sea producido (Enríquez 2016).

- Product placement, cuando aparece un producto o marca específica en un contenido que se supone no es publicitario (Enríquez 2016).

\subsubsection{Publicidad en el UGC y product placement en Youtube}

Dentro del concepto tradicional de publicidad donde las marcas emiten sus mensajes considerando a los consumidores como un receptor pasivo, la forma de informar a los usuarios se efectuaba mediante el PGC o Producter-Generated Content. Luego, cuando la comunicación entre marcas y consumidores se volvió un asunto bilateral por el desarrollo de la web 2.0, apareció un nuevo tipo de contenido: el UCG.

El User-Generated Content (UGC) se refiere a cualquier material creado y subido a la red por los usuarios (Azlin y Mazinni, 2016). Este material puede ser informativo o apuntar al entretenimiento del público, y se comparte en Internet mediante alguna plataforma o soporte. El UGC debe tener la capacidad de tener un impacto en su público gracias a la interacción que ofrecen las nuevas tecnologías.

Es obvio que para los publicistas esto representa una gran oportunidad de conectar con posibles clientes. Por ello, Hennig-Thurau, Gwinner, Walsh, \& Gremler definieron el UCG como "cualquier declaración positiva o negativa hecha por clientes potenciales, actuales o antiguos de un producto o compañía, puesta a disposición de una multitud de personas e instituciones a través de Internet” (2004, p. 42).

Por otro lado, desde la óptica del espectador, el UGC representa una forma confiable y entretenida de obtener la información que necesita. Como el contenido de los vloggs está basado en las experiencias de los Youtubers, las recomendaciones o reviews son 
considerados más confiables y honestas, puesto que provienen de otros usuarios de la red (Azlin y Mazinni, 2016).

En muchos casos, solo la aparición de una marca específica ya es suficiente para orientar al consumidor en favor de su consumo (Westenberg, 2016). Para ejemplificar, se puede ver la siguiente gráfica de cómo los youtubers influencian el comportamiento de sus seguidores y de su propia comunidad.

Figura 8. Rol de los Youtubers en la vida de los adolescentes ${ }^{8}$

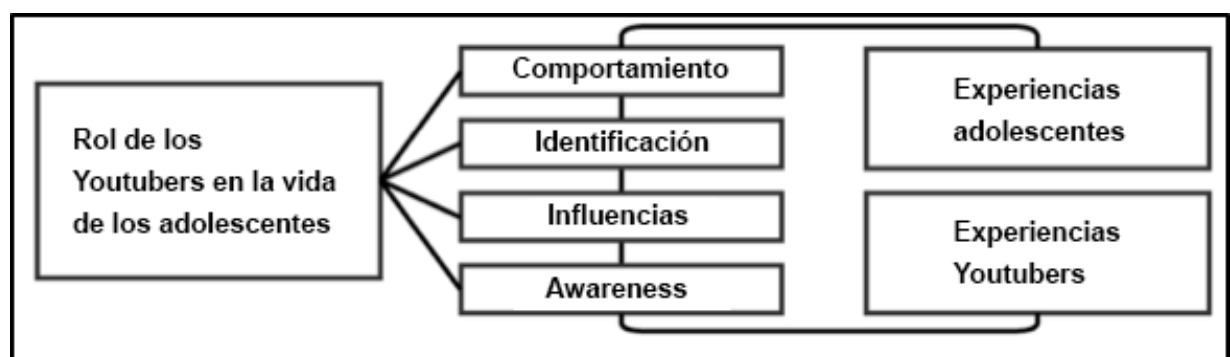

Hay quienes ya hablan de la era de la web 3.0 gracias al UGC. Supuestamente, esta versión 3.0 de la web es descrita como tecnología digital interconectada que soporta la colaboración humana, además de tener la característica de entender el contenido que alberga y elaborar más a partir de su análisis (Wastenberg, 2016).

El product placement dentro de UGC (como cuando se hace en los vlogs de los youtubers) tiene un impacto importante, sobretodo, entre el público perteneciente a la llamada Generación Z, los sucesores de los millenials. Ellos nacieron entre 1990 y el 2010, crecen en la era de los smartphones y no se imaginan un mundo en el que esa tecnología no fuera una realidad (Wastenberg, 2016). Ven menos televisión y consumen más contenido en línea que los millenials y pasan un promedio semanal de 11 horas viendo videos en línea a través de distintas redes sociales, entre las que figura definitivamente Youtube como una de las favoritas (Wastenberg, 2016).

\footnotetext{
${ }^{8}$ Figura 8. Diagrama que muestra el rol de los Youtubers como un actor influyente sobre la vida de los adolescentes. Adaptado del artículo de Wilma Wastenberg The influence of Youtubers on Teenagers: A descriptive research about the role Youtubers play in the life of their teenage viewers, 2016.
} 
Esto demuestra que el uso de youtubers como agentes de promoción por medio del product placement ha sido una de las innovaciones más acertadas considerando la necesidad de los consumidores, que necesitaban conseguir información más confiable; y de las marcas, que necesitaban formas menos intrusivas para anunciar sus productos a dichos consumidores.

Además, esta práctica ha revitalizado ciertos sectores que no parecían tan prometedores durante los primeros años de la plataforma. Por ejemplo, la industria de la belleza que en un inicio no representaba una fracción tan relevante del contenido alojado por Youtube (ver Figura 6), se convirtió en uno de los segmentos más dinámicos en cuanto a la cantidad de material UGC que produce.

La verdad es que, por ahora y pese a la proliferación de las youtubers influyentes en la industria de la belleza, faltan más estudios que incursionen en el impacto que tiene el product placement sobre los usuarios (Lavalle y Atarama, 2016). La mayoría de los estudios encontrados se centran en el impacto del product placement sobre la venta y la influencia de los youtubers en el público, pero casi ninguno toma los conceptos de posicionamiento y recordación de marca, que configuran dos pasos fundamentales para la decisión de compra en los consumidores fuera del mundo en línea (Torres, 2014).

De igual forma, son pocos los teóricos que han indagado sobre la influencia del UGC en los usuarios, pero la velocidad a la que se desarrolla y expande este fenómeno sugieren que la colaboración entre youtubers y marcas comerciales seguirá en crecimiento. Una encuesta efectuada por una conocida revista de entretenimiento concluía que 6 de 10 influencers de los jóvenes entre los 13 y 18 años son youtubers (Variety, 2014). En ese entonces la tendencia de los youtubers y los influencers apenas estaba en alza, así que resulta sensato pensar que estas cifras puedan haberse incrementado.

Este estudio espera probar una relación positiva entre el uso de product placement por parte de marcas cosméticas y de belleza en videos de youtubers y la recordación de marca por parte de los consumidores. De este modo, se espera incentivar la decisión de compra al mejorar el posicionamiento de estas marcas entre las usuarias de 24 a 32 años de los niveles socio-económicos BC pertenecientes a la zona de Lima Metropolitana. 
La hipótesis que se espera probar en esta investigación es que las consumidoras se sienten influenciadas por el product placement de productos de belleza en los vlogs de youtubers al momento de decidir sus compras pues consideran relevantes las recomendaciones por parte de estas estrellas digitales a las que siguen y, muchas veces, también imitan. Como se ha mencionado anteriormente, ya existen marcas reconocidas que se han acoplado al uso de nuevas tecnologías para hacer marketing, y la ubicación de estos productos en contenido generado por los usuarios podría ser una buena manera de acercarse a los consumidores que cada vez se muestran más esquivos ante los distintos estímulos publicitarios. 


\section{CASO: VOGUE COSMÉTICOS}

PERÚ 
Youtube ha generado 9.8 billones de vistas en videos dedicados a hablar de maquillaje (Coursaris y Van Osch, 2016). Así mismo, más mujeres están viendo videos con contenido relacionado a la belleza y las vistas siguen creciendo en la categoría: en 2010 sumaban 300 millones de vistas por mes, y luego, en 2013 la cifra subió a 700 millones (Coursaris y Van Osch, 2016). Algunos de los youtubers más seguidos de la red social son populares por sus videos con consejos y tutoriales de belleza para sus fans. Tal es el caso de Michelle Phan, la primera vlogger de cosméticos y maquillaje en los Estados Unidos. Ella alcanzó rápidamente más de 7 millones de suscripciones y 1 billón de vistas en su canal (Coursaris y Van Osch, 2016).

Michelle Phan es una de las muchas "gurús de la belleza", un fenómeno que ha ido en crecimiento entre los $v \log s$ de belleza que abundan en Youtube. Ellas — son en su mayoría mujeres - hacen tutoriales de maquillaje, recomiendan o revisan productos cosméticos, comparten sus rutinas de cuidado facial con sus seguidores y hacen todo tipo de cosas relacionadas al rubro (Fischer, 2014). Adicionalmente, las vloggers pueden hacer videos siguiendo una tendencia temporal entre su comunidad. Estas tendencias se conocen como tags.

Algunos ejemplos de tags son "Mi novio me maquilla" y "Colores del arcoíris". Se trata de retos específicos que debe resolver el youtuber mientras hace destacar su personalidad. El objetivo de estos videos es integrar a los usuarios y a los youtubers como parte de una misma comunidad ya que todos interactúan bajo una misma premisa (Fischer, 2014). Los usuarios piden a los youtubers que se unan a los retos de moda o que resuelvan los tags más actuales y ellos lo hacen. Este tipo de contenido abre un espacio interesante para posicionar determinadas marcas o productos por medio del product placement.

En el 2010, Lancôme conviritó a Michelle Phan en su primera "artista de videos de maquillaje" para crear videos especiales y otros pedidos de la marca. Un año antes, la revista Seventeen la había contratado para desarrollar video tutoriales para el sitio web de la revista junto a otras gurús de la belleza bajo el nombre de "Beauty Smarties" (Fischer, 2014).

Este capítulo está dedicado a darnos más información sobre la marca que será protagonista de esta investigación. Antes de ello haremos un repaso por la situación actual de la industria de la belleza y la relación que sostiene con el mundo publicitario. 
Igualmente, se dará un vistazo rápido a la importancia que tienen algunas variables de mercadeo, tales como el posicionamiento de un producto y la recordación de marca para una industria tan peleada a nivel publicitaria como es la industria cosmética y de belleza.

Posteriormente, nos centraremos en el estudio de la marca Vogue Cosméticos para identificar los antecedentes de la compañía y los objetivos que tenía antes de su incorporación al mercado peruano mediante el uso de una campaña digital apoyada por youtubers e influencers. 


\subsection{La industria cosmética y la publicidad moderna}

La evolución experimentada por la industria publicitaria en los últimos años es notoria. En los años 50, el objetivo de las marcas que anunciaban publicidad era buscar a sus clientes para explicarles cómo funcionaban sus productos (Martín y Alvarado, 2007). Con la aparición del Internet esto quedó en segundo plano pues lo podían hacer de manera sencilla mediante una página web, un enlace en Wikipedia, una reseña en una página especializada. Es por eso que entonces los clientes buscaron simpatizar con las marcas, recibir algo más que solo información. La comunicación publicitaria ya no se trata de persuadir; sino que necesita entretener para generar un vínculo con el usuario; luego de eso la venta está asegurada (Martín y Alvarado, 2007).

Los estudios que buscan encontrar los estímulos publicitarios más influyentes del público han detectado ciertos elementos o características que generan empatía en los consumidores y los fidelizan a una marca. Entre estos se encuentran la difusión de un estilo de vida alineado a los valores de la marca y de su público, además del refuerzo de estereotipos sociales mediante los cuales se narra una situación publicitaria (Gobè, 2011). Del mismo modo, entran en juego conceptos como el posicionamiento de la marca y la recordación que tiene por parte de sus consumidores (Gobè, 2011).

En el caso de las marcas cosméticas y de belleza funciona exactamente igual que en el resto de industrias. O peor, ya que el proceso de acercamiento es más sensorial. El estímulo y el look influyen mucho en el mensaje que reciben los consumidores, puesto que les da una idea de si creen en lo que dice una marca o no.

Desde los años 80 hasta el día de hoy, se impuso en la publicidad y en la sociedad el culto al cuerpo, a la estética y al consumo. El mundo cosmético y de la belleza se desarrolló a la par que una industria dedicada a endiosar el físico, lo que trajo como consecuencia la difusión de una cultura en extremo estética y saludable para el cuerpo, así como problemas psicológicos resultantes de la frustración que anidaban los segmentos más vulnerables al no encajar en los cánones de belleza (Díaz, 2001). 
Esta problemática trajo una gran responsabilidad para los anunciantes del rubro y, a su vez, presentó la oportunidad de buscar un nuevo enfoque para su comunicación. ¿Debían mantener la belleza y el cuidado personal como un secreto reservado para unos pocos? O, por el contrario, ¿debían acercarse a los usuarios con un mensaje trasversal al que todos tuvieran acceso? La respuesta, acertadamente, partió de los mismos consumidores (Díaz, 2001).

Las marcas empezaron a ver la importancia de acercarse a su público y empoderarlos resaltando sus atributos naturales. Campañas como las que fueron realizadas por Dove hablaban de la verdadera belleza mientras lograban informar sobre las propiedades de sus productos que poseían ingredientes naturales y gentiles con la piel del consumidor. Se empezó a hablar de cuidado más que de cambio (Antolín y Clemente, 2016). La idea ya no era convertir al usuario en una superestrella, sino hacerle saber que se veía increíble siendo tal y como es.

\subsubsection{Importancia del posicionamiento y la recordación de marca para la industria cosmética}

Se define el posicionamiento como:

El proceso de estudio, definición e implementación de una oferta diferenciada cuyos atributos proporcionen una posición ventajosa sostenible de una marca en relación con la competencia en una categoría, desde el punto de vista de la percepción de un público-objetivo (Serralvo y Tadeu, 2005, p. 3).

En la industria de los productos de belleza, el posicionamiento es sumamente importante porque representa un ideal de belleza o rasgos estéticos que insinúan la pertenencia a una determinada esfera o grupo social. Las marcas más exitosas saben explotar los valores que las hacen tan atractivas para sus usuarios e innovan desde ahí. Ya se dejó atrás la idea de que las personas deben cambiar para verse bellas. Ahora la tendencia radica en el concepto de autenticidad y la marca solo es un elemento de cuidado para impulsar los atributos naturales de sus usuarios (Gobè, 2011). 
Hace poco, luego de que las mujeres lograran oponerse a las imposiciones de una publicidad machista y sesgada, campañas publicitarias exitosas empezaron a dar una relevancia nueva a las marcas cosméticas. Las marcas se volvieron las generadoras del cambio al interior de algunos grupos, coincidentemente, sus principales consumidores (Carvajal, 2013). Las compradoras de pronto escogían una marca porque las hacía sentir auténticas, porque no las limitaba a una visión plástica de ellas mismas. En cuanto a sus productos, los resultados que ofrecía eran sencillos de lograr y estaban avalados por una celebridad de Youtube que les sugería tal marca o tal producto (Coursaris y Van Osch, 2016). La premisa se volvió la siguiente: ¿si a él o a ella le funciona, por qué a mí no?

Se logró influir en la recordación de marca para productos de belleza, un segmento antes dominado por el boca a boca. En la antigüedad, cuando alguien cercano te recomendaba una crema, ibas corriendo hasta la misma tienda y la comprabas; si te decía que cierto cosmético era dañino, lo tachabas de tu lista indefinidamente. Así eran las cosas antes. Con la democratización de la información mediante la Internet, las marcas se volvieron capaces de reinventarse y de comunicarse a través de un mensaje masivo y más potente (Torres, 2014).

La publicidad, desde ese punto, se hizo más necesaria que nunca para una industria marcada por el gusto de lo estético y del alto impacto visual. Ya no solo se trataba de los avisos publicitarios en las calles, los afiches en las revistas y quién salía en ellos; empezó a tratarse también de quién lo podía usar, de dónde lo conseguías, de qué tan accesible era el producto y de qué se decía de él en la red (Carvajal, 2013).

Para las marcas también empezó a ser importantísimo saber qué se pensaba de ellos, de su competencia, y a su vez, querían saber con qué facilidad el consumidor accedía a este conocimiento (Torres y Muñoz, 2006). Entre tantas marcas de productos de belleza y cuidado personal, ¿qué marcas son las primeras que el usuario recuerda? ¿qué producto desea comprar porque se lo recomendaron o porque oyó de él? ¿qué producto no usaría nunca, aunque jamás lo haya probado antes? Se entiende que la respuesta ya no está en las marcas, sino en el consumidor mismo. 


\subsection{Antecedentes de la marca}

Vogue comenzó como el negocio de una mujer barranquillera. Con ayuda de su esposo, María Chaves instaló en el garaje de su casa en Bogotá un área de trabajo para poder preparar esmaltes de uñas. María tenía una trayectoria en el mundo de la cosmética, así que había aprendido la técnica y el procedimiento para poder elaborarlos. El salto se dio tras aliarse con un antiguo empleador para empezar a producir esmaltes para la empresa Love Lines (Cosméticos Vogue, 2017).

Los socios trabajaron un tiempo juntos, pero luego tuvieron algunos tropiezos que llevaron a que María y su esposo tomasen un camino distinto. Ella había estado experimentando con distintos colores hasta lograr unas bellas mezclas de tonalidad intensa, así que pensaron en arriesgarse con una iniciativa propia a la que llamaron Jolie de Vogue (Cosméticos Vogue, 2017). Así nacería el nombre de la marca y se sentaría uno de sus mayores atributos: la variedad de tonos que posee. Con el pasar de los años, el negocio creció hasta posicionarse como una de las empresas cosméticas más destacadas de Colombia e incluso ha llegado a adornar elogiados atuendos del Concurso Nacional de Belleza, que es un certamen de mucha visibilidad en un país que es bien conocido por la belleza de sus mujeres (Cosméticos Vogue, 2017).

Tras 50 años de trayectoria con sus productos, María Chaves decidió vender Vogue a un gigante en la industria de la belleza: L'Oreal (Cosméticos Vogue, 2017). La empresaria vio en este acuerdo una manera de preservar el trabajo de toda su vida y permitirle a más mujeres disfrutarlo. Tal fue la acogida del producto que, luego de su compra, L'Oreal llevó la marca Vogue por toda la región hasta posicionarla en Argentina, Aruba, Chile, Colombia, Costa Rica, Curazao, Ecuador, El Salvador, Guatemala, México, Panamá, República Dominicana, Uruguay y Perú (Cosméticos Vogue, 2017).

Vogue ingresó al mercado peruano a mediados del año 2015. Por sus precios accesibles, L'Oreal quiso aprovechar la marca en su sector de consumo masivo para llegar a los sectores tradicionales y modernos satisfaciendo la demanda con un producto de excelente calidad y buena reputación gracias a su origen colombiano (Gestión, 2015). La compañía entró con una estrategia agresiva que buscaba capturar al 5\% del mercado de maquillaje 
en Perú y se planteaba levantar 1,300 puntos de venta tradicional en el país, además de otros 200 en el canal moderno (Gestión, 2015). 


\subsection{Objetivos de campaña}

Luego de que L'Oreal tomara el control de Vogue, se buscó impulsar el alcance masivo con el que contaba la cartera de productos de la marca. Sandra Alegre, Jefa de Producto para Vogue Perú, mencionó en una entrevista informativa que "L'Oreal tiene el objetivo de convertirla en la marca líder del mercado latinoamericano porque es una marca hecha para la mujer latina" (comunicación personal, 10 de octubre, 2017). Por este motivo, Vogue apuntó a posicionar su producto con esta campaña. El problema que debía superar la transnacional era que la marca estaba más asociada a los productos para uñas, por lo que debía posicionar a Vogue como una marca de maquillaje completo cercana las tendencias a la mujer latina bajo un precio accesible (S. Alegre, comunicación personal, 10 de octubre, 2017).

L'Oreal quiso impulsar la presencia de Vogue en Perú implementando muchos más puntos de cobertura y distribución. Una vez alcanzó dicho crecimiento, quedó todo preparado para empezar con una campaña de comunicaciones que impactara fuerte en el entorno digital. Para el 2017, se planificó una campaña online masiva que pudiera hablarle al target y resaltar los valores que la marca quería transmitir a sus clientas potenciales: colorida, moderna y accesible. La campaña también contaría con la participación de influencers que colaboren en los videos y actividades para redes sociales, así como material para medios masivos (S. Alegre, comunicación personal, 10 de octubre, 2017).

Sandra bien resume los objetivos de la campaña al afirmar que

Buscaba comunicar que somos una marca completa de maquillaje, generar mayor alcance de la marca porque está orientada al público masivo y, por último, comunicar que somos una marca de precios accesibles que combina tendencia con alta calidad (S. Alegre, comunicación personal, 10 de octubre, 2017). 


\subsection{Desarrollo de la campaña}

La campaña ha tomado como ejes centrales su soporte en las redes sociales y en los puntos de venta mediante material gráfico, que es donde más contacto se tiene con el público al que va dirigida la marca. Para contar con la opinión de una especialista sobre el tema con experiencia local, se realizó una entrevista para usarla como un juicio de experto como criterio de evaluación. Sobre la estrategia detrás de la campaña, Sandra Alegre comentó lo siguiente:

Se ha basado en comunicar los productos con innovación de la marca, los productos que tienen mucha tecnología detrás y que, aparte, tienen muy buen performance, como los esmaltes en gel y los labiales líquidos, las máscaras multibeneficios... La comunicación busca que la gente conozca los productos más trendy y que nos vean como una marca accesible, pero que ofrece mucho más por el valor de tu dinero (comunicación personal, 10 de octubre, 2017).

Las piezas gráficas que son colgadas periódicamente en el fanpage de la marca buscan destacar la personalidad de los productos y asociarlos a un precio que resulta cómodo para el público masivo al cuál están dirigidos. Los colores de las gráficas son intensos, cálidos y modernos, de esta manera se quiere generar impacto visual sobre el público millenial y llamar su atención sobre una marca que le ofrece nuevas tendencias a precios bastante asequibles (S. Alegre, comunicación personal, 10 de octubre, 2017).

A continuación, se mostrará algunas publicaciones tomadas del fanpage de Vogue para la región de Perú. De esa manera será más fácil identificar los ejes de la campaña y cómo fueron implementados en su comunicación comercial. Por ejemplo, en la siguiente gráfica se puede apreciar la estética juvenil y moderna con la que quieren comunicarse en sus redes sociales. Los nuevos puntos de venta que son comunicados en las publicaciones online también complementan una estrategia que busca posicionar a Vogue como una marca cercana para la mujer latina. 
Figura 9. Captura de publicidad en el fanpage de Vogue Perú del día 8 de septiembre ${ }^{9}$

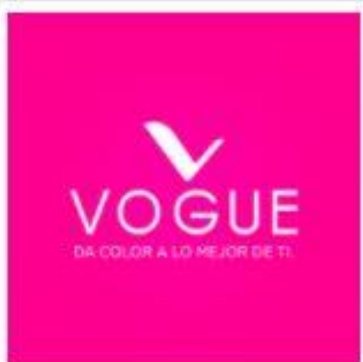

Vogue Cosméticos Perú

@VogueCosmeticosPeru

Inicio

Publicaciones

Fotos

Videos

Información

Notas

Comunidad

Crear una página

\section{It Me gusta Al Seguir $\nrightarrow$ Compartir $\ldots$}

8 de septuembre - w

¡Labios envidiables con esta \#PROMOCIÓN de locura!

Por la compra de un labial \#ColoríssimoLíquidoMate llévate cualquier otro labial con $50 \%$ de dscto.

Válido del 08 al 22 de Setiembre solo en tiendas Oechsle de Huánuco, Huancayo, Jirón de la Unión, Juliaca, Mall del Sur, Piura, Plaza Lima Norte y Pucallpa.

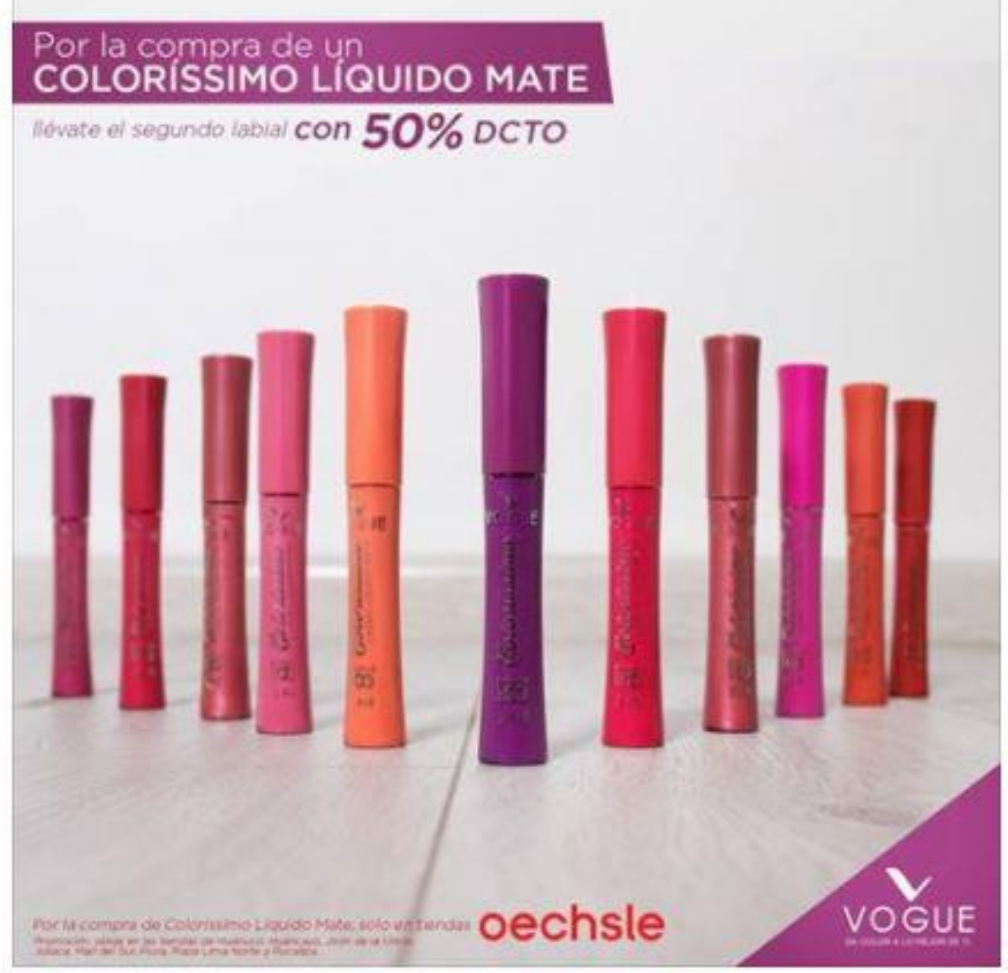

Ya que Vogue está dirigido a un segmento de consumidoras masivo, comunicar los atributos directos del producto y las distintas promociones que van sacando es una buena manera de atraer la atención del target. Así mismo, hay publicaciones donde se puede ver que el precio del producto está indicado en la misma gráfica, lo que no es usual para este tipo de piezas promocionando artículos cosméticos.

${ }^{9}$ Figura 9. Vogue Cosméticos Perú (8 de septiembre de 2017). 
Figura 10. Captura de publicidad en el fanpage de Vogue Perú del día 4 de septiembre ${ }^{10}$

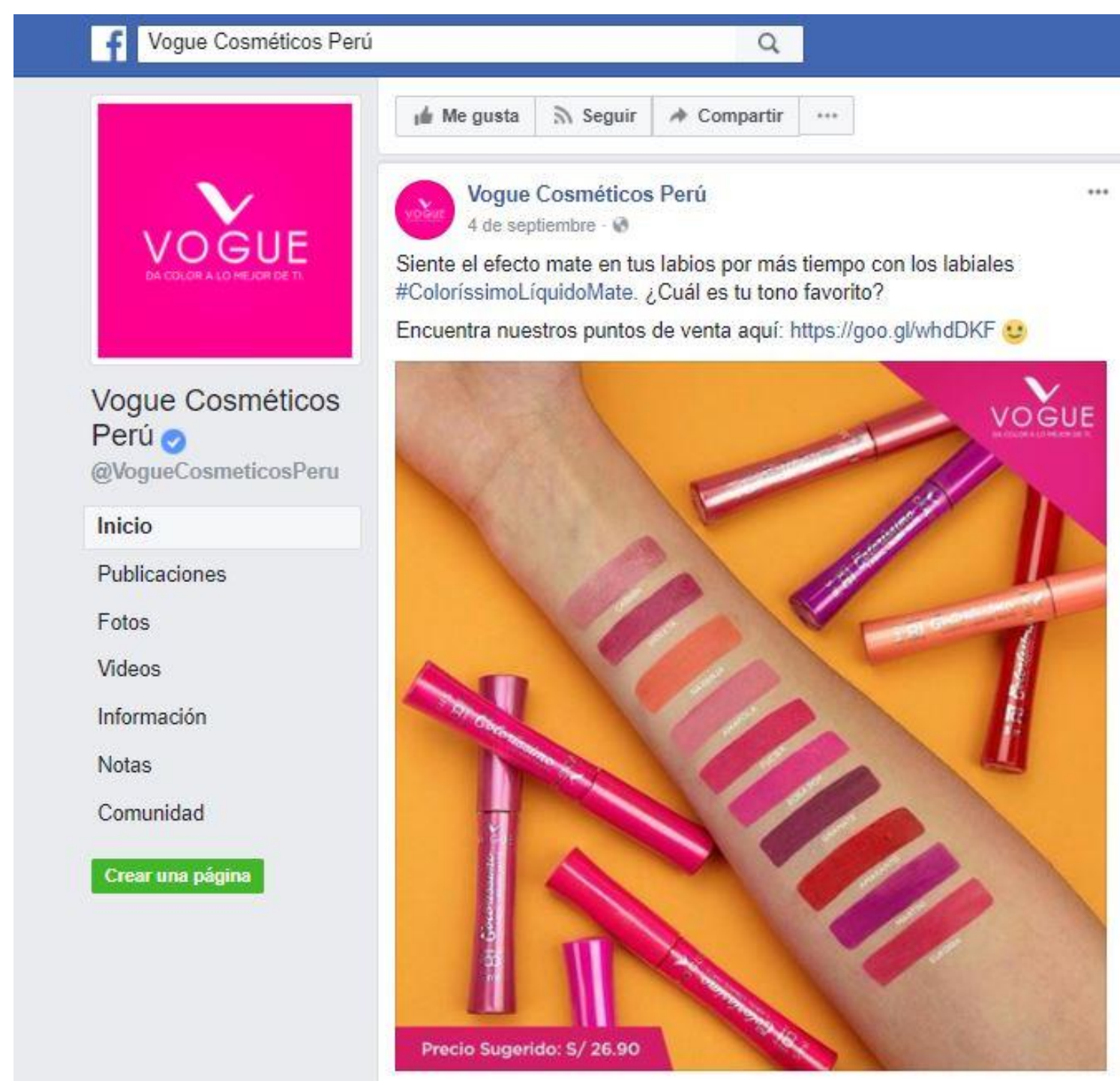

Las publicaciones que cuentan con un mejor desempeño en redes sociales, son las que están relacionadas a la aparición de las influencers utilizando o recomendando los productos. En su camino a volverse la marca líder del mercado cosmético latinoamericano, la participación de colaboradoras que ayuden a acercar la marca a sus usuarias finales son una acción estratégica de suma importancia. No obstante, este recurso no es nuevo para Vogue, pues como explica Sandra Alegre, es el modo en el cual viene trabajando desde hace un tiempo:

${ }^{10}$ Figura 10. Vogue Cosméticos Perú (4 de septiembre de 2017). 
Vogue tiene una influenciadora local dentro de cada país donde trabaja. Por ejemplo, en Colombia tenemos a Carolina Cruz, que es la presentadora de Colombia's Next Top Model. En el caso de México tenemos a una cantante que es conductora de La Voz. En Chile y los demás países igual. Esto nos ayuda a acercar la marca a las personas, porque a veces es muy lejano mostrar imágenes de alguien que no es muy conocido en su localidad. Imagínate, Carolina Cruz puede ser muy conocida en Colombia, pero en otro país tal vez no tenga la misma presencia (comunicación personal, 10 de octubre, 2017).

En Perú se escogió a la presentadora y ex reina de belleza Karen Schwarz para ser la cara de la marca en redes sociales. Debido a la cercanía e influencia que tiene Schwarz entre las mujeres peruanas, la marca apostó por su imagen para continuar acercando la marca a su público objetivo, dándole un tono local y veraz (S. Alegre, comunicación personal, 10 de octubre, 2017). Karen Schwarz anunció su unión a la familia Vogue a través de sus redes sociales usando el hashtag que lideraría el resto de la campaña: \#soyvoguera.

Figura 11. Captura de video promocional en el fanpage de Vogue Perú ${ }^{11}$
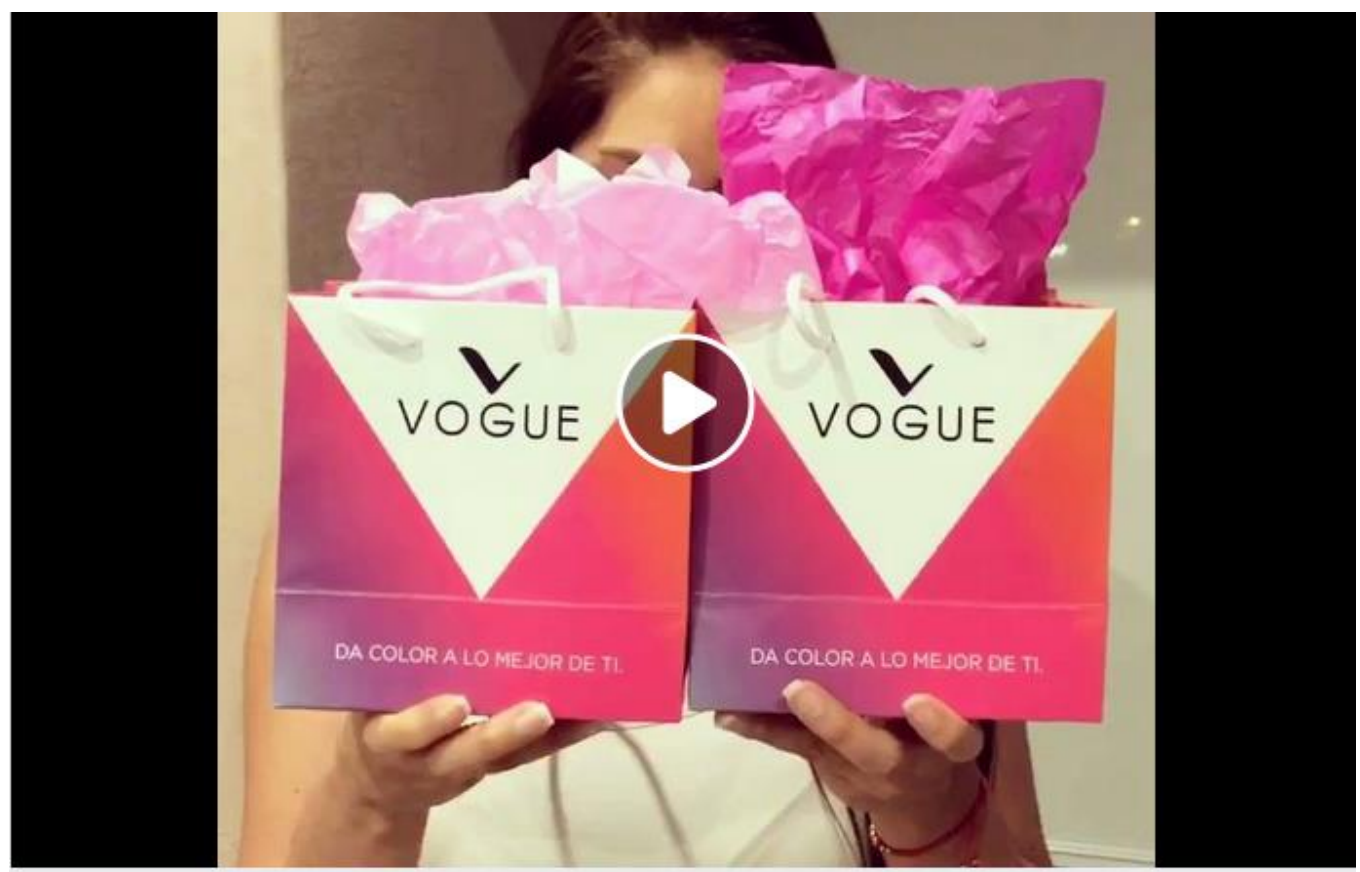

Karen Schwarz Espinoza (OFICIAL)

26 de mayo $\cdot$

It Me gusta esta página $\cdots$

Feliz de ser parte de la familia Vogue. Empezaremos a conocer juntas cada color!!! Mañana les cuento todo, atentas : \#soyvoguera

29.127 reproducciones

${ }^{11}$ Figura 11. Karen Schwarz Espinoza (26 de mayo de 2017). 
Figura 12. Captura de publicidad en el fanpage de Vogue Perú del día 31 de agosto $^{12}$

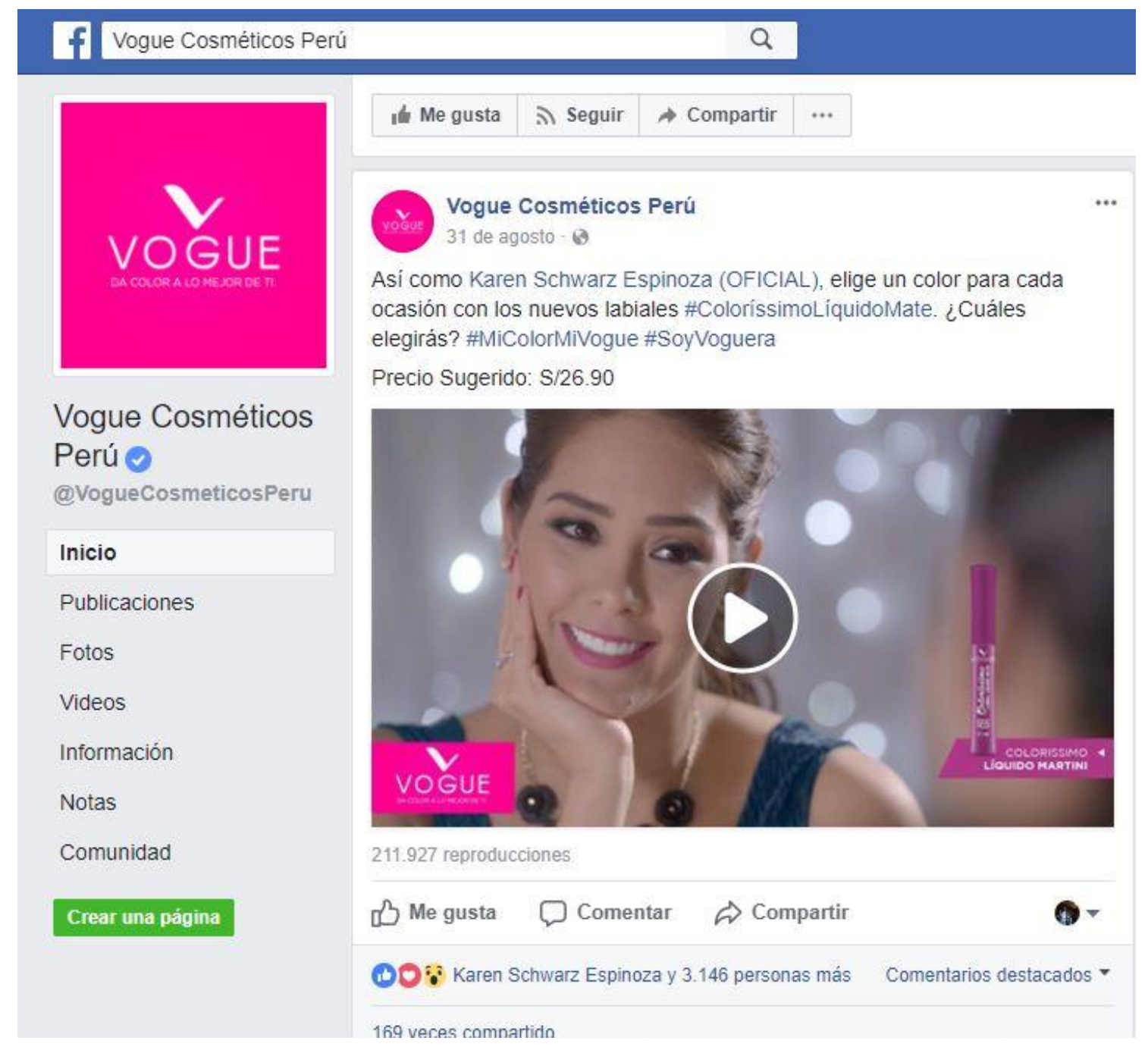

Para acompañar a Karen en el transcurso de la campaña digital, Vogue invitó a tres youtubers con canales dedicados al cuidado personal y temas de belleza. Se necesitaba que tuvieran mucho carisma, además de un estilo particular y mucha interacción con sus respectivas comunidades. Estas youtubers fueron Maya Zavala (alias Vibela Mood), Adriana Timoteo (alias Adristyling) y (alias ManiMake Perú). Las tres abrazaban la imagen de mujer latina y tenían un contacto cercano a sus audiencias en Youtube, igual que en otras redes atractivas para el target, como Facebook e Instagram.

${ }^{12}$ Figura 12. Vogue Cosméticos Perú (31 de agosto de 2017). 
En sus videos, las youtubers dan consejos de belleza a sus seguidoras, explican tutoriales de maquillaje, recomiendan y prueban productos, sugieren atuendos o comparten lo que ellas usan en su día a día. La mayoría de recomendaciones se dan de forma tácita pues no aluden directamente a una marca específica. Por el contrario, ellas cuentan un proceso de maquillaje y simplemente dan fe de las marcas que están utilizando al momento de hacer el video. Estas marcas no necesariamente están colaborando con las vloggers sino que pueden ser productos escogidos por ellas mismas. Sin embargo, entre la cantidad de productos que cada una utiliza para un solo video, hay espacio más que suficiente para marcas que sí hayan llegado a un acuerdo formal con las chicas, como es el caso de Vogue a raíz de esta campaña. Al momento de realizar este estudio, el número de seguidores que aglomeraban estas vloggers en sus canales de Youtube eran los siguientes: Vibela Mood contaba con 14,248; Adristyling tenía 28,699 y ManiMake, 137,944 seguidores (Youtube, 2017).

Vogue quiso reforzar la interacción de la marca con su público no solo en el plano digital, sino también en la vida real. Por este motivo, mediante su fanpage de Facebook empezó a impulsar actividades para formar una comunidad de usuarias que den mayor awareness a los productos y familiarizarlas con los atributos de sus productos (S. Alegre, comunicación personal, 10 de octubre, 2017).

Figura 13. Captura de los canales de ManiMake Perú, Adistyling y Vibela Mood

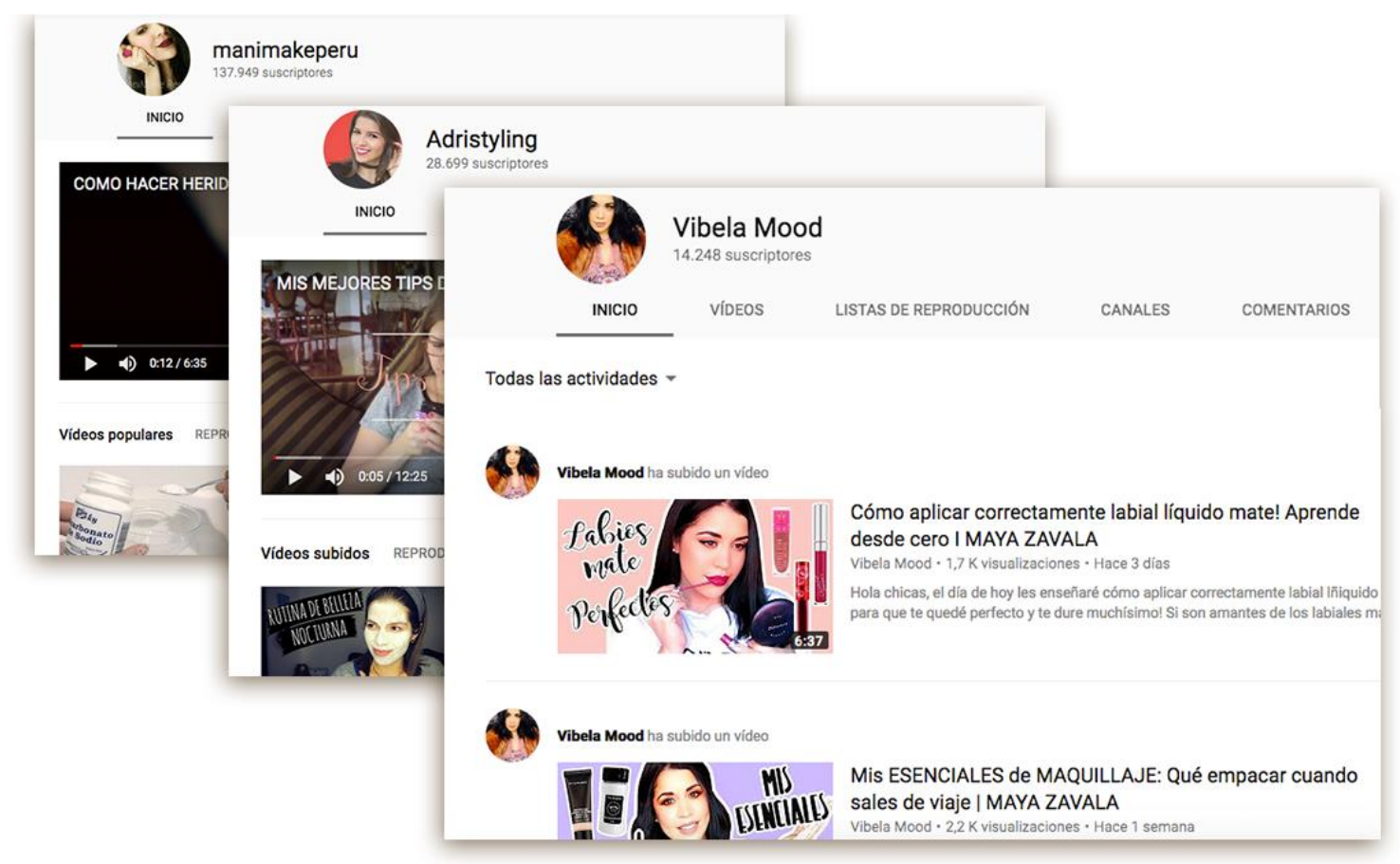


Figura 14. Captura de publicidad en el fanpage de Vogue Perú del día 15 de septiembre ${ }^{13}$

Vogue Cosméticos Perú Q

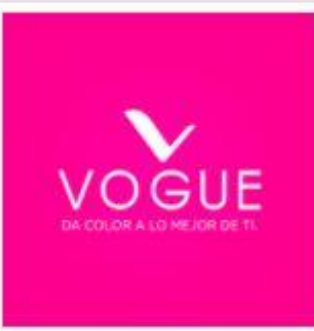

Vogue Cosméticos

Perú $\odot$

@VogueCosmeticosPeru

Inicio

Publicaciones

Fotos

Videos

Información

Notas

Comunidad

Crear una página

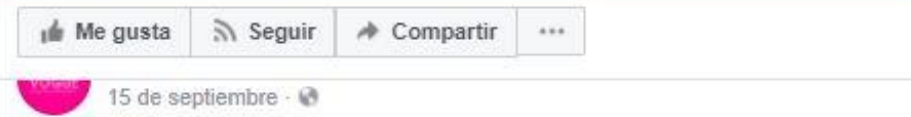

\#EVENTO

¡No te pierdas este fin de semana estaremos en Ripley de Plaza Lima Sur brindando asesorías de maquillaje! Además habrán sorteos y más sorpresas. $\alpha^{\prime} \oplus \mathbb{i}$ iTe esperamos, \#Voguera! is is

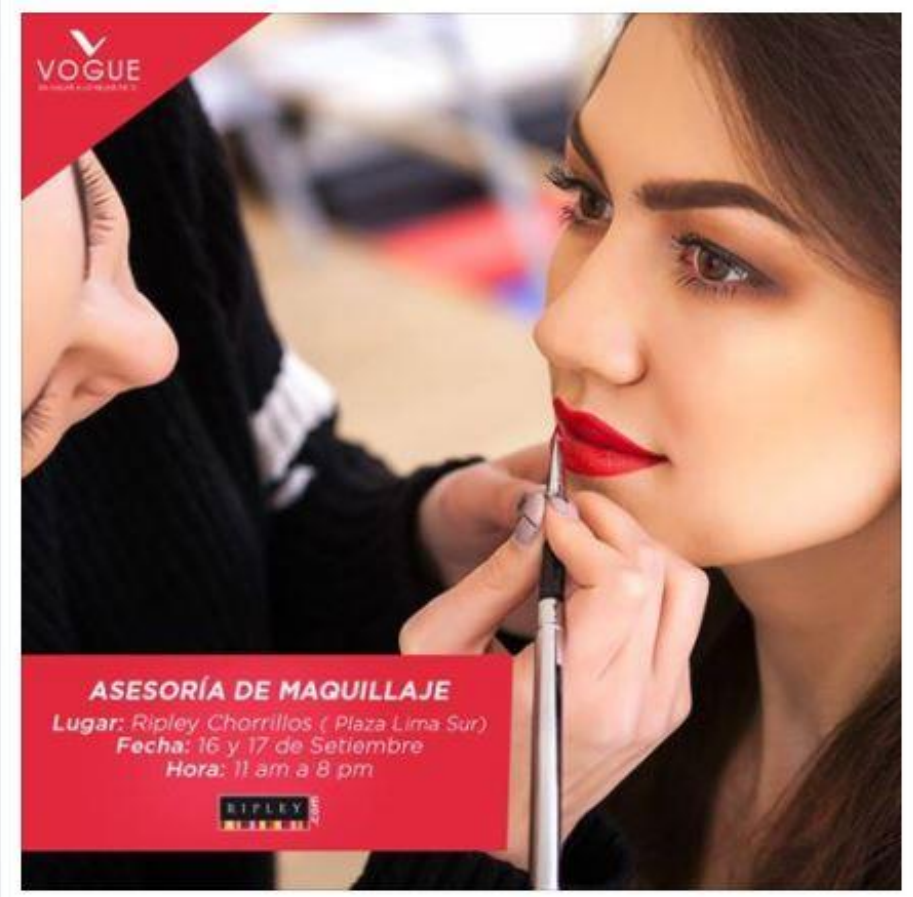

${ }^{13}$ Figura 14. Vogue Cosméticos Perú (15 de septiembre de 2017). 


\subsection{Proyección de resultados}

Para los directivos de Vogue, la campaña digital apunta más al posicionamiento que a la rentabilidad inmediata. Con competidores tan fuertes en el mercado cosmético, los objetivos de la marca apuntan a acercar el concepto de mujer "voguera" (un juego de palabras entre el nombre de la marca y el concepto de "bloguera") y latina a su público objetivo (S. Alegre, comunicación personal, 26 de setiembre, 2017). Así mismo, le hablan al target y lo incentivan a que pruebe los productos, que son relativamente nuevos en el mercado.

Sandra Alegre, jefa de producto para Vogue Perú, considera que la asociación de la marca es clave para generar awareness entre las consumidoras potenciales y darle recordación a la cartera de productos. Sin embargo, le parece difícil atribuirle un impacto importante sobre el aumento en su volumen de ventas porque: "Dentro del túnel de conversión hacia una compra hacen falta más pasos" (comunicación personal, 10 de octubre, 2017). Aunque la campaña digital ayuda a generar un posicionamiento de la marca entre su público objetivo, no se ha puesto en práctica una forma de medir si las chicas que recibieron la recomendación de las influencers terminó por comprar los productos de la marca (S. Alegre, comunicación personal, 26 de setiembre, 2017).

Así mismo, Sandra Alegre también menciona que las acciones que mayor impacto generan para la marca son las que se realizan en el mismo punto de venta:

El frente más eficiente para incentivar la compra son las acciones en punto de venta. Que las chicas vayan al punto de venta e interactúen con las posibles consumidoras también ayuda, pero lo que nos funciona más son las acciones masivas. Te hablo de los puntos de venta tradicional (comunicación personal, 26 de setiembre, 2017). 


\section{Resultados}


El tercer capítulo nos servirá para explicar a detalle la metodología usada a lo largo de esta investigación publicitaria. Además, dejará constancia del grupo que fue escogido como muestra para el estudio aquí presente y mostrará los resultados preliminares que arroja el análisis de las encuestas realizadas.

Para llegar a una conclusión más clara, se ha decidido dividir los resultados en dos momentos. El primer momento corresponde al control realizado al inicio de la investigación, cuando la campaña de Vogue Cosméticos Perú aún se encontraba en curso. Por consiguiente, el segundo momento corresponde al control realizado al final de la campaña digital dirigida por la marca para su incursión en el mercado de belleza peruano. 


\subsection{Metodología}

Con el fin de validar la hipótesis establecida se ha apostado por un estudio exploratorio cuasi experimental con un enfoque cuantitativo basado en el estudio de la campaña por la introducción al Perú de Vogue Cosméticos llevada a cabo en agosto de 2017. De esta manera se podrá profundizar más en la percepción de la influencia y costumbres del uso de la Internet en las consumidoras modernas que se empiezan a relacionar con las nuevas tecnologías. Para entender mejor a qué se refiere el término cuasi experimental, a continuación se ofrece una definición:

En la investigación experimental existen diversos tipos de diseño, que se clasifican de diferentes formas. Sin embargo, la clasificación más usada, según Salkind (1998) e investigadores como Briones (1985), es la de Campbell y Stanley, quienes identifican tres categorías generales de diseños de investigación: preexperimentales, cuasi experimentales y experimentales verdaderos. Para Salkind (1998), esta clasificación se fundamenta en dos características básicas de los diseños: 1) el grado de control que se ejerce sobre las variables objeto de estudio, y 2) el grado de aleatoriedad con que se asignan los sujetos de la investigación a un grupo o a varios de ellos (Bernal, 2010, p. 145).

Para continuar con la explicación de la metodología, también hay que referirse al término exploratorio para manifestar que los hallazgos de esta investigación no deben ser tomados como concluyentes, sino como un mero acercamiento a la respuestas que se desea hallar. Tal y como menciona Fidias G. Arias en su libro El proyecto de investigación: Introducción a la metodología científica, este tipo de investigación "es aquella que se efectúa sobre un tema u objeto desconocido o poco estudiado, por lo que sus resultados constituyen una visión aproximada de dicho objeto, es decir, un nivel superficial de conocimientos" (2006, p.23).

\subsubsection{Planteamiento de la investigación}

A lo largo de esta investigación se ha presentado información variada sobre la influencia, la recordación de marca, el posicionamiento y otras variables que podrían tener cierta influencia sobre la decisión de compra de los consumidores dado el contexto que se 
instauró con la aparición de redes sociales, como Facebook y Youtube, y la figura de los influencers. Esta investigación busca definir cuál es la percepción de la influencia del product placement de productos belleza sobre el proceso de decisión de compra en base a la muestra escogida. También se busca recabar más información sobre el comportamiento de las consumidoras que empiezan a relacionarse más con las nuevas tecnologías y las recomendaciones que pueden encontrar online, así como los actores que más influyen sobre sus comportamientos de consumo.

La conclusión a la que se espera llegar finalizado este estudio es que, efectivamente, las consumidoras de Lima metropolitana entre los 24 y 32 años se sienten influenciadas al momento de la compra por el uso del product placement de productos de belleza mientras se encuentre alineado a la personalidad de la marca al aumentar la recordación que estas tienen del producto o marca. Para ello, se analizarán las siguientes variables: medios y frecuencia de las impresiones publicitarias, percepción de influencia, preferencia, reconocimiento y recordación de marca.

\subsubsection{Trabajo de campo}

Se escogió una muestra de manera no-aleatoria (Centro Centroamericano de Población, 2017). En ambas encuestas participaron 82 mujeres pertenecientes al nivel socioeconómico BC. Dichas participantes afirmaban ser usuarias de la red social Youtube, además de ser consumidoras de productos cosméticos y residir en la ciudad de Lima. Las participantes cumplían con el perfil de "mujer moderna", contaban con acceso a Internet y estaban familiarizadas con el fenómeno de las vloggers en Youtube. Así mismo, se consideró para el estudio a mujeres provenientes de distintos distritos de la ciudad y con edades entre los 24 y los 32 años.

La encuesta buscó determinar la presencia que tenía este tipo de contenidos orientados a la belleza y estilo de vida en la vida de las encuestadas. Además, se buscaba profundizar en las opiniones que tenían sobre las youtubers, el nivel de influencia que le atribuían a estas últimas sobre su decisión de compra y, por último, conocer sus costumbres como consumidoras. Para contar con una conclusión significativa sobre la pregunta de investigación, se efectuaron encuestas a las participantes en dos momentos del mismo año: pre lanzamiento (del 1 al 31 de julio) y post lanzamiento (1 al 31 de agosto). 


\subsection{Principales hallazgos}

La investigación, efectivamente, reflejó la novedad de los productos cosméticos Vogue en el mercado peruano. Cuando se les preguntó a las participantes por las marcas de maquillaje que recordaban (top of mind) al inicio de la encuesta, los nombres más recurrentes fueron Mac Cosmetics y Maybelline. Justo detrás estaban Avon, L'Oreal, Cyzone y Unique. Sin embargo, cuando se les preguntó específicamente por la marca Vogue, más del 50\% de las encuestadas respondió que sí conocían la marca, sea por referencia o por haber probado alguno de sus productos con anterioridad. Las usuarias decían que usaban maquillaje por gusto propio y la mayoría se dividía entre quienes lo usaban para ocasiones especiales o quienes lo usaban de forma cotidiana en su día a día.

\subsubsection{Resultados pre lanzamiento}

En un inicio, era importante para el estudio conocer la situación en la que entraba la marca al mercado peruano, por lo que se le preguntó a las participantes cuáles era sus marcas de cosméticos más recordadas y si recordaban a Vogue como una marca del rubro (ver Figuras 15 y 16).

Figura 15. Las marcas de cosméticos más recordadas por la muestra

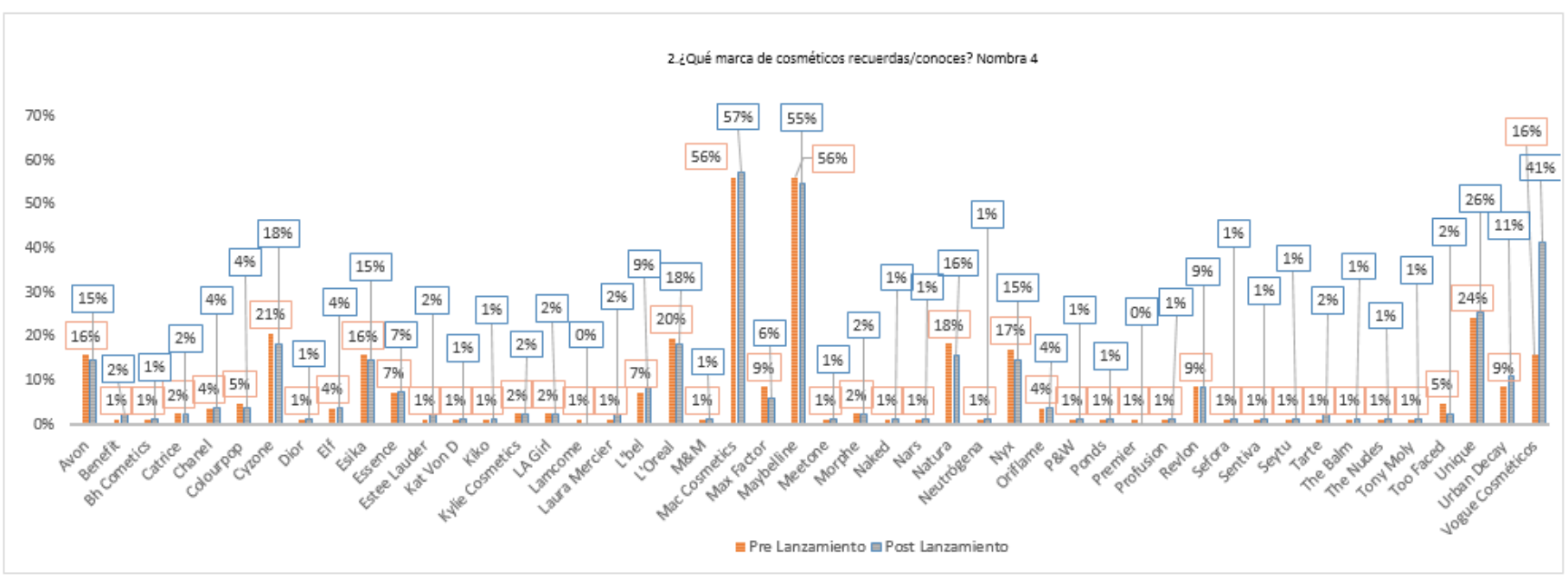


Figura 16. Reconocimiento de la marca Vogue antes y después de la campaña

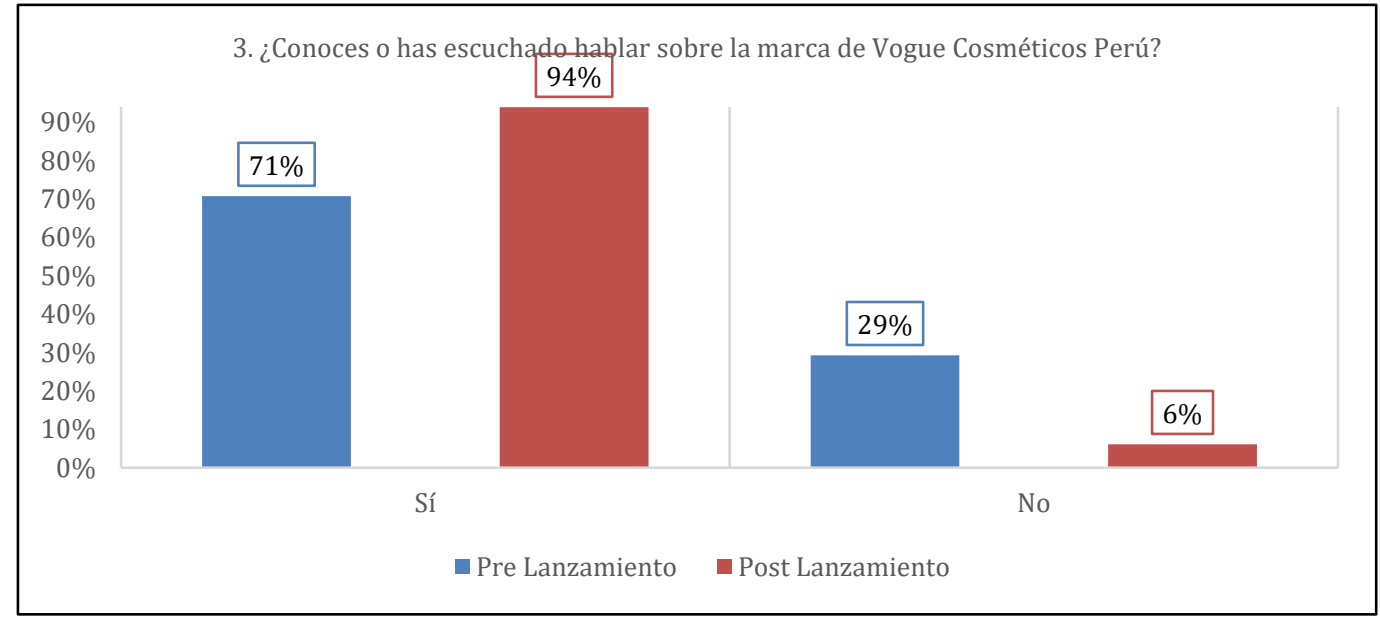

La primera encuesta reveló que antes de empezar a posicionarse mediante su nueva estrategia en redes sociales, la marca ya contaba con una buena presencia entre su público potencial en el plano digital. De las 82 encuestadas, 51 de ellas habían tenido contacto previo con los anuncios de Vogue (ver Figura 17) mediante las redes sociales (62\%) y por las recomendaciones de vloggers en sus canales de Youtube (35\%) o blogs (27\%).

Así mismo, cuando se les preguntó con qué frecuencia solían ver videos en Youtube (ver Figura 18), en una escala ascendente del 1 al 5, gran parte de las participantes afirmaron hacerlo con regularidad, sea con una frecuencia bastante alta (41\%), alta (32\%) o moderada (20\%). Cuando se les preguntó por el tipo de videos que solían ver (ver Figura 19), la preferencia indiscutiblemente fue para la categoría de videos de belleza con tutoriales de maquillaje y cuidado de la piel (56\%), seguido de un empate (ambos con $18 \%$ ) entre videos relacionados al mundo de la moda y lifestyle. Mientras que en el primero el foco del contenido está en mostrar una diversidad de atuendos o marcas de ropa; la otra categoría enseña rutinas de ejercicios, recetas caseras o enmarca los famosos tags, retos compartidos entre los cibernautas que resultan tan atractivos para los millenials en las redes sociales. 
Figura 17. Presencia de Vogue Cosméticos en medios y publicidad

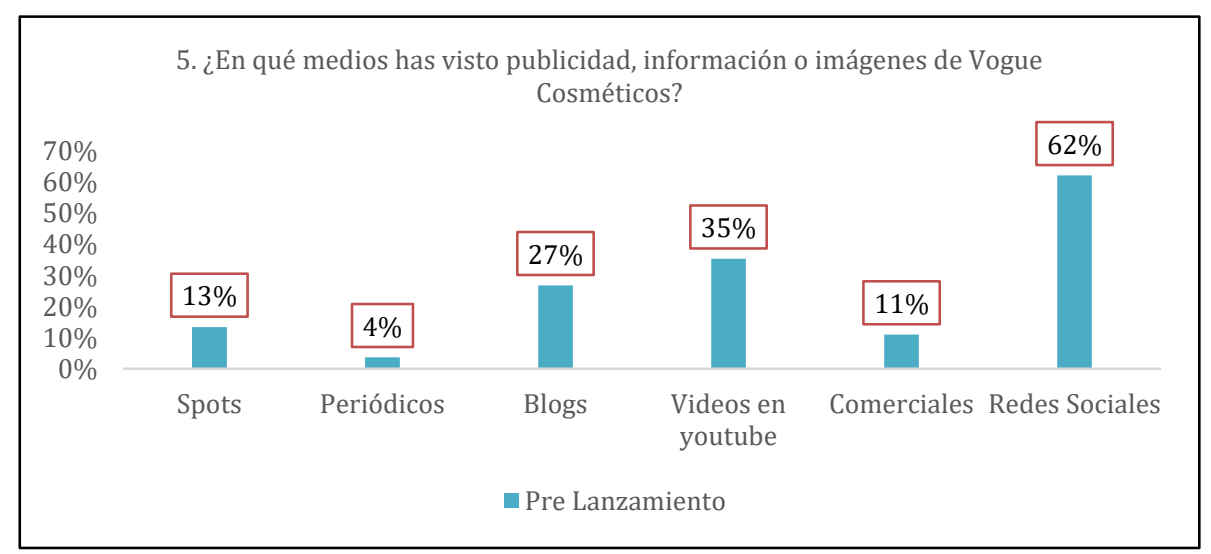

Figura 18. Frecuencia de visualización de videos en Youtube

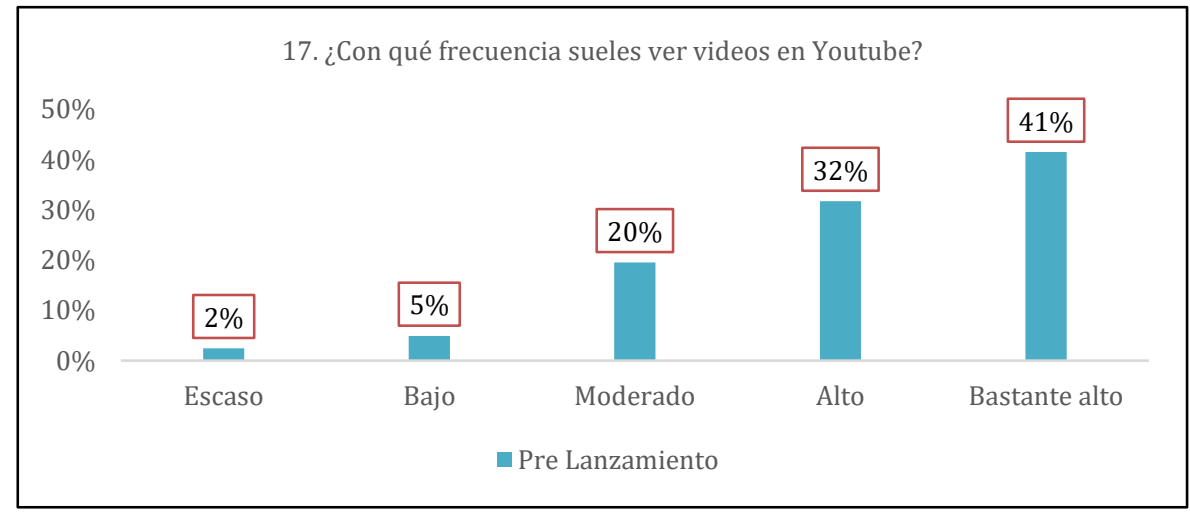

Figura 19. Videos más vistos por la muestra en Youtube

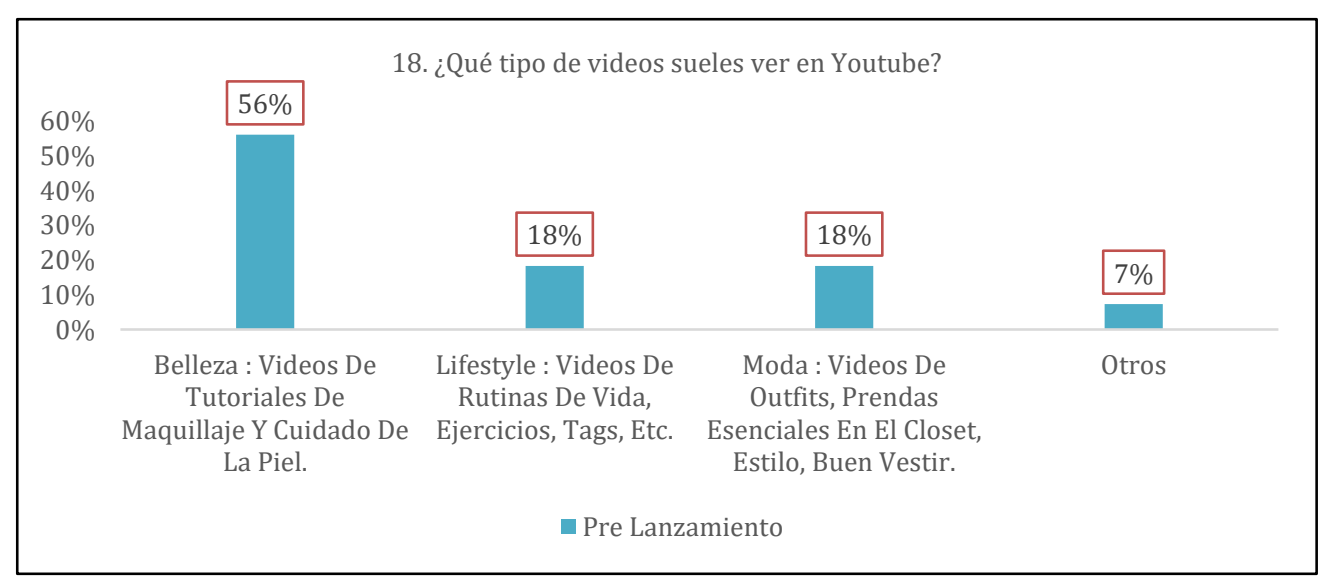


En otro momento de la entrevista, también se les preguntó a las participantes sobre los actores y medios que influenciaban su compra en favor de determinada marca o producto cosmético. Cuando se les preguntó qué tanto influía la recomendación de sus amistades al momento de comprar un producto de belleza (ver Figura 20), en una escala ascendente del 1 al 5, el mayor segmento de las encuestadas respondió que sí influía, en mayor o menor medida. El $43 \%$ de la muestra marcó que la percepción de influencia era alta. Los colegas y colaboradores en el ámbito del trabajo también eran percibidos como una fuente de influencia relevante en las encuestadas a la hora de escoger una marca de productos de belleza (ver Figura 21). El mayor porcentaje (30\%) indicó que la recomendación de sus amigos tenía una percepción de influencia moderada en sus compras, seguidas de un grupo que señaló una percepción de influencia alta (24\%).

Figura 20. Percepción de la influencia de las amistades al momento de comprar un producto cosmético

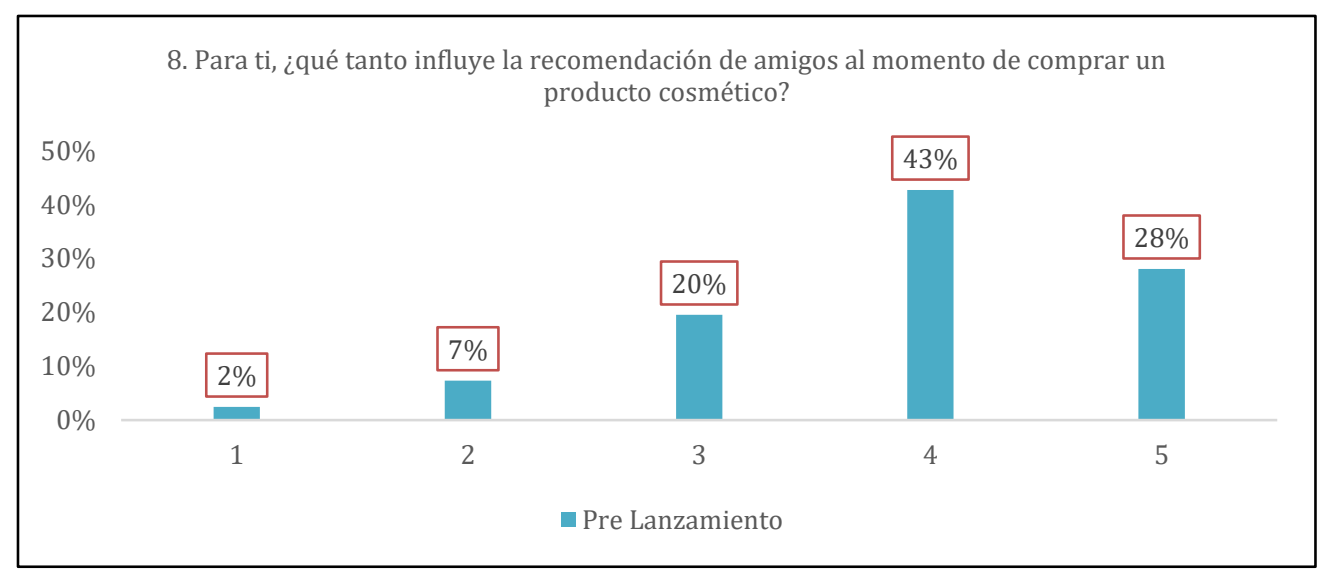


Figura 21. Percepción de influencia de los colegas al momento de comprar un producto cosmético

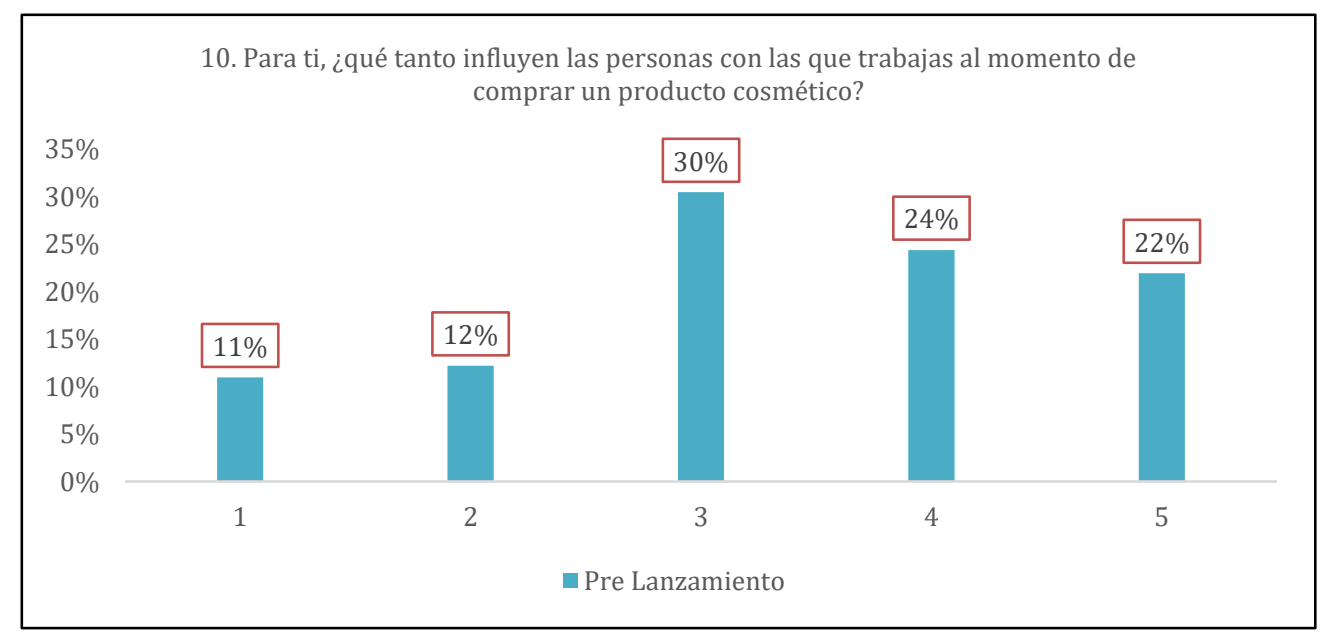

Posteriormente, las encuestadas respondieron sobre la influencia que le atribuían a algunos de los medios de comunicación más conocidos sobre la elección de los productos de belleza que decidían comprar. El que tuvo peor desempeño fue la televisión (ver Figura 22), que mostró una percepción de influencia moderada (39\%) o baja (25\%). En oposición, Facebook gozaba de mayor influencia sobre la decisión de compra de las participantes (ver Figura 23).

Figura 22. Percepción de influencia de los comerciales de televisión en la compra de cosméticos

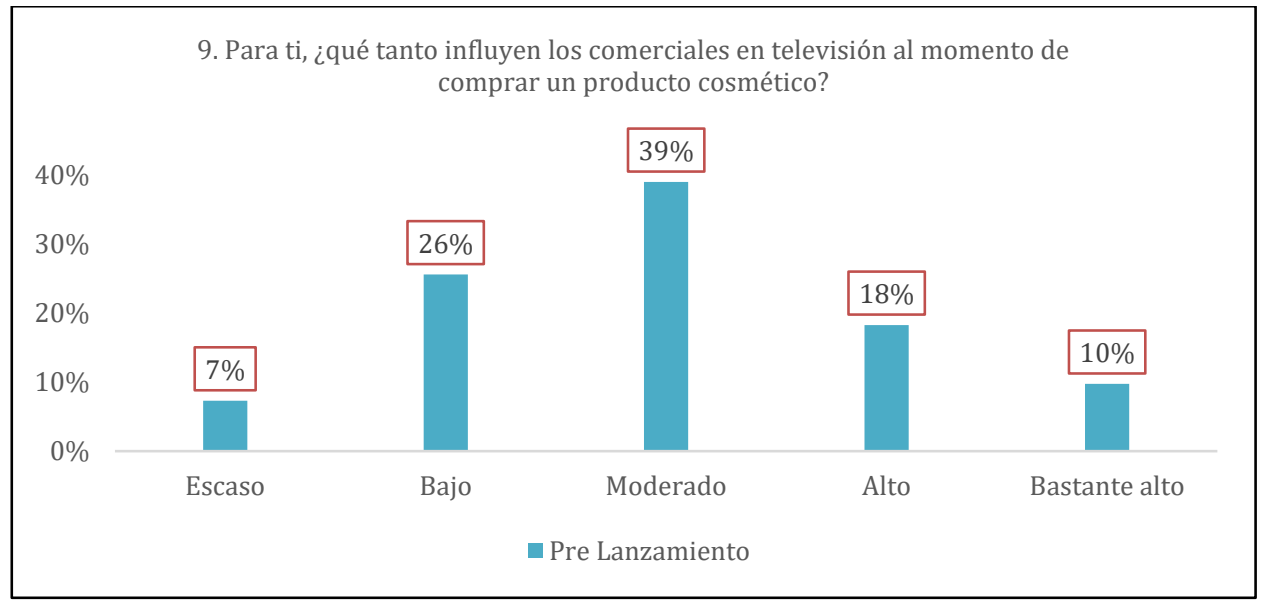

Figura 23. Percepción de influencia de Facebook en la compra de productos cosméticos 


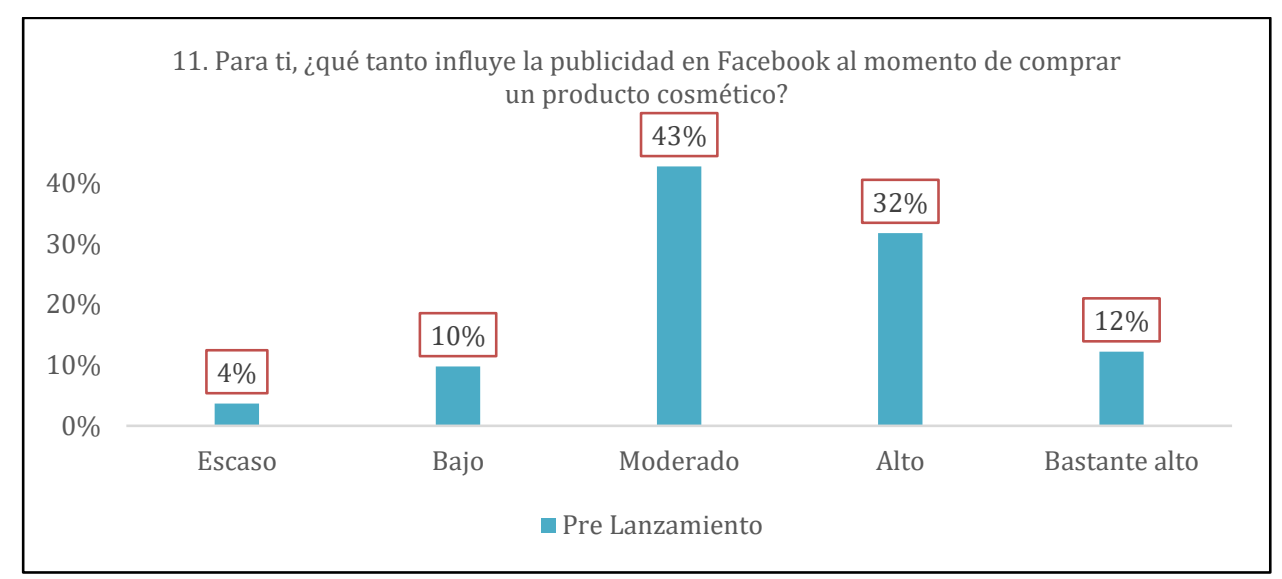

Por último, era necesario determinar la importancia de las recomendaciones para este tipo de productos en los canales de youtubers, blogueras y otro tipo de influencers. El 63\% de ellas mencionó que la influencia de las youtubers era alta (ver Figura 24) y el 24\% que era muy alta. Sobre las blogueras e influencers respondieron algo parecido (ver Figura 25), ya que el $43 \%$ admitía que su influencia era alta y el $28 \%$ decía que era muy alta. Las recomendaciones de la tienda también resultaron muy significativas para el público objetivo (ver Figura 26).

Figura 24. Percepción de la influencia de la recomendación de youtubers en la compra de cosméticos

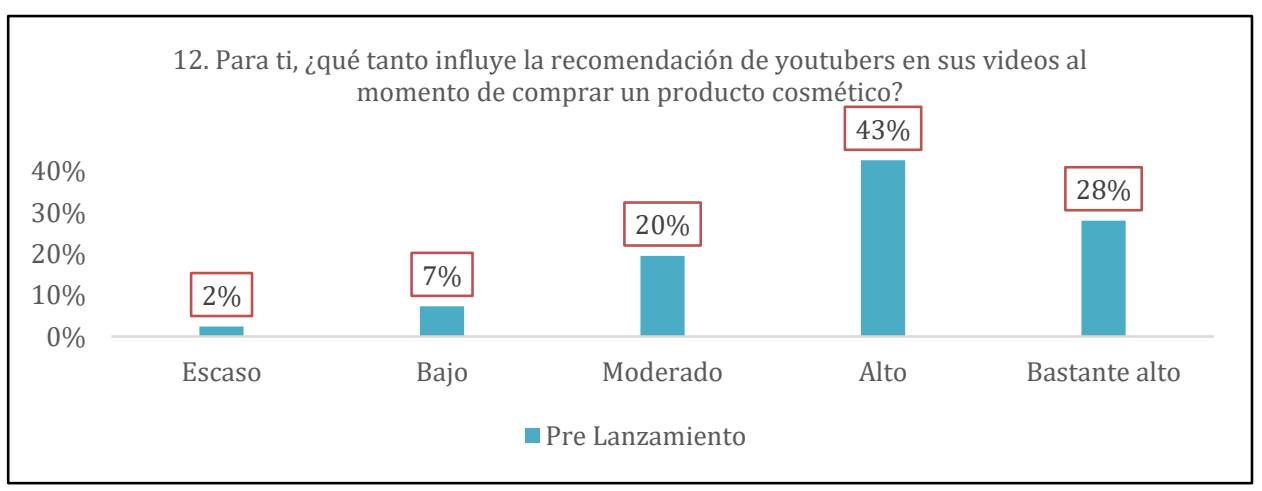

Figura 25. Percepción de influencia de blogueras e influencers en la compra de productos cosméticos 


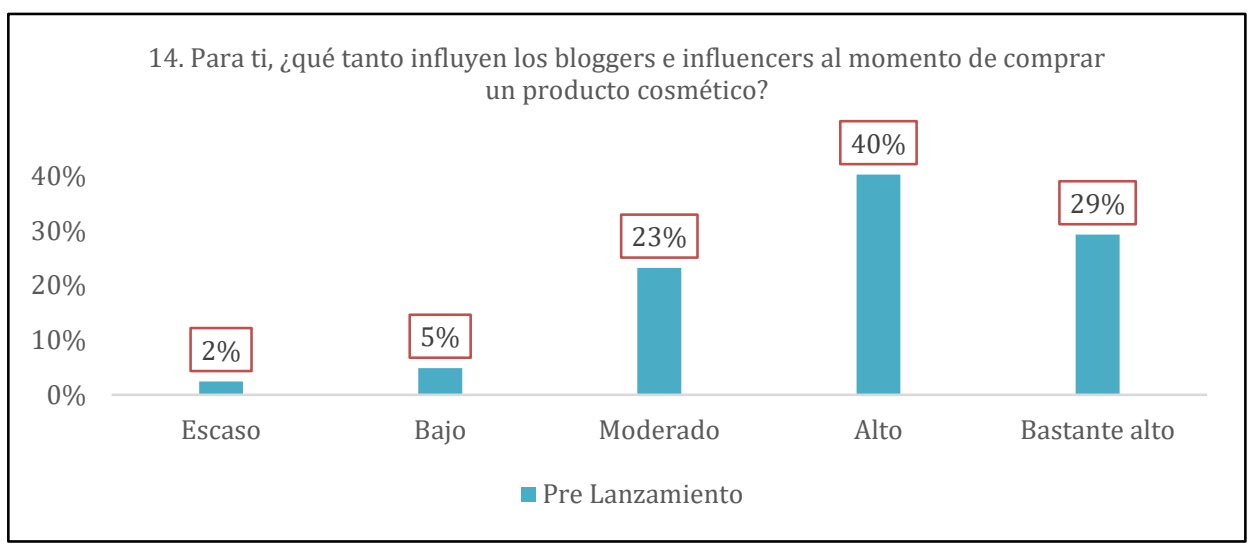

Figura 26. Percepción de la influencia de las recomendaciones de tiendas en la compra de cosméticos

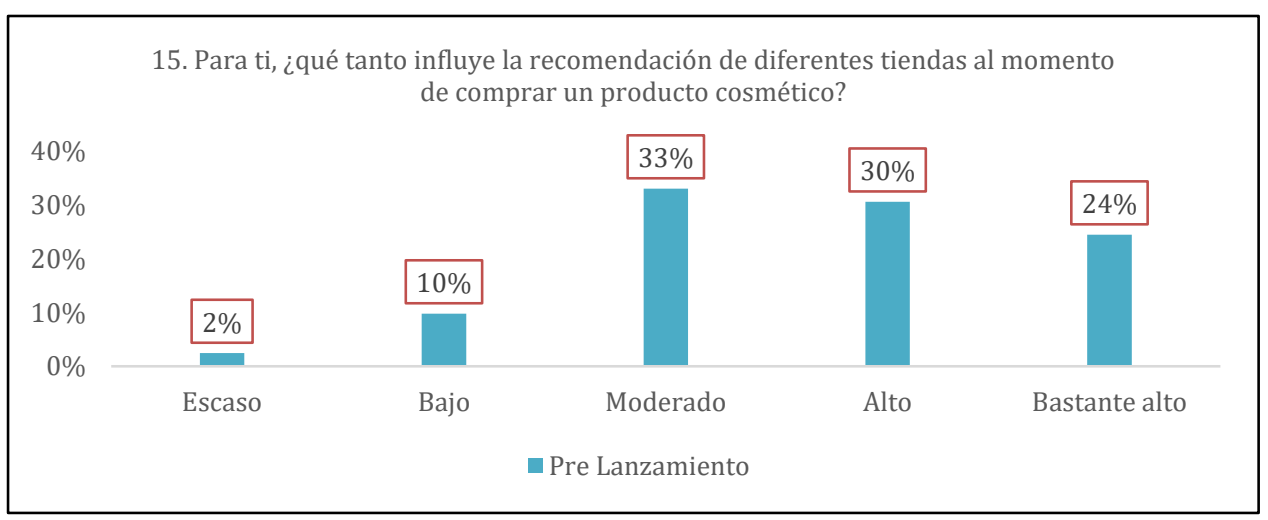

Luego de analizar la información de las encuestas, quedó claro que para la muestra escogida era muy importante probar la calidad del producto antes de adquirirlo, o al menos recibir una reseña de alguien de confianza, como una vlogger. En este punto, el mayor porcentaje (65\%) manifestó que la prueba del producto al momento de elegir un cosmético influía mucho en su decisión de compra (ver Figura 27). Con una cifra menor 
pero igualmente mayoritaria, el 39\% de las encuestadas declaró que les parecía de mucha importancia que una bloguera de belleza o youtuber usara un producto cosmético (ver Figura 28).

Figura 27. Percepción de la influencia de la prueba de producto antes de comprar un cosmético

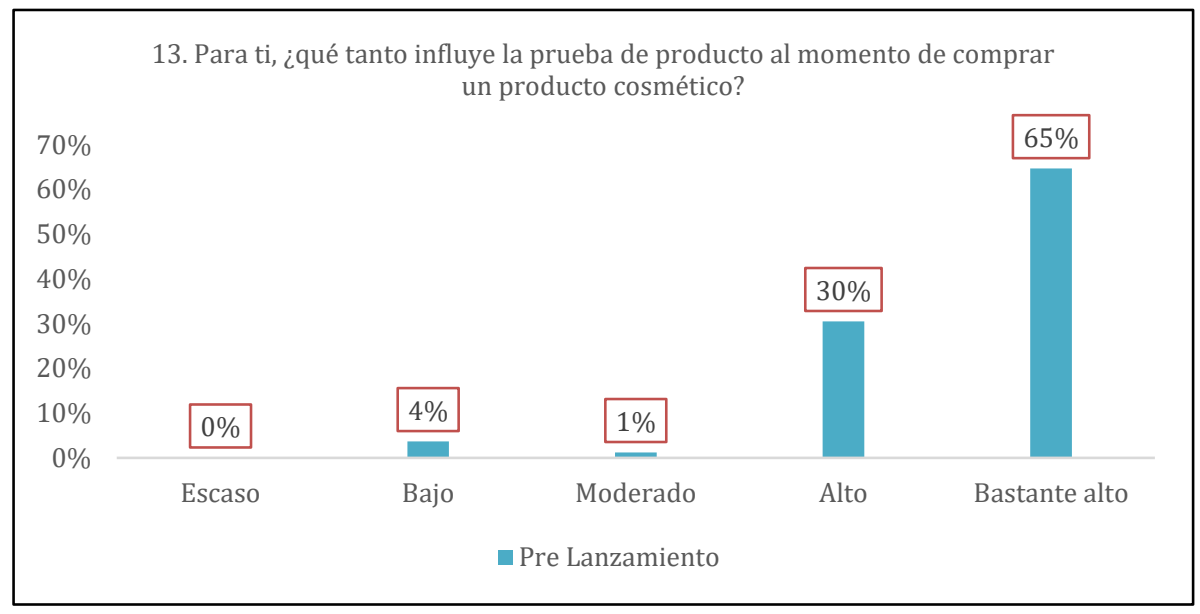

Figura 28. Percepción de la importancia del product placement en blogs de belleza para la decisión de compra de un producto cosmético

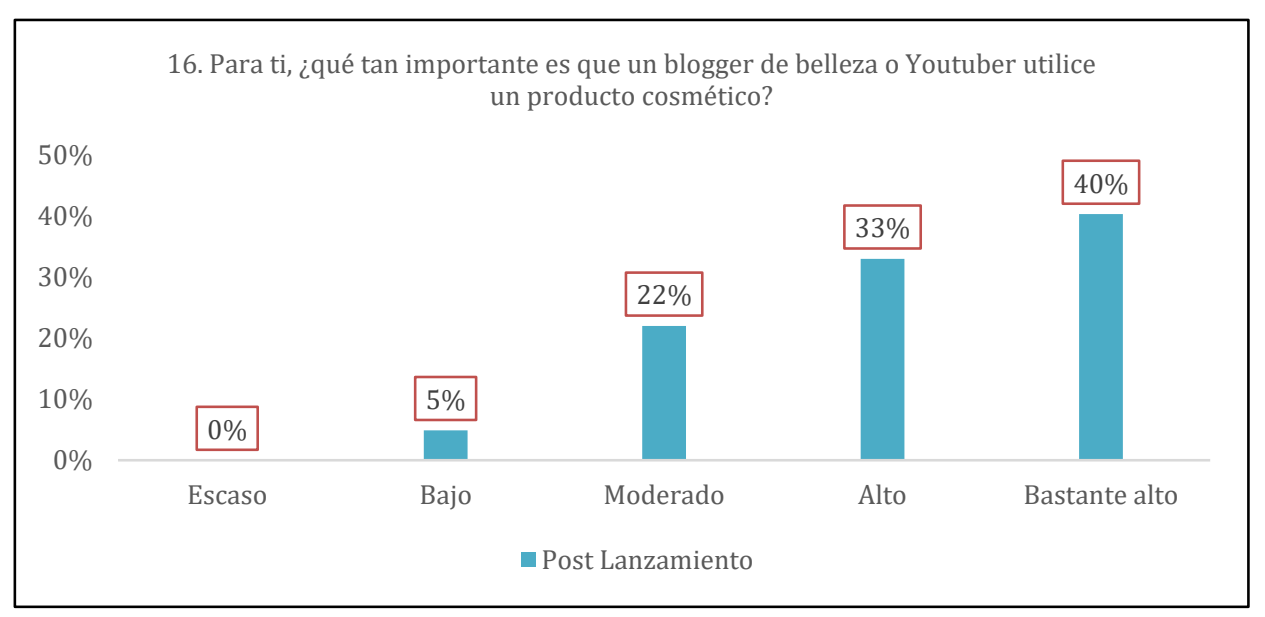

\subsubsection{Resultados post lanzamiento}

Transcurrido el trimestre de la campaña digital, se realizó un segundo control de la muestra para ver cómo se había modificado su relación con la marca. Cuando se le pidió a las participantes que nombraran las marcas de belleza que más recordaban, esta vez 
Vogue pasó a figurar entre las tres más populares, justo después de Mac Cosmetics y Maybelline (ver Figura 15). Del mismo modo, aumentó el porcentaje de participantes que recordaba la marca incrementándose desde un $71 \%$ hasta el 91\% (ver Figura 16).

Los efectos de la campaña se mostraron positivos al encuestar por segunda vez a las mujeres de la muestra. No solo recordaban mejor la marca, sino que las participantes terminaron una variedad más amplia de productos al finalizar la campaña digital a diferencia de cuando fueron entrevistadas en primer lugar (ver Figura 29).

Figura 29. Uso de los productos de la marca Vogue

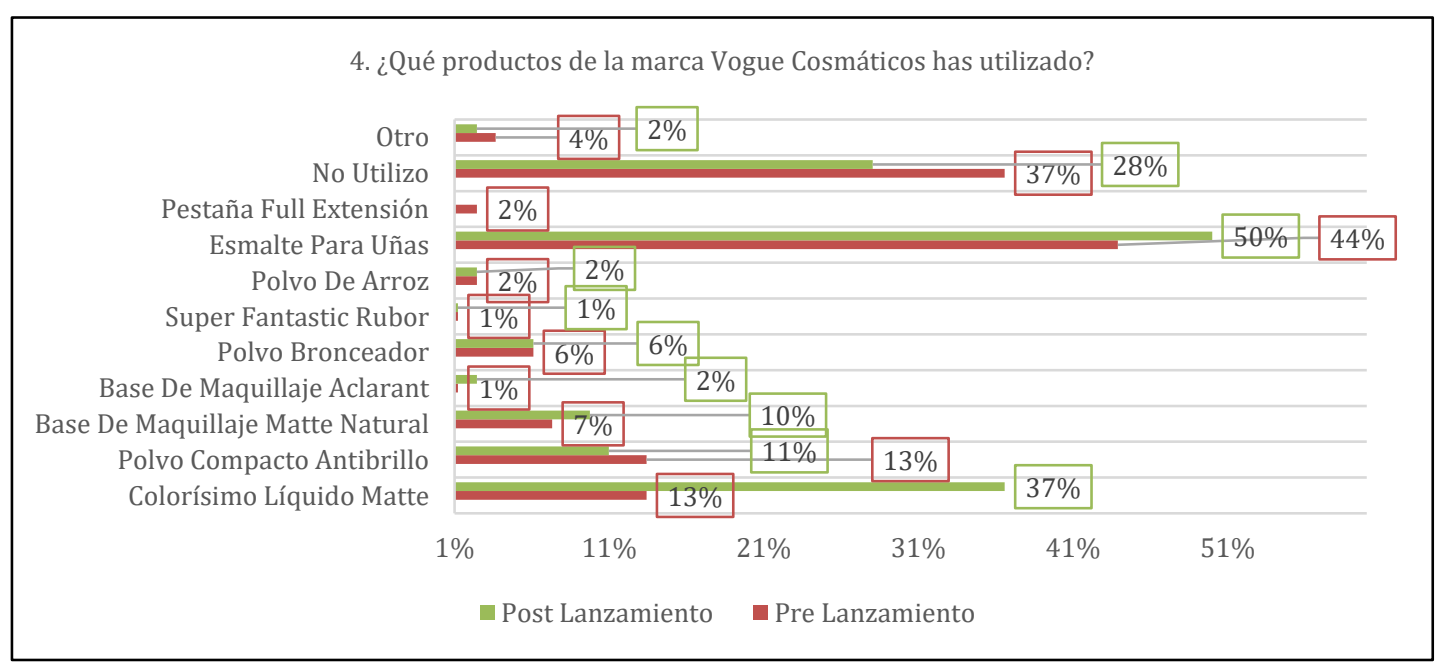

Cuando las participantes volvieron a puntuar la influencia que tenían los anuncios en Facebook, así como youtubers, blogueras e influencers sobre su decisión de compra para productos cosméticos, los cambios en sus respuestas fueron ligeros (ver Figuras 30, $31 \mathrm{y}$ 32). En todo caso, el mayor segmento reafirmaba la influencia de ambas redes sociales y de estas personalidades al momento de escoger una marca en particular.

Figura 30. Comparación de la percepción de la influencia de la publicidad en Facebook 
sobre la decisión de compra de productos cosméticos

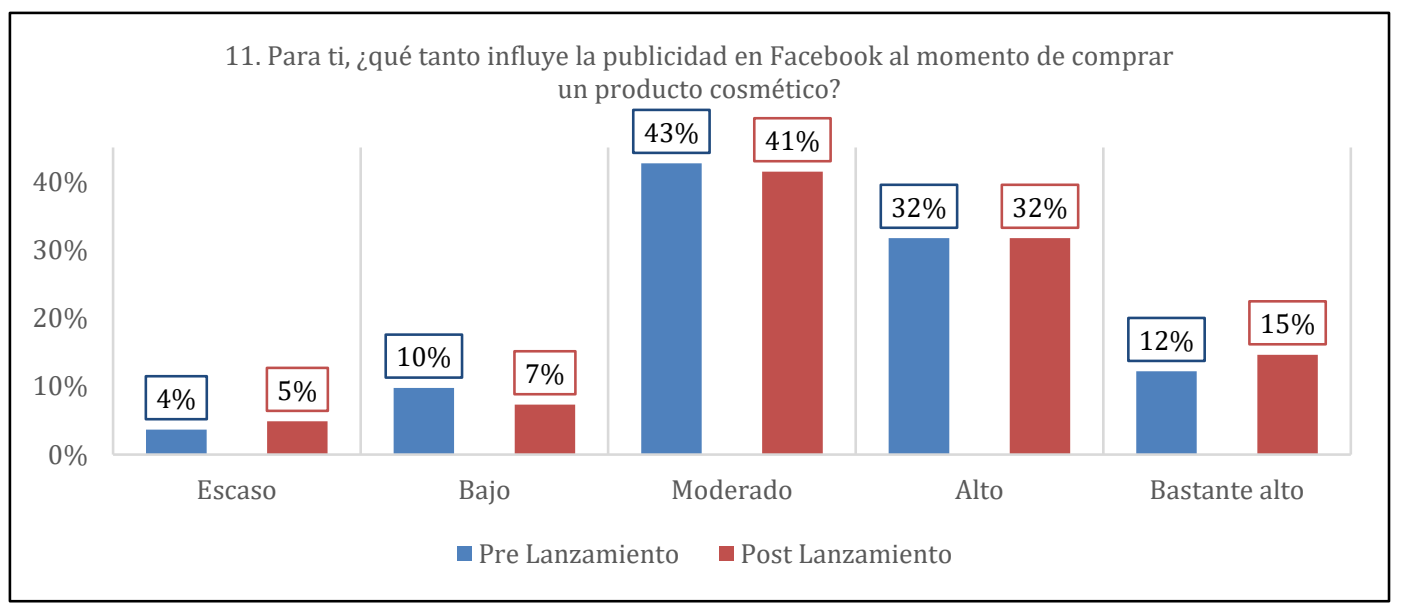

Figura 31. Comparación de la percepción de la influencia de las recomendaciones de Youtubers sobre la decisión de compra de productos cosmético

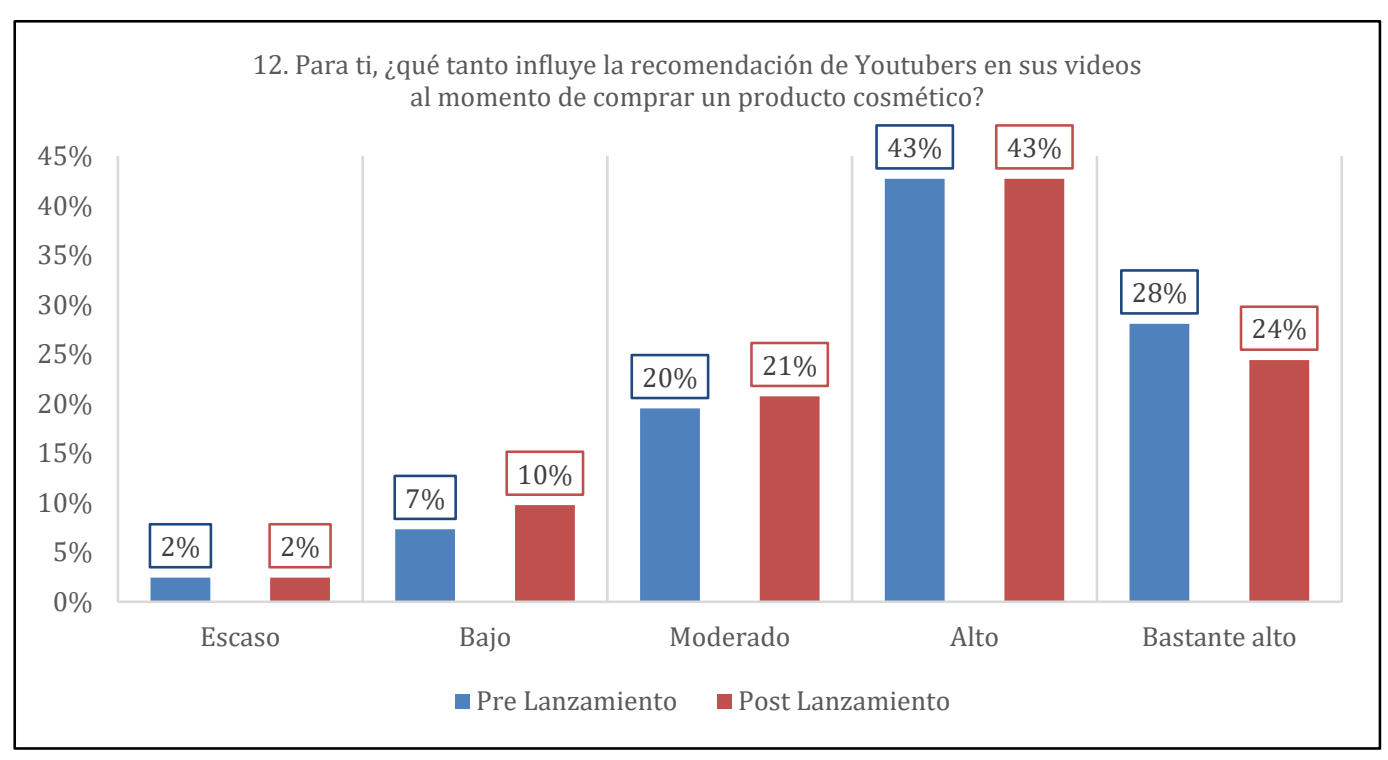

Figura 32. Comparación de la influencia de recomendación de blogueras e 
influencers sobre la decisión de compra de productos cosméticos

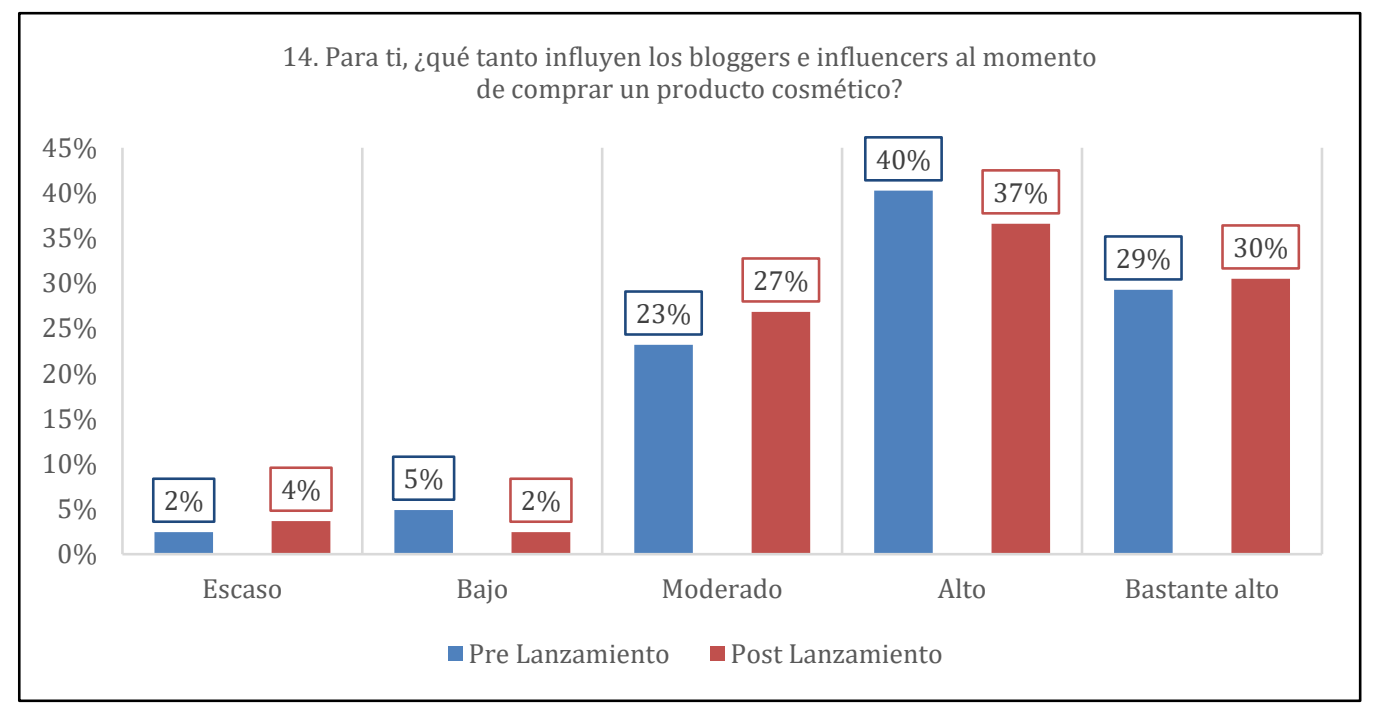

Finalmente, uno de los indicadores que incrementaron positivamente luego de la campaña digital fue la importancia de que las blogueras de belleza o youtubers usen los productos de belleza y los recomienden a su público. En este caso, las encuestadas le atribuyeron una importancia mayor en relación al control inicial (ver Figura 33).

Figura 33. Comparación de la importancia que tiene el uso de productos cosméticos por parte de blogueras de belleza o youtubers sobre la decisión de compr

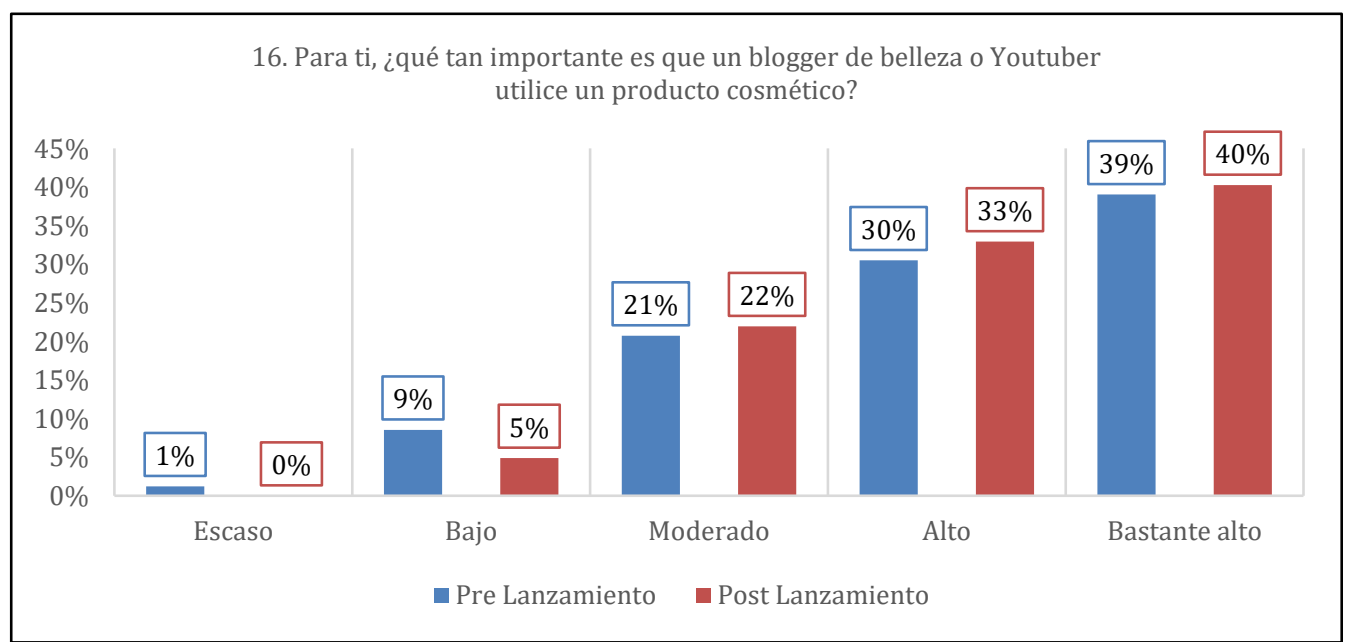




\subsubsection{Análisis de resultados}

Si bien es cierto que los hallazgos han resultado positivos para responder a la pregunta de investigación, la significancia de los resultados son muy marginales como para establecer todavía una conclusión determinante sobre este asunto. Al cruzar la información estadística obtenida, vemos que existe una relación débil entre las menciones de marcas realizadas por las youtubers en el contenido de su canal y la recordación que tenía Vogue antes y después de la campaña (ver Tabla 1). Del mismo modo, los resultados mostraron que había una débil relación entre una mejora en la recordación de marca y el reconocimiento que la muestra daba a la influencia de Youtubers (ver Tabla 2) y blogueras (ver Tabla 3) al final de la campaña.

Tabla 1. Mención de la marca en Youtube y su relación con la recordación de marca pre y post campaña

\begin{tabular}{|ll|r|r|r|}
\hline & \multicolumn{2}{|c|}{ Mención YouTube POST } & \multicolumn{1}{c|}{} \\
\cline { 3 - 4 } & & \multicolumn{1}{c|}{ No } & \multicolumn{1}{c|}{ Sí } \\
\hline Diferencia de recordación de & No ha mejorado & $76,1 \%$ & $77,8 \%$ & $76,8 \%$ \\
marca PRE vs POST & Ha mejorado & $23,9 \%$ & $22,2 \%$ & $23,2 \%$ \\
Total & & $100,0 \%$ & $100,0 \%$ & $100,0 \%$ \\
\hline
\end{tabular}

Tabla 2. Influencia de la recomendación de Youtuber y su relación con la recordación de marca terminada la campaña

\begin{tabular}{|c|c|c|c|c|}
\hline & & \multicolumn{2}{|c|}{ Influencia de YouTuber POST } & \multirow[b]{2}{*}{ Total } \\
\hline & & No influye & Sí influye & \\
\hline Diferencia de recordación de & No ha mejorado & $66,7 \%$ & $78,6 \%$ & $76,8 \%$ \\
\hline marca PRE vs POST & Ha mejorado & $33,3 \%$ & $21,4 \%$ & $23,2 \%$ \\
\hline Total & & $100,0 \%$ & $100,0 \%$ & $100,0 \%$ \\
\hline
\end{tabular}


Tabla 3. Influencia de la recomendación de bloguera y su relación con la recordación de marca terminada la campaña

\begin{tabular}{|c|c|c|c|c|}
\hline & \multicolumn{2}{|c|}{ Influencia de bloguera POST } & \multirow[b]{2}{*}{ Total } \\
\hline & & No influye & Sí influye & \\
\hline Diferencia de recordación & No ha mejorado & $68,2 \%$ & $80,0 \%$ & $76,8 \%$ \\
\hline de marca PRE vs POST & Ha mejorado & $31,8 \%$ & $20,0 \%$ & $23,2 \%$ \\
\hline Total & & $100,0 \%$ & $100,0 \%$ & $100,0 \%$ \\
\hline
\end{tabular}

Por otra parte, la mayor significancia en su relación con la recordación de marca radicaba en el uso de los productos cosméticos en los videos de las youtubers. Al comparar la recordación de la marca entre las participantes antes y después de la campaña con la influencia que le atribuían sobre su decisión de compra al uso de un producto por parte de una youtuber (ver Tabla 4), se mostró que la recordación de marca aumentó junto con la influencia que la muestra le atribuía a las youtubers sobre su decisión de compra. En este caso, el estudio demuestra que la relación es directa, pero débil (ver Tabla 5).

Tabla 4. Influencia del uso de los productos por Youtubers antes y después de la campaña y su relación con la recordación de marca pre y post campaña.

\begin{tabular}{|c|c|c|c|c|}
\hline & & $\begin{array}{r}\text { Diferencia de in } \\
\text { PRE vs }\end{array}$ & $\begin{array}{l}\text { uencia de uso } \\
\text { OST }\end{array}$ & \\
\hline & & $\begin{array}{c}\text { No ha } \\
\text { aumentado }\end{array}$ & Ha aumentado & Total \\
\hline Diferencia de recordación & No ha mejorado & $78,4 \%$ & $62,5 \%$ & $76,8 \%$ \\
\hline de marca PRE vs POST & Ha mejorado & $21,6 \%$ & $37,5 \%$ & $23,2 \%$ \\
\hline Total & & $100,0 \%$ & $100,0 \%$ & $100,0 \%$ \\
\hline
\end{tabular}

Tabla 5. Factor de correlación del uso de los productos por Youtubers y

la recordación de marca pre y post campaña.

\begin{tabular}{|c|c|c|c|c|c|}
\hline & & Valor & $\begin{array}{c}\text { Error estándar } \\
\text { asintótico }^{\mathrm{a}}\end{array}$ & $\begin{array}{c}\text { Aprox. } \\
S^{b}\end{array}$ & $\begin{array}{l}\text { Aprox. } \\
\text { Sig. }\end{array}$ \\
\hline Intervalo por intervalo & $\mathrm{R}$ de persona &, 112 &, 125 & 1,005 &, $318^{c}$ \\
\hline Ordinal por ordinal & Correlación de Spearman & 112 &, 125 & 1,005 &, $318^{c}$ \\
\hline $\mathrm{N}$ de casos válidos & & 82 & & & \\
\hline
\end{tabular}




\subsubsection{Discusión}

Estudios posteriores podrían ser conducidos para determinar los factores que impulsaron este crecimiento en la recordación de marca. De esta manera, podrían aprovechar esta etapa introductoria de la marca en el mercado peruano para descubrir la relación que tiene el target con esta forma de publicidad. Una de las posibilidades es que la recordación de la marca haya aumentado simplemente por la inclusión de Vogue a las redes sociales y su ingreso al mercado peruano. Hacen falta más estudios que le hablen de frente al consumidor sobre sus preferencias, comportamientos de compra y sobre cómo recuperar la confianza que ha perdido en el mundo del retail. De la misma forma, sería interesante evaluar la importancia que tiene la duración de la campaña para la obtención de resultados. Tal vez hace falta sostener de manera más extendida la campaña para ver resultados positivos, ya que inicialmente se ha encontrado una relación marginal entre el uso del product placement en videos de belleza en Youtube y un incremento en las ventas o en la recordación de una marca cosmética. Por su parte, las mujeres comprueban abiertamente la influencia que causan sus ídolos y modelos a seguir cuando de comprar un cosmético se trata. 


\section{Conclusiones}


En conclusión, el estudio apunta a que las recomendaciones elaboradas por youtubers, blogueras e influencers sí se perciben como influyentes sobre la decisión de compra de las mujeres a la hora de escoger un producto cosmético, aunque esta sea débil. Esto ocurre, sobre todo, porque la consumidora moderna desconfía de los mensajes emitidos por la publicidad y los medios de comunicación tradicional.

Gracias a su campaña digital, Vogue Cosméticos se posicionó como una marca más cercana al target, lo que incluso pudo verse traducido en más ventas puesto que el estudio mostró cómo las participantes se habían decidido a probar más productos pertenecientes a la cartera de productos de la marca. Sorprende especialmente cómo la marca aumentó tanto su nivel de recordación hasta el punto de ubicarse entre las 3 marcas cosméticas más nombradas por la muestra (top of mind), aún cuando en el primer control pocas la nombraron.

Los comerciales son vistos como un método de persuasión, por lo que las usuarias ya no se fían tanto de ellos al momento de decidir sus compras (Zevallos-Miranda, 2014). Siendo el maquillaje un artefacto de tanto cuidado (;porque lo aplicamos sobre nuestros rostros!), la primera experiencia y la recomendación de otras fuentes sí tienen una repercusión significativa sobre las compradoras potenciales de una marca nueva en el mercado, tal y como sugieren los modelos de decisión de compra revisados por Luis Vivar (1991).

Las estrellas mundiales han dejado de ser un referente y ahora las estrellas locales son las que han ganado el poder de llevar en una dirección u otra a sus seguidoras. Después de todo, ellas confían en que las blogueras, al ser usuarias reales también, den una opinión sincera sobre los productos que aparecen en sus videos. Por otra parte, las youtubers y blogueras igualmente cuidan su reputación, así que es difícil imaginar que arriesguen su credibilidad por un auspicio.

No obstante, las menciones de productos cosméticos en los canales de belleza de las youtubers no han mostrado una relación significativa con un aumento en la recordación de marca. Siguiendo las declaraciones de Sandra Alegre (2017), jefa de producto de Vogue Perú, pareciera que el product placement en Youtube no tuvo un impacto real sobre la recordación de la marca entre la muestra. Entre quienes mencionaron el medio Youtube en la encuesta post campaña, en un 22.2\% de ellos ha mejorado la recordación: 
se pasa de un "No recuerda la marca" a un "Sí recuerda la marca" (ver Tabla 6). Este porcentaje es menor al encontrado entre quienes no mencionarion Youtube como medio.

Tabla 6. Diferencias en la recordación de marca pre/post campaña y su relación con la mención de la marca en Youtube

\begin{tabular}{|ll|r|r|r|}
\hline & \multicolumn{2}{|c|}{ Mención YouTube POST } & \multicolumn{1}{|c|}{} \\
\cline { 3 - 4 } & \multicolumn{1}{|c|}{ No } & \multicolumn{1}{c|}{ Sí } & \multicolumn{1}{c|}{ Total } \\
\hline Diferencia de recordación de & No ha mejorado & $76,1 \%$ & $77,8 \%$ & $76,8 \%$ \\
marca PRE vs POST & Ha mejorado & $23,9 \%$ & $22,2 \%$ & $23,2 \%$ \\
Total & & $100,0 \%$ & $100,0 \%$ & $100,0 \%$ \\
\hline
\end{tabular}

Así mismo, la prueba Chi-cuadrado muestra que no hay relación entre un aumento en la recordación de marca con que contaba Vogue antes y después de su campaña y las menciones hechas en Youtube. Con un porcentaje de significación de 0.857 se prueba que no hay relación entre ambas variables del estudio aquí presente (ver Tabla 7).

Tabla 7. Prueba Chi-cuadrado para las diferencias en la recordación de marca pre/post campaña y su relación con la mención de la marca en Youtube

\begin{tabular}{|l|r|r|r|r|r|}
\hline & Valor & gl & $\begin{array}{c}\text { Sig. asintótica } \\
\text { (2 caras) }\end{array}$ & $\begin{array}{c}\text { Significación } \\
\text { exacta (2 caras) }\end{array}$ & $\begin{array}{c}\text { Significación } \\
\text { exacta (1 cara) }\end{array}$ \\
\hline Chi-cuadrado de Pearson &, $032^{\mathrm{a}}$ & 1 &, 857 & & \\
Corrección de continuidad &, 000 & 1 & 1,000 &, 857 & \\
Razón de verosimilitud &, 033 & 1 & & \\
Prueba exacta de Fisher &, 032 & 1 &, 858 & & \\
Asociación lineal por lineal & 82 & & & & \\
N de casos válidos & & & & & \\
\hline
\end{tabular}

a. 0 casillas $(0,0 \%)$ han esperado un recuento menor que 5 . El recuento mínimo esperado es 8,34.

b. Sólo se ha calculado para una tabla $2 \times 2$

Aunque al final del estudio para esta tesis se hayan obtenido resultados más positivos, un cruce en la data recogida mostraría que esta mejora no está relacionada a la presencia de product placement dentro de los videos de distintas Youtubers locales, sea por menciones de los productos en la marca o por la recomendación de la misma youtuber hacia sus seguidores. Esta conclusión se puede comprobar también al analizar el Factor de 
Correlación entre estas variables (ver Tabla 8). Al observar la significancia del Factor de Correlación se ve que la probabilidad es mucho mayor a 0.05 (en este caso de 0.373 ), lo que quiere decir que no existe una correlación entre ambas variables.

Tabla 8. Factor de Correlación entre las diferencias en la recordación de marca de Vogue pre/post campaña y la mención de la marca en Youtube.

\begin{tabular}{|c|c|c|c|c|c|}
\hline & & Valor & $\begin{array}{c}\text { Error estándar } \\
\text { asintótico }^{\mathrm{a}}\end{array}$ & $\begin{array}{c}\text { Aprox. } \\
S^{b}\end{array}$ & $\begin{array}{l}\text { Aprox. } \\
\text { Sig. }\end{array}$ \\
\hline Intervalo por intervalo & $\mathrm{R}$ de persona &,- 100 &, 121 &,- 896 &, $373^{c}$ \\
\hline Ordinal por ordinal & Correlación de Spearman &,- 100 &, 121 &,- 896 &, $373^{c}$ \\
\hline $\mathrm{N}$ de casos válidos & & 82 & & & \\
\hline
\end{tabular}

a. No se supone la hipótesis nula.

b. Utilización del error estándar asintótico que asume la hipótesis nula.

c. Se basa en aproximación normal.

Con estos resultados, se hace más notoria la necesidad de estudiar la relación que existe entre el product placement, las recomendaciones en redes sociales y la recordación de distintas marcas de productos de belleza. El estudio aquí presente muestra que hace falta evaluar muchos más factores en esta tendencia y su relación con otras variables como el awareness, así como la etapa de madurez en la que se encuentra la marca o producto. La moda de los influencers en las redes sociales parece ser muy nueva como para no esperar sorpresas. Si bien es notorio que resultan actores importantes para el ejercicio publicitario, tal vez no estarían consiguiendo los logros que normalmente se le atribuyen al momento de desarrollar una estrategia digital. 


\section{Referencias}

Abdul Adis, A.A. Phang, G.; Osman, Z.; Razli, A.; Pang, Y.X.; Sondoh, S. y Abdul Madij, R. (2015). Mediation Role of Attitude towards Product Placement in Social Media. En: Journal of Sustainable Development, vol. 8, $\mathrm{n}^{\mathbf{o}}$ 3. Canadian Center of Science and

Education. Recuperado de https://pdfs.semanticscholar.org/c21c/99a87065e6585a5ace9618701f42d9feb4f7.pdf

Adhiambo, C. (2012) Social Media as a Tool of Markerting and Creating Brand Awareness. Tesis para la obtención del grado de Bachiller en Administración de Negocios. Vaasan Ammattikorkeakoulu University Of Applied Sciences.

Alegre, S. (2017) Comunicación personal vía telefónica del día 10 de octubre de 2017. Entrevistada por Génesis Polo.

Alexa (2015). Alexa Traffic Ranks: How popular is youtube.com. Recuperado de http://www.alexa.com/siteinfo/youtube.com

Al-Kadi, T. (2013). Product placement: A booming industry in search of appropriate regulation. En: Journal of Marketing Research \& Case Studies, 2013, pp. 1-13.

Ansons, T.; Wan, F. y Leboe, J. (2011). The Influence of Immersion on Product Placement Effectiveness: A Synthesis and Review of Product Placement in Traditional and Digital Media.

Antolín, R. y Clemente, J. (2016). Youtube como herramienta significativa para la estrategia de comunicación de marcas: caso de estudio de engagement, insight y creatividad de las cinco campañas más relevantes a nivel mundial de la plataforma de video. En: Comunicación y Hombre. Revista interdisciplinar en Ciencias de la Comunicación y Humanidades. Madrid: Universidad Francisco de Vitoria.

Arias, F. (2006) El proyecto de investigación: Introducción a la metodología científica. Editorial Episteme: Caracas.

Armelini, G. y Villanueva, J. (2011). The Power of Word of Mouth: Adding Social Media to the Marketing Mix. En: IESE Insight “Social media: are you in the conversation?”, n 9, pp. 29-36.

Association Of National Advertisers (2010). TV Advertising Budgets Are Under Siege. Recuperado de http://www.ana.net/content/show/id/574 
Azlin, Z. y Mazini, M. (2016). The Impact of User - Generated Content (UGC) on Product Reviews towards Online Purchasing - A Conceptual Framework. En: Procedia Economics and Finance n ${ }^{\circ} 37$, pp. $337-342$.

Balasubramanian, S.; Patwardhan, H., Pillai, D. y Coker, K. (2014). Modeling attitude constructs in movie product placements. Journal of Product \& Brand Management, vol. 23, nº 7, pp. $516-531$.

Baños, M. y Rodríguez, T. (2003). Product placement. Estrella invitada: la marca. Madrid: Cied Dosat 2000.

Baños, M. y Rodríguez, T. (2012). Imagen de marca y product placement. Madrid: ESIC Editorial.

Bernal, C. (2010) Metodología de la investigación: administración, economía, humanidades y ciencias sociales. Universidad de La Sabana: Bogotá.

Bornstein, R.F. (1989). Exposure and Affect: Overview and meta-analysis of research. En: Psychological Bulletin, no 106, pp. 256-289.

Bouton, C.C. y Yustas, Y. (2012). Product placement (product placement): La publicidad eficaz. Madrid: Ediciones Pirámide.

Burgess, J. y Green, J. (2009). YouTube, Digital Media and Society Series. Cambridge, UK: Polity Press.

Carvajal, A. (2013). Análisis del impacto de publicidad en el comportamiento de mujeres, en edades comprendidas entre 18 a 30 años en cuanto a productos cosméticos, en el distrito metropolitano de quito, para el año 2013. Tesis para la obtención de grado en Ingeniería Comercial. Pontificia Universidad Católica del Ecuador. Quito.

Centro Centroamericano de Población (2017). Cuasi-experimentos. Recuperado de http://ccp.ucr.ac.cr/cursoweb/242cuas.htm

Chen, C.P. (2013). Exploring personal branding on YouTube. En: Journal of Internet Commerce, vol. $12, n^{\circ} 4$, pp. 332-347.

Córdoba, S. (2015). Product placement: Historia, modalidades y casos. Tesis para la obtención del grado en Publicidad y Relaciones Públicas. Universidad de Valladolid. Segovia.

Díaz, J.A. (2001). La belleza es salud. La medicalización lingüística de la publicidad de los cosméticos. En: Contextos, XIX-XX/37-40, pp. 109-121.

Diccionario de la lengua española (2018) Influencia. Recuperado de http://dle.rae.es/srv/search?m=30\&w=influencia 
Enríquez, V. (2016). La publicidad en la red social YouTube: Creación de un canal, uso de Google AdWords y youtubers. Tesis para la obtención de grado en Administración y Dirección de Empresas. Universidad de Valladolid. Segovia.

Fischer, T. (2014). Makeup, Youtube and Amateur Media in the Twenty-First Century. En: Crash/Cut - Undergraduate Film Journal no 3, pp. 1-8. University of Calgary.

Franssen, E. (2017). Building brands on Youtube: communication strategies of three successful beauty vloggers. Tesis para la obtención de máster. Erasmus University Rotterdam.

Gageler, L. y Van Der Schee, J. (2016). Product placement on social media: a study on how Generation Y's brand perception and purchase intention are influenced. Tesis para obtención de grado en Marketing Internacional. Jönköping University. Småland.

Gobè, M. (2001). Emotional branding: the new paradigm for connecting brands to people. New York: Allworth Press.

Gupta, P.B. y Lord, K.R. (1998). Product Placement in Movies: The Effect of Prominence and Mode on Audience Recall. En: Journal of Current Issues \& Research in Advertising, vol. 20, no 1 , pp. 47-59.

Haist, F., Shimamura, A.P. y Squire, L.R. (1992). On the Relationship Between Recall and Recognition Memory. En: Journal of Experimental Psychology: Learning, Memory, and Cognition, vol. 18, $\mathrm{n}^{\circ} 4$, pp. $691-702$.

Hauser, J.R. (2011). A Marketing Science Perspective on Recogition-Based Heuristics. En: Judgement and Decision Making, nº 6, pp. 396 - 408.

Hennig-Thurau, T., Gwinner, K.P., Walsh, G., y Gremler, D.D. (2004). Electronic Word-ofMouth. En: Consumer Opinion Platforms: What Motivates Consumers to Articulate Themselves on the Internet? Journal of Interactive Marketing, vol. 18, $\mathrm{n}^{\circ}$ 1, pp. 38-52. Howard, J.A. y Sheth, J.N. (1969) The Theory of Buyer Behavior. New York, Wiley.

Karen Schwartz Espinoza (26 de mayo de 2017) Feliz de ser parte de la familia Vogue!! [Estado de Facebook]

Recuperado de https://www.facebook.com/karen.schwarzespinoza.5/videos/10155059055615709/ (consulta: 11 de noviembre)

Keller, K. (1998). Strategic Brand Management. Building, Mesuring and Managing Brand Equity. Prentice Hall.

Kowalczyk, C. y Royne, M. (2012). Are products more real on reality shows? An exploratory study of product placement in reality television programming. En: Journal of Current Issues \& Research in Advertising, vol. 33, nº 2, pp. 248-266. 
Kureshi, S. y Sood, V. (2010). A Review of Placement Literature: Conceptual and Managerial Implications. En: The IUP Journal of Marketing Management, vol. 9, n 1-2, pp. 23-39.

La Ferle, C., Edwards, S. y Lee, W. (2008). Culture, attitudes and media patterns in China, Taiwan and The U.S.: Balancing standarizations and localization decitions. En: Journal of Global Marketing, vol. 21, nº 3, pp. 191-205.

Larrañaga, J. y Ruiz, A. (2009). El modelo de negocio de Youtube. En: Revista Ícono 14, nº 12. Madrid.

Lavalle, G. y Atarama, T. (2016). Youtube como herramienta de marketing estratégico para la moda: Análisis del canal oficial What the chic en el 2015. Universidad de Piura. Lima.

Lynch, J. y Srull, T. (1982). Memory and Attentional Factors in Consumers Choice: Concepts and Research Methods. En: Journal of Consumer Research, vol. 9, nº 1, pp. 18-37.

Maraña, J. (2016). El product placement como mensaje híbrido entre publicidad tradicional y publicity. Tesis para la obtención de grado en Marketing e Investigación de Mercados. Universidad de León. Quito.

Martí, J., Cabrera, Y. y Aldás, J. (2012). La publicidad actual: retos y oportunidades. En: Pensar la publicidad, vol. 6, $\mathrm{n}^{\mathrm{o}} 2$, pp. 327-343.

Martín, I., Alvarado, M.C. (2007). Nuevas tendencias en la publicidad del siglo XXI. Recuperado de http://eprints.ucm.es/7051/1/Segovia._Nuevastendenciasenlapublicidad.pdf

Nebenzahl, I. y Secunda, E. (1993). Consumers' attitudes toward product placement in movies. En: International Journal of Advertising, $\mathrm{n}^{\circ}$ 12, pp. 1-11.

Nelson, E.; Ellison, E. (2005) In a Shift, Marketers Beef Up Ad Spending Inside Store. En: Wall Street Journal. Recuperado de http://online.wsj.com/news/articles/SB112725891535046751

Newell, J., Salmon, C.T., y Chang, S. (2006). The hidden history of product placement. Journal of Broadcasting \& Electronic Media, n 40, pp. 575-595.

Page, R. (2012). The linguistics of self-branding and micro-celebrity in Twitter: The role of hashtags. En: Discourse \& Communication, vol. 6, nº 2, pp. 181-201.

Panda, T.K. (2004). Consumer Response to Brand Placements in Films Role of Brand Congruity and Modality of Presentation in Bringing Attitudinal Change Among Consumers with Special Reference to Brand Placements in Hindi Films. South Asian Journal of Management, vol. 11, no 4, pp. 7-26.

Plambeck, J. (2010). Product Placement Grows in Music Videos. New York Times. Recuperado de http://www.nytimes.com/2010/07/06/business/media/06adco.html 
Rose, S. (2014). As Seen on TV: why product placement is bigger than ever. The Guardian. Recuperado de https://www.theguardian.com/tv-and-radio/2014/jun/24/breaking-bad-tvproduct-placement

Russel, A. y Belch, M. (2005). A managerial investigation into the product placement industry. Journal of Advertising Research, 45, pp. 73-92.

Schor, J. (2004). Born to buy: the commercialized child and the new consumer culture. New York: Scribne

Segrave, K. (2004). Product Placement in Hollywood Films: a history. Jefferson, North Carolina. McFarland \& Company, Inc. Publishers.

Serralvo, F. y Tadeu, M. (2005). Tipologías del posicionamiento de marcas. Un studio conceptual en Brasil y en España. En: Revista Galega de Economía, vol. 14, nº 1-2, pp. $1-15$.

Smith, D. (2014). Charlie is so 'English'-like: nationality and the branded celebrity person in the age of YouTube. En: Celebrity Studies, vol. 5, n³, pp. 256-274.

Sosa, A. (2016). La publicidad encubierta y nuevas modalidades publicitarias. En: Revista de Actualidad Mercantil, no 4, pp. 252-266.

Thielman, S. (2013). How Lego Became the Most Valuable Toy Company in the World. Adweek. Recuperado de http://www.adweek.com/brand-marketing/how-lego-became-mostvaluable-toy-company-world-148578/

Thoma, V. y Williams, A. (2013). The devil you know: The effect of brand recognition and product rating on consumer choice. En: Judgment and Decision Making, vol. 8, nº 1, pp. 34-44.

Torres, E. y Muñoz, J.P. (2006). Publicidad exterior: uso exploratorio de recordación de marca y motivación de compra. En: Revista Venezolana de Gerencia, año 11, nº 36, pp. 581 594. Universidad de Zulia.

Torres, K. (2014). Youtube, como una estrategia de publicidad para Palladio. Tesis para la obtención de grado en Comunicación Publicitaria. Universidad San Francisco de Quito. Quito.

Trout, J. y Ries, A. (1972) The Positioning Era Cometh. En: Advertising Age, April 24, 1972. Recuperado de http://www.ries.com/wp-content/uploads/2015/09/PositioningArticles002.pdf

Tuck School of Business (2017). Faculty director: Kevin Lane Keller. Recuperado de http://www.tuck.dartmouth.edu/faculty/faculty-directory/kevin-lane-keller 
Van Reijmersdal, E.A., Neijens, P.C. y Smit, E.G. (2009). A New Branch of Advertising: Reviewing Factors that Influence Reactions to Product Placement. En: Journal of Advertising Research, diciembre, pp. 429-449.

Variety Magazine (2014). Survey: YouTube Stars More Popular Than Mainstream Celebs Among U.S. Teens. Recuperado de http://variety.com/2014/digital/news/survey-youtubestars-more-popular-than-mainstream-celebs-among-u-s-teens- 1201275245/

Vivar, L. (1991) Los modelos microanalíticos del comportamiento del comprador como herramientas para la estrategia comercial de la empresa. En: Anales de estudios económicos y empresariales, $\mathrm{n}^{\circ}$ 6, pp. 97-122.

Vogué Cosméticos Perú (15 de septiembre de 2017) ¡No te pierdas este fin de semana estaremos en Ripley de Plaza Lima Sur brindando asesorías de maquillaje! [Estado de Facebook] Recuperado de https://www.facebook.com/VogueCosmeticosPeru/photos/a.1426210437429284.10737 41828.1180348335348830/1627870087263317/?type=3\&theater $\quad$ (consulta: 11 de noviembre)

Vogué Cosméticos Perú (31 de agosto de 2017) Elige un labial para cada ocasión. [Estado de Facebook] Recuperado de https://www.facebook.com/VogueCosmeticosPeru/videos/1614479355269057/ (consulta: 11 de noviembre)

Vogué Cosméticos Perú (4 de septiembre de 2017) Siente el efecto mate en tus labios por más tiempo con los labiales \#ColoríssimoLíquidoMate. [Estado de Facebook] Recuperado de https://www.facebook.com/VogueCosmeticosPeru/photos/a.1426210437429284.10737

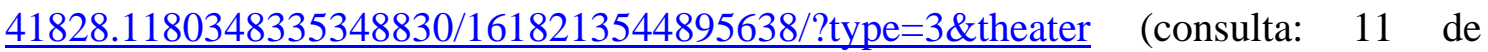
noviembre)

Vogué Cosméticos Perú (8 de septiembre de 2017) ;Labios envidiables con esta \#PROMOCIÓN de locura! [Estado de $\quad$ Facebook] Recuperado de https://www.facebook.com/VogueCosmeticosPeru/photos/a.1426210437429284.10737

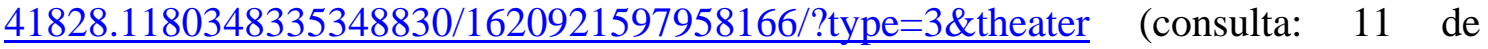
noviembre)

Westenberg, W. (2016). The influence of YouTubers on teenagers: A descriptive research about the role YouTubers play in the life of their teenage viewers. University of Twente: Netherlands. 
Williams, K.; Petrosky, A.; Hernández, E. y Page, R. (2011). Product placement effectiveness: revisited and renewed. En: Journal of Management and Marketing Research, vol. 7. Recuperado de http://www.aabri.com/manuscripts/10712.pdf

Wolfe, C. (2010). Product Placement and Viral Buzz: New Ethical Dilemmas. En: Journal of Business Management and Entrepeneurship vol. 1, $\mathrm{n}^{\circ} 9$.

Youtube (2017). Canal de Adristyling. Recuperado de https://www.youtube.com/channel/UCAI155UUh1sjhWTA2-Gr5uw

Youtube (2017). Canal de Mani Make Perú. Recuperado de https://www.youtube.com/channel/UCLP-XsYYT57HHhcyVBjZy9w

Youtube (2017). Canal de Vibela Mood. Recuperado de https://www.youtube.com/channel/UCxEqjCWaFknyikty2xJWU5g

Zajonc, R. (1968). Attitudinal Effects of Mere Exposure. En: Journal of Personality and Social Psychology, nº 9, pp. 1-27. 